\title{
Who Bears Firm-Level Risk? \\ Implications for Cash Flow Volatility *
}

\author{
Mindy Xiaolan Zhang ${ }^{\dagger}$
}

February 4, 2014

\begin{abstract}
Public firms in the United States that provide better insurance against productivity shocks to their workers experience higher cash flow volatility. Difference in intra-firm risk sharing between workers and capital owners accounts for more than $50 \%$ of the variation in firm-level cash flow volatility. I develop a theory in which wages can act either as a hedge or as leverage, depending on the history of the productivity shocks the firm has faced. Heterogeneous roles of workers in the firm are derived by analyzing the dynamic equilibrium wage contracts between risk-neutral owners and risk-averse workers who can leave with a fraction of the accumulated human capital. Owners of the firm will optimally bear more risk when the current value of the firm's human capital is lower than the peak value it has reached. The model successfully explains the joint distribution of cash flow volatility and the wage-output sensitivity. Also, the model produces predictions for the dynamics of cash flow volatility that are consistent with the time series properties of the firm-level data.
\end{abstract}

Keywords: Dynamic Contracts, Firm-Level Cash Flow Volatility, Wage-Output Sensitivity, Human Capital Investment

${ }^{*}$ I am deeply grateful to my advisor Hanno Lustig, as well as to Antonio Bernardo, Andrea Eisfeldt, and Mark Garmaise for invaluable support, ideas and advice. For helpful comments and discussions, I would like to thank Daniel Andrei, Andrew Atkeson, Simon Board, Jonathan Berk, Bruce Carlin, Mikhail Chernov, Mark Grinblatt, Barney Hartman-Glaser, Hugo Hopenhayn, Yaron Levi, Jiasun Li, Robert Novy-Max, Ichiro Obara, Lukas Schmid, Qi Sun, Ye Wang, Brian Waters, Ivo Welch, Lei Zhang, and participants at the UCLA Anderson Finance seminar, UCLA Economic Theory seminar, Asian Meeting of Econometric Society 2013, and LBS Trans-Atlantic Doctoral Conference. Special thanks to Selale Tuzel for generously providing data. All the errors are my own.

${ }^{\dagger}$ UCLA Anderson School of Management, Finance Area, Email: xzhang@anderson.ucla.edu, Phone: (310) $666-9186$. 


\section{Introduction}

Cash flow risk has long been a topical and challenging question for finance academia. Firmlevel cash flow volatility of U.S. public firms has increased over the past five decades Comin and Philippon (2005), Irvine and Pontiff (2009a), Kelly et al. (2012), etc.). In particular, the fraction of the firm's final output accrued to its capital owners has also become more volatile. Figure 1 presents the time series of firm-level volatility of the cash flow-to-sales ratio. This measure of cash flow volatility has doubled ${ }^{1}$ over the period 1960-2010. Moreover, it exhibits very different growth patterns cross-sectionally over the same time. Firms in the information, computer and technology industry experienced the largest cash flow volatility increase of more than 100\%, while firms in the consumer goods industry experienced a relatively mild $20 \%$ increase. This cross-industry heterogeneity in growth patterns indicates that the intra-firm risk allocation between its claimholders must be changing in different ways for each industry. As the most senior output claimholder of the firm, workers should have first order importance in understanding the capital owners' cash flow risk.

In this paper, I develop a theory in which labor can act either as a leverage or hedge to the cash flow risk, depending on the history of the productivity shocks the firm has faced. Risk neutral capital owners invest in the firm-level human capital of the workers. To retain the risk averse workers, who are embedded with human capital but cannot commit to the wage contract. This limited commitment on the labor side leads to the contract derived by Harris and Holstrom (1982): the owners offer the optimal wage contract with the downwardrigid property. Depending on the history of the productivity shocks, the downward-rigid wage contracts either provide perfect insurance to the workers or meet their outside options. When perfect insurance is achieved, wage contracts, just as debt contracts, lever the cash flow risk. When capital owners have to offer higher compensation to meet the outside option, wage contracts hedge productivity risk for the owners since wage contracts comove with

\footnotetext{
${ }^{1}$ The result is robust when using the corporate earnings as the measure of cash flows, and the percentage change of earnings' growth volatility is more than 200\% since 1950 (Irvine and Pontiff (2009a)).
} 


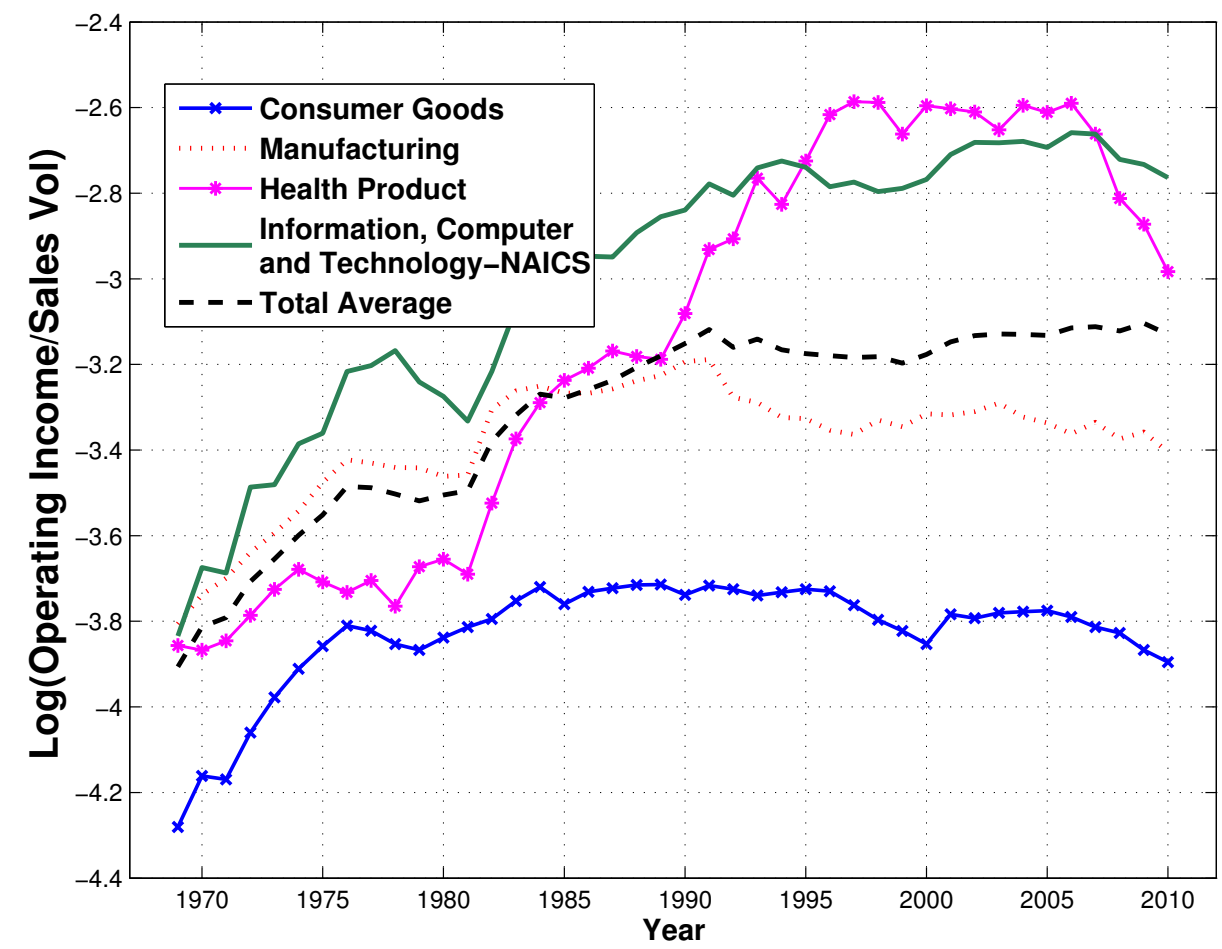

Figure 1: Firm-Level Cash Flow Volatility

The figure reports the cash flow growth volatility at the firm level over 1960-2010. Cash flow growth is measured by $\frac{C F_{t}-C F_{t-1}}{0.5 * \text { Salest }_{t}+0.5 * \text { Sales }_{t-1}}($ Bloom $(2009)$, Jurado et al. $(2013)$ ), and cash flow is measured by operating income (OIBDP). The standard deviation of cash flow growth is estimated over a ten-year rolling window. The firm-level volatility is the log of the standard deviation. The figure plots the cross-firm average of volatility within an industry. Data Source: Compustat Fundamental Annual 1960-2010.

firms' output. The different ways in which optimal wage contracts respond to productivity shocks drive the dynamics of risk allocation between the owners and the workers within the firm.

The dynamics of optimal wage contract is completely capturized by two state variables: the current human capital level and the historical maximum level of the human capital. Unlike Harris and Holstrom (1982), due to the partial portability of firm-level human capital, the history of productivity shocks affects the worker's outside option through the accumulation path of firm-level human capital. The equilibrium "effective" outside option is determined by the firm's historical maximum of human capital. Firms optimally offer the downward-rigid 
wage contract to trade off between incentives and insurance. When the worker's current human capital level is higher than the historical maximum, causing a positive change in her outside option, the owner benefits from retaining the current worker and raising her wage by the smallest possible amount. With a positive wage-output sensitivity, the wage contract acts as a "hedging" device to the owner's cash flow risk. On the other hand, the current human capital level can be lower than the historical maximum level, and the outside option is lower than what the current wage contract is offering, the optimal wage contract provides perfect insurance to the worker. With a zero wage-output sensitivity, wage contracts act as a rigorous "debt" contract and tranfer total output into a volatile cash flow. Moreover, the competitive equilibrium determines a concave outside option as a function of accumulated firm-level human capital. The concavity leads to heterogeneous degrees of risk allocation whenever a firm achieves a new historical maximum of human capital.

In the competitive equilibrium with firm dynamics, the joint distribution of wage-output sensitivity and cash flow risk is determined by the joint distribution of current and historical firm-level human capital accumulation. Cash flow volatility is low and wage-output sensitivity is high when current human capital level exceeds the historical maximum. Cash flow volatility is high and wage-output sensitivity is low when the worker's current human capital level is below the historical maximum. When wage contracts hedge the cash flow risk, firms with a higher historical maximum of human capital have lower wage-output sensitivity and higher cash flow volatility.

Quantitatively, the model produces predictions that are consistent with the cross-sectional and time-series evidence on the joint distribution of cash flow volatility and wage-output sensitivity. Cross-sectionally, the wage-output sensitivity explain a significant fraction of the cross sections of the firm-level cash flow volatility. More than $50 \%$ of firm-level cash flow volatility is explained by the changing risk sharing patterns within the firm. The calibrated model produces the same scale of cash flow volatility variation and also matches the joint distribution of firm-level cash flow volatility and wage-output sensitivity with the data. I 
further evaluate the model's implications on the driving force of the intra-firm risk sharing dynamics. I find that the higher historical maximum of firm-level human capital predicts (conditionally) lower wage growth and lower wage-output sensitivity, but higher cash flow volatility. The joint distribution of the historical maximum of firm-level human capital and cash flow volatility in the data lines up with the model prediction through the link of the wage-output sensitivity.

In time series, the time-varying intra-firm risk allocation provides a novel explanation of the increasing firm-level cash flow volatility. The average wage-output sensitivity decreases $38 \%$ over the period from 1960 to 2010, which suggests that workers were getting better insurance in U.S. public firms over time. On average, the estimated historical maximum firm-level human capital is growing over the same period. The historical human capital accumulation path explains the incremental cash flow volatility through the channel of intra-firm risk allocation. The historical maximum firm-level human capital increases most dramatically in information, computer and technology industry, as does its average cash flow volatility at the firm level. This industry also experiences the largest decline (more than 60\%) in wageoutput sensitivity. However, in consumer goods and manufacturing industries, I didn't find a significant positive trend either in the historical maximum firm-level human capital or in the average wage-output sensitivity at the industry level.

Finally, I conduct the panel analysis and confirm model's implications in the data. I generate the following three main empirical implications: 1) a positive relationship between the historical maximum of firm-level human capital and wage contracts; 2) a negative relationship between compensation sensitivity and the maximal firm-level human capital conditionally; 3) a positive relationship between cash flow volatility and maximum firm-level human capital. The history dependence of the cross-sectional pattern of risk allocation between workers and capital owners is sizable and significant in the data. Unconditionally, one standard deviation increase in the historical maximum human capital level leads to a $30 \%$ change in cash flow volatility. 
Literature Review This paper contributes to the literature on firm-level volatility dynamics (e.g., Malkiel et al. (2001), Comin and Philippon (2005), Comin and Mulani (2006), Irvine and Pontiff (2009b), Kelly et al. (2012), etc.). Robust evidence is found (Comin and Philippon (2005) ) on the increase in firm-level volatility using different real measures and financial data, while my paper explores and documents the increasing trend in firm-level cash flow (accrued to its capital owners). Comin and Mulani (2009) explain the dynamics of productivity volatility with an endogenous growth model that predicts an endogenous increase in the share of resources spent on innovation. Kelly et al. (2013) propose a model of firm volatility based on customer-supplier networks. My paper takes a novel intra-firm perspective and is the first that links wage contract dynamics to cash flow volatility both theoretically and empirically. Empirical effort has also been made to understand the firmlevel labor income risk in the literature. Guiso et al. (2005) evaluates the allocation of risk between firms and their workers using matched employer-employee panel data. Comin et al. (2009) relates firm-level volatility to wage volatility using both firm-level and worker-level dataset. Also, Lagakos and Ordonez (2011) are among the few to examine which workers get insurance within the firm using industry-level data, but my paper proposes the leverage effect of wage contracts which few have yet emphasized in the literature on firm-level volatility.

This paper combines the organizational capital theory (Atkeson and Kehoe (2005), Jovanovic and Rousseau (2008), etc.) with dynamic implicit wage contract in a productionbased framework. Theoretically, the optimal wage contract in my paper shares the downwardrigid property as in the seminal papers (Harris and Holstrom (1982), Thomas and Worrall (1988), etc) in which, however, cash flow is exogenous and does not interact with the optimal contracting decision. Lustig et al. (2011) is the first study to relate production to implicit labor contracts to shed light on CEO compensation inequality. Eisfeldt and Papanikolaou (2013) model the effect of the outside option of key talents on the systematic cash flow risk that shareholders face. Ai et al. (2013) model the equilibrium mechanism design with 
limited commitment to explain the inequality in CEO compensation. In contrast, I explore the endogenous relationship between organization capital accumulation and the wage contract stickiness. My paper also contributes to the empirical literature on wage structure at the firm level. Baker et al. (1994) use an employee-employer matched database for a single firm and find that employees are partly shielded against changes in external market conditions. Wachter and Bender (2007) find the persistent cohort effect on wages within the firm. Beaudry and DiNardo (1991) show that there is a time-varying degree of risk sharing between workers and firms at the time of entry. My model implications are consistent with the empirical evidence on wage structure in the existing literature, and provides additional insights into the second moment of wage structure.

This paper is related to both the empirical and theoretical corporate finance literature that focuses on the optimal compensation scheme and the interaction between financial decisions and agency frictions (e.g., He (2011), Demarzo et al. (2012)). I study dynamic wage contracts with limited commitment, similar to Berk et al. (2010), to generate the labor-induced operating leverage effect. Different from Berk et al. (2010), where the amount of risk sharing between investors and employees depends on the debt level, the degree of risk sharing in my paper depends on the high-water mark of human capital reached in the firm's entire history. Michelacci and Quadrini (2009) study the long-term wage contract in the financially constraint firms and find a positive relationship between firm size and wages. My model produce predictions consistent with Michelacci and Quadrini (2009) but with emphasis on implications for wage-output sensitivity and cash flow volatility. There is rising attention on labor in empirical corporate finance. Garmaise (2008) and Benmelech et al. (2011) among others, study the interaction between firms' employment decisions and financial frictions. Tate and Yang (2013) estimate the labor market consequences of corporate diversification using worker-firm matched data. My paper suggests implications concerning the inefficiency of human capital investment at the firm level and provides a novel link between corporate investment and labor compensation. Related to the empirical work starting with Jensen and 
Murphy (1990), my model produces a stickier performance-pay wage contract that survives the empirical tests.

This paper also incorporates several successful themes from the emerging literature that examines the relation between labor frictions and risk and asset returns. Berk and Walden (2013) studies the limited capital market participation as an equilibrium outcome in the neoclassical asset pricing model, where firms offer labor contracts that insure workers who then optimally choose not to participate in capital markets. My paper assumes exogenous nonparticipation in the capital markets and focuses on the implications for intra-firm risk sharing. The leverage effect of wage stickiness has been shown by Danthine and Donaldson (2002), Favilukis and Lin (2012) and Favilukis and Lin (2013), who document the importance of labor leverage in explaining equity premium. In a competitive labor market setting, Gourio (2008) shows the empirical implications of sticky wages for the cross-sectional differences in return as well. Donangelo (2013) studies that labor mobility amplifies the firms' existing exposure to systematic risk. In my paper, I emphasize the heterogeneity in the corporate rent-splitting and endogenize the elasticity of wage to output by the implicit wage contracts. Eisfeldt and Papanikolaou (2013) also explore the division of surplus between key talent and shareholders with the accumulation of organizational capital. In their paper, the dynamics of the rent splitting depend on the current level of frontier technology, but not on the historical accumulation path of organization capital. The unmeasured capital is also modeled in Jovanovic and Rousseau (2008) with an emphasis on the managerial function of assembling heterogeneous assets. The specificity of human capital creates rents in the assembly in Jovanovic and Rousseau (2008), but their model does not imply the division of rents between different claimholders of the firm. 


\section{The Model}

I construct an competitive industry equilibrium model in the tradition of Hopenhayn (1992) and Gomes (2001), augmented with human capital and implicit labor contract. I start with a simple version of the model that features only human capital accumulation and production to illustrate the key dynamics of cash flows and wage contracts.

\subsection{The Environment}

The production economy consists of two sectors: capital owners and workers. A continumm of firms is owned by risk neutral capital owners who have limited liability, while a continumm of workers is risk averse and cannot participate in the financial market ${ }^{2}$ and have no access to a storage technology. Both the owners and the workers have the same discount factor $\beta$. The labor contract is the only source of consumption smoothing for the risk averse agent.

\subsubsection{Firm Behavior}

Production requires two inputs, capital $h_{t}$ and labor $l_{t}$, and is subject to an idiosyncratic technology shock, $z_{t} \sim Q\left(z_{t} \mid z_{t-1}\right)$ :

$$
y_{t}=e^{z_{t}} f\left(h_{t}, l_{t}\right)
$$

The production function $f(\cdot)$ is well-defined ${ }^{3}$ and displays decreasing return to scale. The output is homogeneous. Assumption 1 and 2 concern the nature of the productivity shock.

Assumption 1 (a) The stochastic process for the idiosyncratic shock z has bounded support $z=[\underline{z}, \bar{z}],-\infty<\underline{z}<\bar{z}<\infty$; (b) the idiosyncratic shocks follow a common stationary and

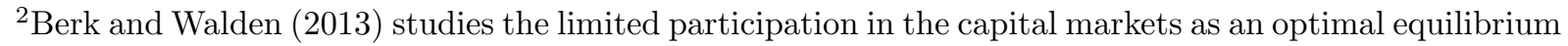
outcome in a production economy.

${ }^{3}$ Production is carried out under the well-defined space, which is strictly increasing, strictly concave, twice continuously differentiable, homogeneous, and constant return to scale, and satisfies Inada conditions.
} 
increasing Markov transition function $Q\left(z_{t} \mid z_{t-1}\right)$ that satisfies the Feller property; (c) the productivity shock $z_{t}$ is independent across firms.

For the sake of simplicity, I normalize the overall labor force of the firm equal to one $\left(l_{t}=1\right)$; hence human capital $h_{t}$ can be interpreted as the productivity per worker. An active firm is equivalent to a match of capital $h_{t}$ and one worker. The space of capital input is a subset of the non-negative bounded real numbers, $\mathcal{H} \in\left[h_{\min }, \infty\right)$, and $h_{\min } \in \mathcal{R}$ is the general human capital (e.g., education) embodied in the worker at the beginning of the match. The match-level human capital is $h_{t} \in \mathcal{H}$. The accumulation law of capital $h_{t+1}$ for the next period follows the traditional investment function $I_{t}$ :

$$
I_{t}=h_{t+1}-\left(1-\delta_{h}\right) h_{t}, \delta_{h} \in(0,1),
$$

where $\delta_{h}$ is the depreciation rate of human capital.

The match-level human capital accumulation is not completely exclusive to the worker $4^{4}$ Unlike the standard neoclassical investment model, this paper emphasizes the sharing property of match-level human capital.

Assumption 2 (Portability) The fraction of match-level human capital $\phi h_{t}$ is portable with the worker when the separation of capital and labor happens, $0<\phi<1$.

Due to the partial portability of human capital, the capital is most efficient in the match where it was accumulated, although it can also be partially adopted by other firms $(\phi<1)$.

I summarize the firm's decision by first writing down the cash flow process:

$$
C F_{t}=e^{z_{t}} f\left(h_{t}\right)-w_{t}-I_{t}^{h}-s,
$$

where $s$ is the fixed production cost for each period. Each firm maximizes the discounted cash flow stream over its life cycle: $\left.E_{0}\left[\sum_{s=t}^{\infty} \beta^{s-t} C F_{s} \mid z_{0}\right)\right]$.

\footnotetext{
${ }^{4}$ For example, the "skill-weights" view suggested by Lazear (2009).
} 


\subsubsection{Labor Market}

A continuum of workers are risk averse and infinitely-lived. Each period, workers consume their wages, but they have limited commitment to the wage contracts. Workers can always walk away whenever an outside option is higher than the contract provided by the match. The owners have full commitment to the wage contracts, but with limited liability. Owners commit to a complete contingent optimal contract at the start of the match $\left\{w_{t}\left(z^{t}\right), \eta_{t}\left(z^{t}\right)\right\}_{t=0}^{\tau}$, where $z^{t}$ denotes the history of shocks, $z^{t}=\left\{z_{t}, z_{t-1}, \ldots\right\}, \eta_{t}$ is an indicator function that governs the optimal decision of dissolving the match, and $\tau$ is the optimal time of termination. Here, for tractability, I assume that the contingent optimal contract cannot be negotiated ex post $:^{5}$

Subject to Assumption 2, the labor mobility cost between firms is captured by $1-\phi$, where $\phi$ is an exogenous parameter and may vary across industries, so the optimal wage contract must be self-enforcing. I provide a simple characterization of the optimal contract following Thomas and Worrall (1988), but with an endogenous equilibrium outside option.

The optimal contract maximizes the total expected payoff of the owner, subject to delivering initial utility $\varphi_{0}$ to the workers:

$$
\varphi_{0}\left(z^{0}\right)=E_{0}\left[\sum_{0}^{\infty} \beta^{t} u\left(w_{t}\left(z^{t}\right)\right)\right]
$$

To make the problem recursive, the worker's promised expected utility is treated as a new state variable. The optimal contract delivers $\varphi_{t}$ today by delivering current wage $w_{t}$ and a state-contingent promised expected utility $\varphi_{t+1}$ tomorrow. The owners commit to deliver $\left\{w_{t}, \varphi_{t+1}\left(z_{t+1}, h_{t+1}, \eta_{t+1}\right)\right\}$ each period, where $\varphi_{t+1}\left(z_{t+1}, h_{t+1}, \eta_{t+1}\right)$ is defined as:

$$
\varphi_{t}\left(z_{t}, h_{t}, \eta_{t}\right)=E_{t}\left[\sum_{s=t}^{\infty} \beta^{s-t} u\left(w_{s}\left(z^{s}, h^{s}, \eta^{s}\right)\right)\right]
$$

\footnotetext{
${ }^{5}$ In some states where the match is terminated, the contract does leave room for renegotiation as long as the turnover is also costly for the worker $(\phi<1)$.
} 
The domain of feasible promised utility $\Phi=[\underline{\varphi}, \bar{\varphi}]$ is defined in Appendix A.1. The capital owners have to keep their promises by setting up the following promise-keeping constraint:

$$
\varphi_{t}=u\left(w_{t}\right)+\beta \int \eta_{t+1} \varphi_{t+1} Q\left(d z_{t+1} \mid z\right)+\beta \int\left(1-\eta_{t+1}\right) \varphi_{r e s, t+1} Q\left(d z_{t+1} \mid z\right) .
$$

Given workers' limited commitment and the partial portability of match-level human capital, the optimal contract should provide retention incentives. Let $\varphi_{r e s, t+1}$ denote the workers' reservation utility, which is defined as the outside option of the workers; thus, the contingent promised utility has to be higher than $\varphi_{r e s, t+1}$ for any realized state at $t+1$. The participation constraint of the workers is given by:

$$
\varphi_{t+1} \geq \varphi_{r e s, t+1}\left(\phi h_{t+1}, z_{t+1}, \eta_{t+1}\right), \forall z_{t+1} \in \mathcal{Z}, \forall h_{t+1} \in \mathcal{H}
$$

The contract offers as high as the worker's outside option, which is an equilibrium outcome from firm dynamics.

\subsubsection{Exit, Entry and Firm Dynamics}

The entry and exit of the firm is defined as the formation and termination of the capital-labor match respectively. The timing of firms' entry and exit decision is shown in Figure 2.

In any given period, the owner of each incumbent firm decides whether to exit or stay before the shock $\left(z_{t+1}\right)$ is observed (see Gomes (2001)). Hence, incumbents know in advance whether or not to exit in the next period, and the exit is completely determined by the current productivity shock $z_{t}$. The indicator variable $\eta_{t+1}$ is one if continuation is optimal and zero otherwise:

$$
\eta_{t+1}=\left\{\begin{array}{l}
1, \text { if } z_{t} \geq \max \left[z_{t}^{*}, \underline{z}\right] \\
0, \text { otherwise }
\end{array}\right.
$$


where $z^{*}$ is the threshold value that satisfies $\left.E_{t}\left[\sum_{s=t}^{\infty} \beta^{s-t} C F_{s}\left(z_{s}, h_{s}, \eta_{s}\right) \mid z_{t}\right)\right]=0$. If $\eta_{t+1}=0$, the match is terminated, and the owner earns zero profit and will stay out of the market forever. If $\eta_{t+1}=1$, the owner chooses the investment decision and the wage contract by maximizing the discounted cash flows over the life cycle.

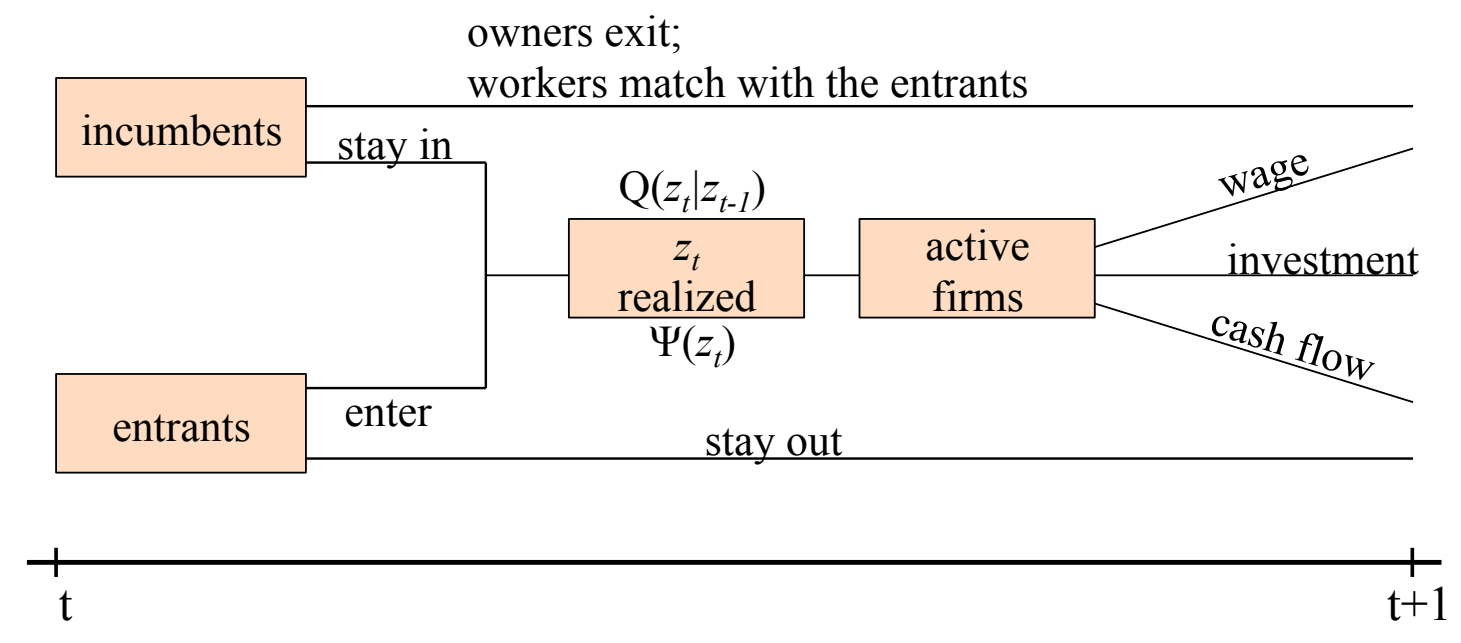

Figure 2: Timing of Exit and Entry

At the same time, there is a continuum of potential entrants (capital owners) who determine whether or not to enter the economy at the beginning of each period. They make their entry decisions before the idiosyncratic shocks are realized. Each period, the entrants draw their initial level of $z$ independently from a common distribution $\Psi(z)$. The initial level of $z_{0}$ is drawn from $\Psi(z)$ to ensure substantial heterogeneity in productivity across all new entrants. Upon entry, owners incur a fixed sunk cost $F 6^{6}$

The turnover of workers happens when the incumbent firm exits. Workers from the dissolved matches will be employed by the potential entrants before $z_{t}$ is realized with an initial human capital level $h_{t}=\max \left[\phi h_{t-1}, h_{\min }\right]$. The competitive entry condition determines the outside option $\varphi_{\text {res, } t \text {. }}$

\footnotetext{
${ }^{6}$ For entrants, the workers they hire are the ones from last period's dissolved matches, or any other laid-off workers from other matches in the previous periods. The supply of labor is inelastic in the model.
} 


\subsection{The Firm's Optimization Problem}

If the capital-labor match dissolves, the owner realizes zero value forever. Hence, the interesting case that remains is the optimal compensation and investment decision of the incumbent firms.

The dynamic formulation of each incumbent firm's problem can be written in a recursive form in which the state variables are $\{h, \varphi, z\} \in \mathcal{H} \times \Phi \times \mathcal{Z}$ and subject to constraints from capital accumulation and labor market friction. Define $V(h, \varphi ; z)$ as the value of a firm that has a capital stock of $h$, promised utility to the worker $\varphi$, and productivity $z$. Both owners and workers discount the future by a common factor $\beta$. Given $\eta_{t+1}=1$, the dynamic problem $\mathcal{P}$ facing the owner of each incumbent is:

$$
V(h, \varphi ; z)=\max _{h_{t+1}, \varphi_{t+1}, w ; z_{t+1} \mid z}\left(C F_{t}+\beta \int V\left(h_{t+1}, \varphi_{t+1} ; z_{t+1}\right) Q\left(d z_{t+1} \mid z\right)\right)
$$

subject to:

$$
\begin{aligned}
C F_{t} & =\exp \left(z_{t}\right) f\left(h_{t}\right)-w_{t}-I_{t}, \\
I_{t} & =h_{t+1}-\left(1-\delta_{h}\right) h_{t}, \quad \delta_{h} \in(0,1), \\
\varphi_{t} & =u\left(w_{t}\right)+\beta \int \varphi_{t+1} Q\left(d z_{t+1} \mid z\right), \\
\varphi_{t+1} & \geq \varphi_{\text {res }, t+1}\left(\phi h_{t+1}, z_{t+1}\right), \forall h_{t+1} \in \mathcal{H}, \forall z_{t+1} \in \mathcal{Z} .
\end{aligned}
$$

Constraint (9) is the budget constraint for the capital owner; constraint (10) is the law of motion of human capital; and constraint (11) is the promise-keeping constraint. Since the incumbent has made the decision regarding $\eta_{t+1}$ before solving $\mathcal{P}$, constraint (11) is the

version of equation (5) with $\eta_{t+1}=1$. The participation constraint (12) is contingent on the endogenous state $h_{t+1}$. This is the main difference from the literature on the risk-sharing contract with one-sided commitment. The model allows for dynamic contracting to interact with the firm's investment behavior. The more the firm invests, the higher the worker's 
outside option as the firm grows.

The limited commitment on the part of workers and the endogenous exit decision com-

plicate the dynamic programming considerably. However, I show that there exists a unique solution to problem $\mathcal{P}$ characterized in the Lemma 1 and 2 .

Lemma 1 Given the outside option $\varphi_{\text {res }}(\phi h) \in[\underline{\varphi}, \bar{\varphi}]$, the solution $V(h, \varphi, z)$ to the Bellman equation $\mathcal{P}$ exists. The value function is strictly monotone, concave, continuous and differentiable in $\varphi$ and $h$.

Proof. See Appendix A.2.

Lemma 2 Given the initial $\varphi_{0}$, the optimal contract $\left\{w_{t}, \varphi_{t+1}\right\}$ and policy function of $h$ is unique and continuous.

Proof. See Appendix A.2. - The risk averse worker is willing to accept a lower expected wage in exchange for a smoother income stream. The capital owner can make a profit by paying a wage lower than the competitive wage when the productivity shock is positive and vice versa. This is an implicit leverage effect generated by the self-enforcing wage contract. The leverage effect consists of two parts. (1) Since the contract wage will be lower than the competitive spot market wage, more room for profit is left to the capital owners; (2) the wage will be stickier than the competitive market wage, and the stickiness is history-dependent. The intra-firm risk allocation is governed by the strength of the implicit leverage effect.

\subsection{Aggregation and Equilibrium}

In the competitive equilibrium, free entry stipulates that the equilibrium value of a new match of labor and capital is equal to the entry cost:

$$
\int V_{t}\left(\phi h_{t}, \varphi_{r e s}\left(\phi h_{t}\right), z\right) \Psi(d z) \leq F
$$


This equilibrium condition indicates that the total utility assigned to the new worker with $\phi h$ is the value that makes the new firm zero expected profit. Therefore, this equilibrium condition determines the outside option $\varphi_{\text {res }}$ in equilibrium. Since the entry decision at time $t$ is made before the realization of productivity $z_{t}$, the equilibrium outside option is independent of $z$, but is only a function of capital level $\varphi_{\text {res }}(\phi h)$. The timing simplifies the optimal decision-making process as the dimension of participation constraints in $\mathcal{P}$ is equal to that of the state space $\mathcal{H}$.

I characterize the aggregate variables for this economy as follows. Let $\mu(h, \varphi, z)$ denote the measure of the mass of firms in the state $(h, \varphi, z)$. Let $\Gamma_{t}$ denote the aggregate law of motion for the measure $\mu$ and the state variables at time $t$. In the invariant industry equilibrium, the mass of new entry equals the mass of the exit in that same period. See Appendix A.1 for the details. The stationary industry equilibrium is defined as follows.

Definition 1 Stationary Industry Equilibrium A stationary recursive equilibrium is a value function $V(h, \varphi, z)$, policy function $h^{\prime}$ and $\varphi^{\prime}$, outside option $\varphi_{\text {res }}: \mathcal{H} \rightarrow[\underline{\varphi}, \bar{\varphi}]$, a positive measure of the law of motion of state variables $\Upsilon$, and the measure of firms $\mu$ on the Borel sets of $\mathcal{H} \times \Phi \times \mathcal{Z}$ :

\section{1. (Agent Optimality)}

(a) (Continuing Firms): Given $\varphi_{\text {res }, t+1}$ for all $h^{\prime} \in \mathcal{H}, V$ solves the dynamic programming problem $\mathcal{P}$, and $h^{\prime}$ and $\varphi^{\prime}$ are the associated policy functions.

(b) (Exiting Firms): The exit decision is summarized by condition (26).

2. (Outside Option): For all $h^{\prime} \in \mathcal{H}$ :

$$
\varphi_{\text {res }} \in \arg \max _{\varphi}\left\{\varphi \mid \int V\left(\max \left[\phi h, h_{\min }\right], \varphi\right) \Psi(d z) \leq F\right\}
$$

3. (Stationary Distribution) Define the measure $\mu$ such that $\forall(h, \varphi, z), \mu(h, \varphi, z)$ denotes the mass of firms in state $(h, \varphi, z)$, and define $\Upsilon$ following equation (23). In equilib- 
rium,

$$
(\Upsilon, \mu)=H(\Upsilon, \mu)
$$

The following proposition summarize the equilibrium properties.

Proposition 1 The stationary equilibrium exists and the equilibrium outside option is strictly increasing and concave in $h$.

Proof. See Appendix A.4.

The nonlinearity of the outside option gives a very distinct impulse response to the productivity shocks, given different human capital accumulation paths. The heterogeneous degree of risk sharing between workers and capital owners arises endogenously across firms.

\section{Equilibrium Risk Allocation}

Perfect consumption-smoothing breaks with limited commitment and firm dynamics. In this section, I describe the heterogeneous degree of stickiness of the wage contracts in the equilibrium. Two state variables summarize all necessary information for risk sharing in equilibrium: the current level of human capital $h_{t}$ and the historical maximal level of human capital: $h_{\text {max }, t-1}=\max \left\{h_{s-1}, s=1 \ldots t\right\}$.

\subsection{Optimal Wage Contract}

Given the existence of the equilibrium, I first characterize the dynamics of the wage contract in Proposition 2

Proposition 2 (Downward-Rigidity) Given the initial wage contract $\left\{w_{0}, \varphi_{0}\right\}$ and $z_{t} \geq$ $\max \left[z^{*}, \underline{z}\right]$, the maximum of human capital $h_{\max , t}=\max \left\{h_{s}, s \leq t\right\}$ is the sufficient statistic of the equilibrium wage. 
Proof. See Appendix A.4.

As in Harris and Holstrom (1982), proposition 2 implies that only the maximum level of $h_{t}$ impacts the wage level as long as the firm stays in the economy. $h_{\max , t}$ governs how much the capital owner needs to transfer to the worker in the optimal contract, and the wage contract is reset whenever $h_{\max , t}>h_{\max , t-1}$.

The perfect risk sharing wage contract provides smooth consumption over time $\left(\frac{1}{u^{\prime}\left(w_{t}\right)}=\right.$ $\left.\frac{1}{u^{\prime}\left(w_{t+1}\right)}\right)$, and the lagged inverse marginal utility (LIMU), $\frac{1}{u^{\prime}\left(w_{t}\right)}$, contains the only relevant information in forecasting next period's wage level, $w_{t+1}$. When perfect consumptionsmoothing is constrained by limited commitment, LIMU is no longer sufficient to determine the next period's wage. The Euler equation is obtained under limited commitment:

$$
\frac{1}{u^{\prime}\left(w_{t+1}\right)}=\frac{1}{u^{\prime}\left(w_{t}\right)}-\theta_{t}\left(h_{t+1}\right)
$$

where $\theta_{t}(\cdot)$ is the Lagrangian multiplier of the participation constraint (12). Conditional only on $\theta_{t}(\cdot)$, the shadow price of the promised utility at time $t+1$, LIMU is sufficient for predicting the next period's wage level. The wage contract is reset to the higher level whenever the participation constraint is binding; it remains at the same level when the participation constraint is not binding. The shadow price of the promised utility $\theta_{t}(\cdot)$ becomes positive only when workers' outside option rises. Given that the outside option is an increasing function of $h$ from Proposition 1, the maximum level of human capital $h_{\max , t}$ contains all the information relevant for forecasting the wage contract in the next period.

With limited commitment on the labor side, the optimal contract should move as little as possible to trade off between the marginal value of retention incentives and the marginal benefit of consumption smoothing. Figure $3($ a) illustrates the equilibrium wage contract. Whenever the productivity shock $z_{t+1}$ induces a positive increase in $h_{\max , t+1}$, the participation constraint binds and the marginal value of increasing $\varphi_{t+1}$ rises and dominates the marginal value of insurance. The firm increases the promised value $\varphi_{t+1}$ to retain the worker in the 
match. The optimal contract depends only on the current state of the firm. Although it is costly for the firm to increase $\varphi_{t+1}$, it benefits the firm from the marginal productivity of the worker. However, when the productivity shock $z_{t+1}$ leads to disinvestment at $t+1$ and $h_{t+1}<h_{\max , t+1}$, the worker's participation constraint is loosened and the optimal wage contract stays constant. As long as $h_{t+1}<h_{\max , t+1}$, the marginal value of smoothing the worker's consumption dominates, and perfect insurance is achieved. The wage contract is completely captured by the maximum level of the human capital stock in the firm's history $h_{\max , t}$. The dynamics of wage contract can be concluded using the following corollary.

Corollary 1 Given that the capital owners and workers are equally patient, equilibrium wage is nondecreasing over time when $z_{t} \geq \max \left[z^{*}, \underline{z}\right]$.

Proof. See Appendix A.4.

Corollary 1 follows from Proposition 2 since $h_{\max , t}$ is non-decreasing as long as $z_{t}>$ $\max \left[z^{*}, \underline{z}\right]$. The efficient allocation is to increase the compensation and make the worker indifferent between staying or leaving the firm whenever the firm faces a positive productivity shock, and to smooth the worker's consumption when the productivity shock is negative. The downward-rigid wage contract is valid only when the productivity shock of this period is not lower than the threshold $\max \left[z^{*}, \underline{z}\right]$.

When $z_{t}<\max \left[z^{*}, \underline{z}\right]$, the workers from the dissolved match are reallocated to the entrants. Upon the termination of the match, the worker leave the firm with a proportion of human capital, $\phi h_{t-1}$. In Figure 3 (b), the initial wage of the worker and $\varphi_{0}$ are set to make the entrant profitable enough to continue production. The wage contract is not downwardrigid at the point of reallocation since workers lose the fraction $1-\phi$ of human capital when they move to a new entrant. 
(a) Optimal Wage Contract Before Exit

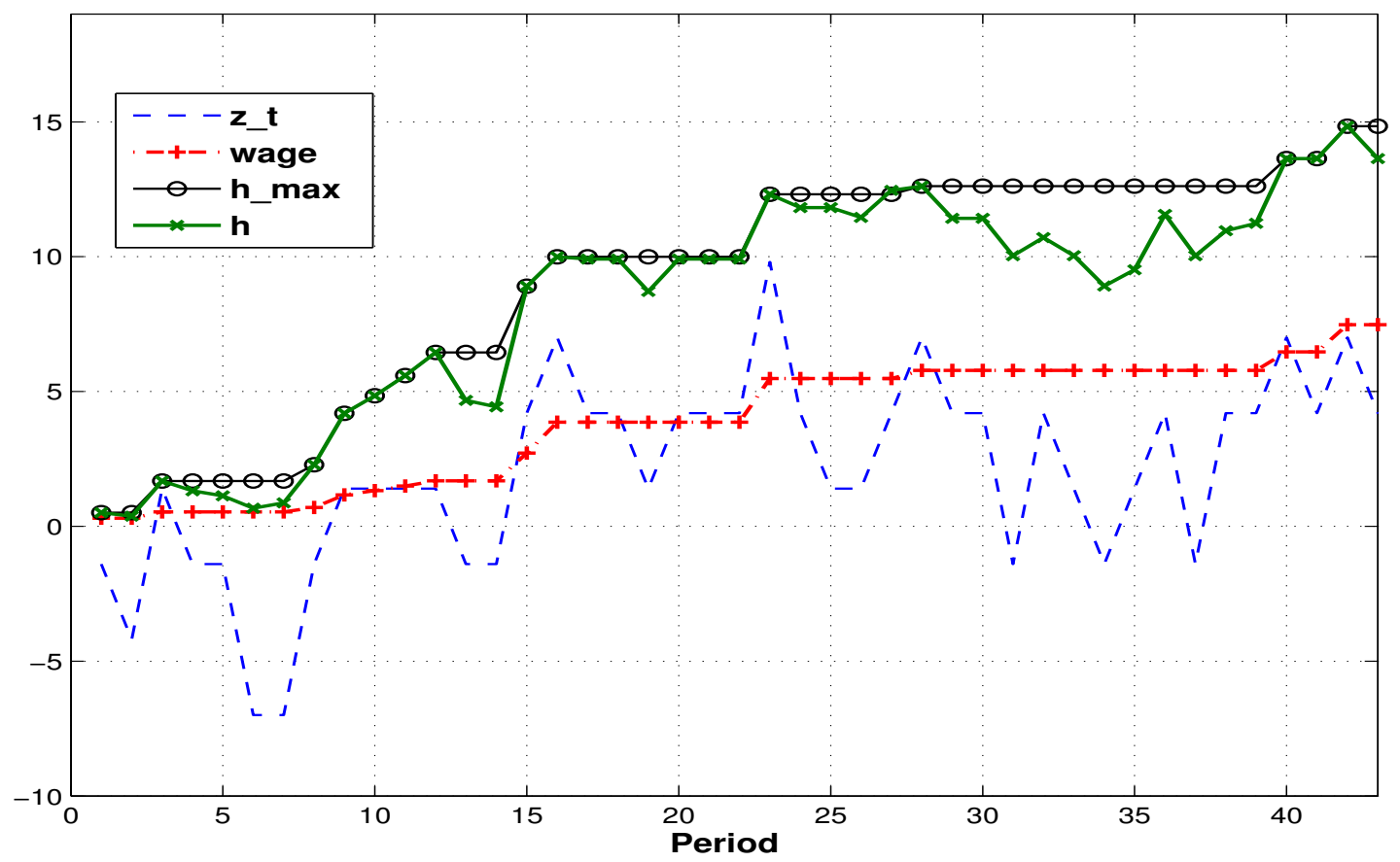

(b) Optimal Wage Contract With Exit

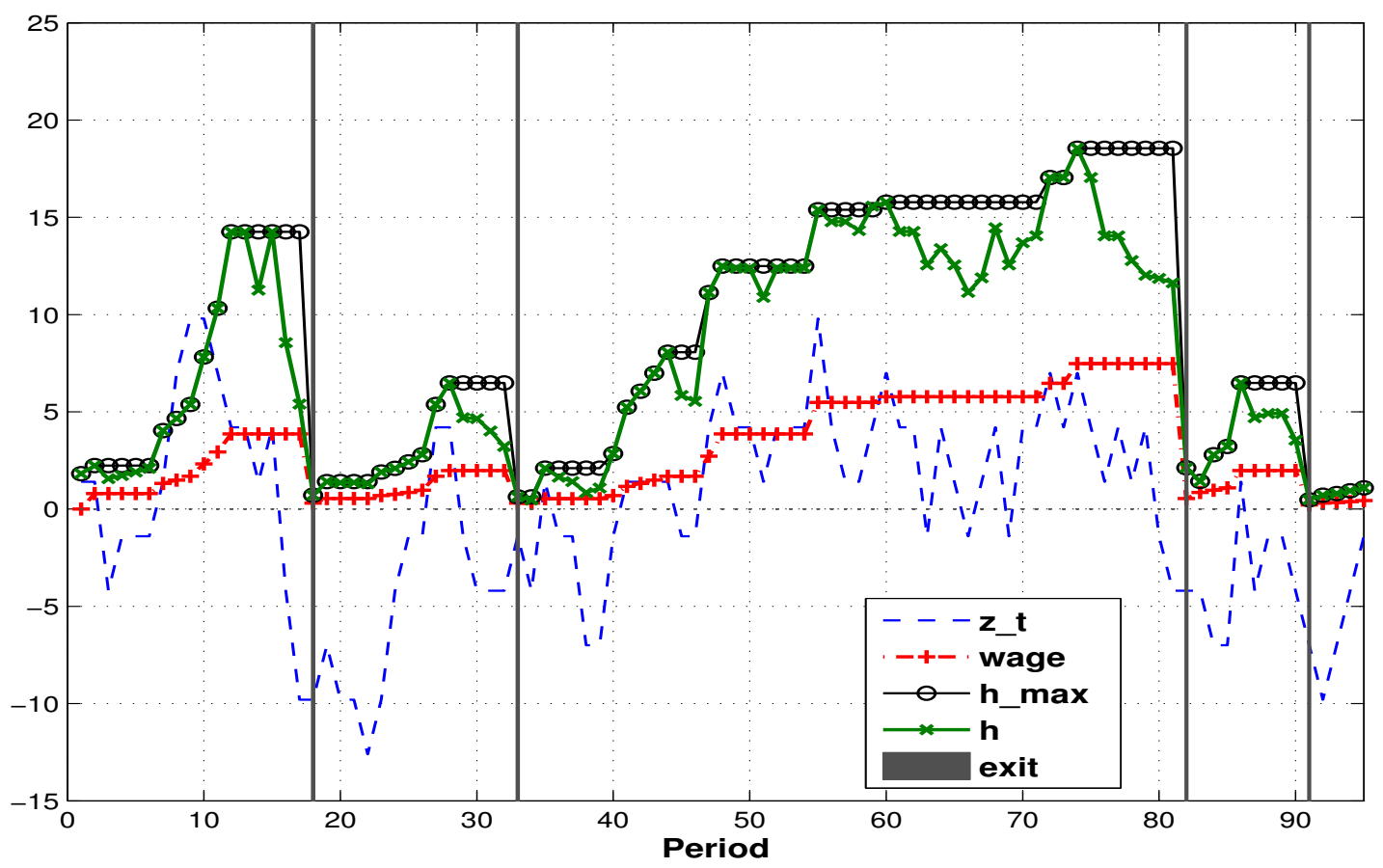

Figure 3: Wage Contract and Human Capital

This figure plots the wage contract and its dynamics with respect to the human capital accumulation path. Figure (a) shows the wage contract dynamics before the termination of the match. Figure (b) shows the wage contract and the exit-and-entry dynamics, where the grey area indicates the termination of the capital-labor match. The unit of productivity shock $z_{t}$ is scaled up ten times. 


\subsection{History-Dependent Risk Allocation in Equilibrium}

In equilibrium, the outside option drives the optimal rent-splitting rule between workers and capital owners, and the sensitivity of the outside option to the productivity shocks differs across firms. The important question before moving on to cash flow volatility is the relative risk-sharing magnitude in equilibrium and its cross-sectional distribution. The equilibrium property of workers' outside option directly implies the following corollary:

Corollary 2 Given $\varphi_{0}, z_{t}<\max \left[z^{*}, \underline{z}\right]$, and the concavity of $\varphi_{\text {res }}(h)$ from Proposition 1 , $\frac{\partial \varphi_{t}}{\partial h_{t}^{1}} \geq \frac{\partial \varphi_{t}}{\partial h_{t}^{2}}$ if $h_{t}^{1} \leq h_{t}^{2}$.

Concavity of the outside option in the human capital level implies a difference in sensitivity of the promised utility on the maximum level of the human capital accumulation. As the maximum of the human capital level gets higher, the promised utility becomes less responsive to the productivity shock and, hence, the consumption. However, when the historical maximum of human capital level is low, the worker gets better insured from the productivity shock, and the wage contract is less responsive. The equilibrium distribution of wage to output sensitivity is consistent with the equilibrium distribution of $h_{\max }$.

Figure 9 shows the impluse response function of cash flows and wage contracts subject to a one-standard deviation shock. Consider two firms with the same starting level of $\varphi_{0}$ and human capital $h_{t}$ level, but with a different history of human capital accumulation $h_{\max , t}$. With high $h_{\max , t}$, the firm offers a wage contract that is less responsive to productivity shocks (both positive and negative), while with low $h_{\max , t}$, the firm offers a wage contract that is more sensitive to productivity shocks. When the wage contract is less sensitive, compensation to the worker is relatively smooth and acts as leverage to the owner's cash flow and firm value. When the wage contract fluctuates with respect to the productivity shocks, the cash flow and the firm value become smoother since the compensation hedges against the productivity risk for the capital owner. 


\subsection{Labor as Hedge or Leverage?}

Allowing the endogenous outside option produces the equilibrium joint distribution of wage contract dynamics and cash flow volatility. The wage contract can act either as a hedge against productivity shocks or as leverage for the owner's cash flow. Also, the leverage and hedge effect differs across firms, depending on the historical maximum level of human capital and the current human capital level. I define $\frac{h_{t}}{h_{\max , t-1}}$ as the distance between the current capital level and the running maximum level of the human capital, $h_{\max , t-1}$.

Proposition 3 Given $\varphi_{0}$ and $w_{0}, h_{\max , t}$ and $\frac{h_{t}}{h_{\max , t-1}}$ are the only relevant state variables that impact wage contract dynamics.

Proof. The dynamics are captured by the tightness of the participation constraint. Given the monotonicity of $\varphi_{\text {res }}(h)$ in equilibrium, the Proposition is straightforward.

The role of labor in the firm is governed by $\frac{h_{t}}{h_{\max , t-1}}$. I first define the wage-output sensitivity $\beta_{w, y}=\beta_{\Delta w, \Delta y}$ of wage growth on output growth as a measure of the degree of risk sharing in equilibrium. When $\frac{h_{t}}{h_{\max , t-1}}$ is greater than one, investment responds to the significant positive productivity shock, and firms optimize the total value by taking advantage of the better investment opportunity and committing to higher labor costs. Both the wageoutput sensitivity is then positive, $\beta_{w, y}>0$. The wage contract acts as a hedge to the cash flow risk. Labor acts as leverage to the cash flow and $\beta_{w, y}=0$ when $\frac{h_{t}}{h_{\max , t-1}} \leq 1$, since the wage contract is downward-rigid. The productivity risk is allocated optimally between the capital owner and the worker conditional on $\frac{h_{t}}{h_{\max , t-1}}$. The wage contract provides insurance to the worker for small positive and negative shocks, but not for large positive shocks. The state variable $\frac{h_{t}}{h_{\max , t-1}}$ has the same feature as all the dynamic contracts with limited commitment, e.g.,(Thomas and Worrall, 1988), (Kocherlakota, 1996), (Krueger and Uhlig, 2006), except that, here, the state variable $\frac{h_{t}}{h_{\max , t-1}}$ is from an endogenous decision.

A nice intuition behind the state variable $\frac{h_{t}}{h_{\max , t-1}}$ is the average $\mathrm{Q}$ value of the firm (as in Lustig et al. (2011)). The market-to-book ratio is defined as $q=\frac{M}{B}=\frac{V(h, \varphi, z)}{h}$. When 
$\frac{h_{t}}{h_{\max , t-1}}$ is low, for a given level $h_{t}$, a higher $h_{\max , t-1}$ indicates that the worker is compensated with higher rent according to the optimal wage contract, so $V(h, \varphi, z)$ is lower and, hence, $\frac{V(h, \varphi, z)}{h}$ is low. Low market-to-book ratio firms are low $\frac{h_{t}}{h_{\max , t-1}}$ firms. On the one hand, firms with a low market-to-book ratio are firms that have a higher historical maximum capital level, $h_{\max , t-1}$, and tend to provide better insurance to their workers. On the other hand, high market-to-book ratio firms have a relatively lower running maximum level of historical human capital, so they share less rent with workers, and the owners of the firms bear less productivity risk. Workers act more like leverage in the low market-to-book ratio firms, but act more like a hedge in the high market-to-book ratio firms.

\begin{tabular}{c|l|l|}
\multicolumn{1}{c}{$\frac{h_{t}}{h_{\max , t-1}} \leq 1$} & \multicolumn{1}{c}{$\frac{h_{t}}{h_{\max , t-1}}>1$} \\
\cline { 2 - 3 } High $h_{\text {max }, t}$ & $\beta_{\Delta w, \Delta y}=0$ & Low $\beta_{\Delta w, \Delta y}$ \\
High Leverage & Hedge \\
High $\sigma(\Delta C F)$ & Median $\sigma(\Delta C F)$ \\
\cline { 2 - 3 } Low $h_{\text {max }, t}$ & $\beta_{\Delta w, \Delta y}=0$ & High $\beta_{\Delta w, \Delta y}$ \\
Low Leverage & Hedge \\
& Median $\sigma(\Delta C F)$ & Low $\sigma(\Delta C F)$ \\
\cline { 2 - 3 } &
\end{tabular}

Table 1: Equilibrium Joint Distribution of $\beta_{w, y}$ and $\sigma(\Delta C F)$

The historical running maximum of human capital, $h_{\max }$, determines how the corporate rent created by the match of capital and labor is split between these two claimholders. When labor acts as leverage to the cash flow risk, $h_{\max }$ governs the difference in the leverage ratio. When labor acts as a hedge on productivity risk for the owners, $h_{\max }$ controls the difference in the magnitude of risk that the wage contract helps offset.

The dynamics of the wage contracts are characterized jointly by $\frac{h_{t}}{h_{\max , t-1}}$ and $h_{\max , t}$. The joint distribution of sensitivity of wage growth on output growth, $\beta_{w, y}$, and cash flow volatility in equilibrium lines up with the joint distribution of $\frac{h_{t}}{h_{\max , t-1}}$ and $h_{\max , t}$ in equilibrium (Table 1).

Figure 4 shows the dynamics of sensitivity and volatility with respect to the change of $\frac{h_{t}}{h_{\max , t-1}}$ and $h_{\max , t}$ before the match dissolves. The wage-output sensitivity is increasing in 
$\frac{h_{t}}{h_{\max , t-1}}$ and decreasing in $h_{\max , t}$. When $\frac{h_{t}}{h_{\max , t-1}} \leq 1$, wage growth responds little to output growth and wage-output sensitivity stays close to zero. When $\frac{h_{t}}{h_{\max , t-1}} \geq 1$, wage gets less sensitive and less responsive to output as $h_{\max , t}$ gets higher. The dynamic risk allocation is consistent with the cash flow volatility dynamics: the better the consumption smoothing provided to the worker, the more risk the capital owner bears.

(a) Risk Allocation: Sensitivity

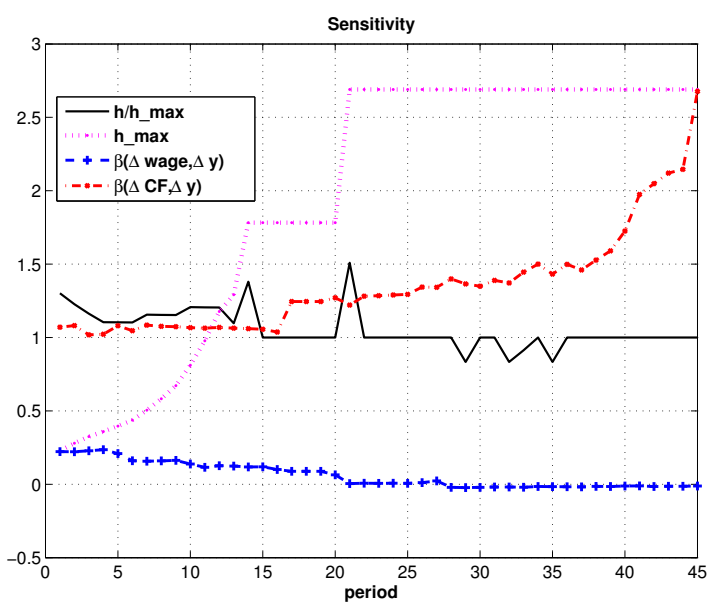

(b) Risk Allocation: Volatility

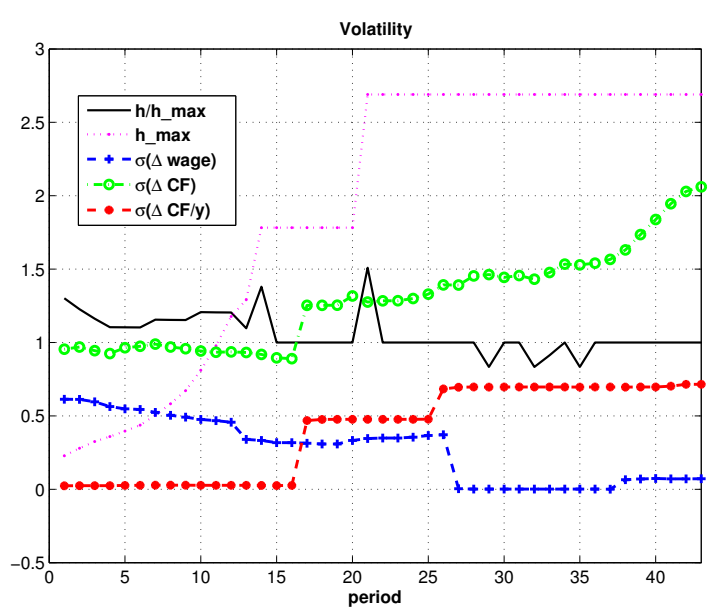

Figure 4: Risk Allocation in Equilibrium

This figure shows the equilibrium risk allocation in the simulated economy. Cash flow-output sensitivity and wage-output sensitivity are measured by the regression coefficient of cash flow/wage growth on the output growth $\Delta y$. I estimate the regression coefficient the volatility $\sigma_{t}$ at time $t$ using ten periods (forward) simulated data points.

The policy function of a numerical excercise in Figure 8 shows wage-output sensitivity and cash flow volatility as the function of $h$ and $\varphi$ implied by the model. To facilitate the quantitative analysis, Figure 8 shows the policy for the volatility of cash flows scaled by output $\left(\frac{C F}{y}\right)$. The result is preserved when cash flow is scaled by output. Since $h_{\max }$ is the sufficient statistic for the worker's promised utility $\varphi$, the policy function illustrates the dynamics of wage-output sensitivity and cash flow volatility with respect to $h$ and $h_{\max }$. The volatility of cash flow increases in $h_{\max }$ because of the leverage effect, but decreases in $h$. The reason why cash flow volatility decreases in $h$ in the policy function is as follows. When $h$ exceeds $h_{\max }$, wage contracts comove with the human capital level $h$ and act as 
hedges, so cash flow volatility remains at a low level; when $h$ is lower than $h_{\text {max }}$, the implicit wage contract becomes effective leverage, hence cash flow volatility is high. The wage-output sensitivity increases with respect to $h$, but decreases with respect to $h_{\max }$. In the bottom panel (left picture), wherever wage-output sensitivity hits zero, the value of promised utility $\varphi$ implies the value of $h_{\max }$ equal to $h$, and as $h_{\max }(\varphi)$ increases, the sensitivity is equal to zero. Higher wage-output sensitivity is obtained when $h$ is higher than $h_{\max }$.

\section{Quantitative Results}

This section presents the quantitative results of the stationary industry equilibrium. Computing the equilibrium requires the specification of the functional forms and determination of the parameter values. Because the exact analytical solution is impossible to obtain under this framework, the computational procedure is provided in Appendix B.

\subsection{Measurement and Data Construction}

One of the key features of the model is that it generates the distribution of firm-level human capital and the evolution of firm-level human capital accumulation. Measuring human capital or intangible capital has a long history in the economics literature. The conceptual and measurement approach depends on my theoretical predictions as well as the availability of firm-level data.

\subsubsection{Defining and Measuring Firm-Level Human Capital}

The key variable $h$ that governs the risk allocation dynamics is firm-level human capital: human capital that is accumulated along with production. Different from the standard definition of human capital (general skill of labor), firm-level human capital has more overlap with the intangible assets of the firm in both accounting terms and qualitative properties. Borrowing from the definition of intangible assets in Brynjolfsson et al. (2002), I focus on 
a firm's intellectual assets and innovation, as well as its organizational structure (including information technology and computer expenses).

According to the existing literature (Corrado et al. (2004), Lev and Radhakrishnan (2005), Hulten and Hao (2008), Eisfeldt and Papanikolaou (2013), Falato et al. (2013), etc.), in the Compustat database, the computerized information (including organizational structure, etc.) and the economic competencies (knowledge embedded in firm-specific human and structural resources, including brand names) are recognized as a fraction of Selling, General and Administrative (SG\&A) expenses, and the corresponding line for innovative property is R\&D expenses. I attribute $30 \%$ of SG\&A outlay: 7 plus R\&D expenses to labor-related intangible spending. All the investment spending is deflated by the production price index from NIPA.

To obtain the firm-level human capital stock, I start with the estimates of real investment spending and apply the perpetual inventory method $h_{t+1}=\left(1-\delta_{h}\right) h_{t}+I_{h}$. I need two further elements to implement the capital accumulation method: a depreciation rate $\delta_{h}$ and the capital benchmark $h_{0}$. Relatively little is known about depreciation rates for human capital. I borrow the depreciation rate estimated by Corrado et al. (2006) for all three categories of intangible assets. The initial capital stock, $h_{0}$, for each category is set to the same amount of capital spending as that of the first year available in the Compustat database divided by depreciation rate. The assumption of the initial stock value and depreciation rate is not crucial for the result since I am more interested in the relative position of firm-level human capital stock than in its quantitative value. For a robustness check, I use the total SG\&A expenses as labor-related investment at the firm level, and I also exclude R\&D expenses from our firm-level human capital investment estimates. The quantitative result remains robust in general.

\footnotetext{
${ }^{7}$ The labor-related items account for $10 \%$ to $70 \%$ of the SG\&A expenses (from 10-K fillings of public firms). In Hulten and $\mathrm{HaO}$ (2008), 30\% is applied to capture the investment in organizational development and worker training. I use 30\% here to follow the general guidance of Corrado et al. (2006)'s macro research.
} 


\subsubsection{Variables Construction}

\section{State Variable Construction}

Given the calculation of firm-level human capital stock $h_{i, t}$, the measure of $h_{\max , i t}$ is constructed in two ways.

First, I measure $h_{\max , i t}$ by taking the maximum of the whole history (available in the data). Although there are missing data before IPO, I assume that the first available observation captures that history.

Second, I construct $h_{\max , i t}$ by computing the value-weighted average of the past $N$-year firm-level human capital stock, $h_{t-N+1}, \ldots, h_{t}$. Also for robustness, I define a dummy variable $d_{h, t}=1$ if $h_{t-i}>h_{t-i+1}$, and impose the weight in that year, $w_{i, t}=0$. This measure helps to smooth out the noise by taking a moving weighted average of the historical capital stock, but it also rules out the data points where the depreciation of human capital is dominant. I drop the estimates whenever there is a missing observation in the N-year horizon. $h$ is scaled by the physical capital level given by gross property, plant, and equipment (PPEGT) item from Compustat.

\section{Other Variables}

The firm-level wage-output sensitivity $\beta_{w, y}$ is computed by running a ten-year rolling window regression of the per capita wage growth on the growth of per capita value-added. The regression is conducted for each firm, and I record the panel of the regression coefficients $\beta_{w, y, i t}$.

The sample includes all the U.S. public firms in CRSP-Compustat merge file frim 19602010. For consistency, I include firms with fiscal year ending month in December $(\mathrm{fyr}=12)$, firms with non-missing SIC codes, firms with non-negative value of sales and firms with non-missing SG\&A expenses. The details in the data sources, as well as the definition and construction of other variables can be found in Appendix C. All the firm characteristics and target moments for parameter choices are summarized in Table 8 . 


\subsection{Benchmark Parameter Choices}

Given the availability of firm-level public firm accounting data, I calibrate all the parameters of the model at an annual frequency to match the standard macroeconomic moments and firm dynamics.

Preference For convenience, I assume that employees are endowed with CRRA utility with a constant risk-aversion coefficient equal to $2(\gamma=2)$. The time preference parameter $\beta$ is set to 0.96 , which implies an annual risk-free rate of $4 \%$. I calibrate the model to match interest rate at a relatively higher level since the model does not have implications for the risk premium; $4 \%$ is the average of long-term risk premium and the 30-day U.S. Treasury bill return.

Technology Assume that production takes place in each firm according to a decreasing returns-to-scale Cobb-Douglas production function, $y_{t}=e^{z_{t}} h_{t}^{\alpha}$. The parameter $\alpha$ is drawn randomly from $[0.78,0.86]$. The range of human capital intensity is set to match the average labor share jointly with $\phi$. The output $y$ and firm-level human capital $h$ are both scaled by physical capital $k$.

The idiosyncratic productivity shocks are uncorrelated across firms and have a common stationary and monotonic Markov transition function, denoted by $Q_{z}\left(z_{t} \mid z_{t-1}\right)$ as $z_{t}=\rho_{z} z_{t-1}+$ $\sigma_{z} \epsilon_{t}$. The parameters $\rho_{z}$ and $\sigma_{z}$ are calibrated to match the unconditional second moments and first-order autocorrelation of firm-level TFP shocks. $\rho_{z}$ and $\sigma_{z}$ are also chosen to match the degree of persistence and the dispersion in the equilibrium distribution of firms, so I restrict their value to $\rho_{z}=0.7$ and $\sigma_{z}=0.3$. The new entrants draw the initial productivity level $z_{0}$ from a uniform distribution over the same finite support $z$ as the incumbents. See Appendix B.3 for details.

The rate of depreciation in human capital is set to equal $0.2 .8 \mathrm{I}$ also assume it is costly to adjust firm-level human capital in the calibration with the convex adjustment cost $g(h, I)=$

\footnotetext{
${ }^{8}$ A six-year write-off of human capital is suggested by Corrado et al. (2004).
} 
Table 2: Benchmark Calibration

\begin{tabular}{lcc}
\hline \hline Parameter & Symbol & Value \\
\hline Human capital intensity & $\alpha$ & $0.78-0.86$ \\
Human capital depreciation rate & $\delta_{h}$ & 0.2 \\
Symmetric investment adjustment cost & $\xi_{h}$ & 3.2 \\
Persistent coefficient of idiosyncratic productivity & $\rho_{z}$ & 0.7 \\
Conditional volatility of idiosyncratic productivity & $\sigma_{z}$ & 0.3 \\
Time preference & $\beta$ & 0.96 \\
Constant risk-aversion coefficient (CRRA utility) & $\gamma$ & 2 \\
Portability of human capital & $\phi$ & 0.5 \\
Production cost & $\mathrm{s}$ & 0.08 \\
\hline
\end{tabular}

The table presents the calibration parameter choice for the benchmark model. The parameters are either estimates from empirical studies or calibrated to match a set of key moments in the model to the U.S. data at an annual frequency. See Appendix B.3.

$\frac{1}{2} \xi_{h}\left(\frac{I}{h}\right)^{2} h$. The convexity parameter $\xi_{h}$ is set to 3.2 assuming a similar adjustment time of human capital from the empirical evidence (See Appendix B.3.

Labor Market There is little suggested evidence of $\phi$ in the data, and it's reasonable to believe that $\phi$ should vary across firms and over time. The parameters $\phi$ and $\alpha$ are calibrated to determine the labor share. In the benchmark calibration, I set $\phi=0.5$ to match the labor share 0.43 in U.S. public firms, since the major focus in this paper is on equilibrium distribution of human capital accumulation.

Entry and Exit The choice of fixed sunk cost $s$ and entry cost $F$ should be calibrated to match the entry and exit rate, respectively. The Compustat dataset provides an unbalanced panel with significant firm turnover. In the model, the match turnover dynamics are essentially skilled labor turnover at the micro level, so I calibrate the values to match the the plant-level exit and entry rate $6.2 \%$ found in the literature (e.g., Clementi and Palazzo (2010))

Table 2 summarizes the key parameter values used in solving and simulating the baseline model. 


\subsection{Calibration Results}

Table 3: Key Moments Under Baseline Parameterization

\begin{tabular}{lcc}
\hline \hline Target Moments & Model & Data \\
\hline Panel A: Technology & & \\
TFP persistency AR(1) & 0.7 & 0.7 \\
$\sigma(T F P)$ & 0.43 & 0.42 \\
& & \\
Panel B: Human Capital ( $h)$ & & \\
Standard Deviation & 2.55 & 2.59 \\
Skewness & 1.70 & 2.82 \\
Investment to Capital (h) Ratio & 0.21 & 0.23 \\
Investment to Revenue Ratio & 0.28 & 0.18 \\
& & \\
Panel C: Labor Share & 0.49 & 0.43 \\
wage & & \\
\hline output
\end{tabular}

The table presents key moments generated by the model baseline parameterization compared to the data moments. All the second moments reported above are unconditional. The investment to revenue ratio is the ratio of investment in organizational capital devided by net sales. The data source of firm-level cash flow and investment characteristics is from Compustat fundamental annual: 1960-2010 and Eisfeldt and Papanikolaou (2013). The data source of firm-level TFP is from Imrohoroglu and Tuzel (2011).

The model is solved numerically with all the details of solving the firm's optimization problem and the outside option in the industrial equilibrium in the Appendix B. I then simulate the economy with $N$ firms over $T$ periods using the optimal decision rule and value function. Set $N=3000$ and $T=300$ and repeat the simulation in a large number of times. The first 100 periods is discarded to make sure the convergence of the "simulated economy".

Panel A, B and C in Table 3 contain the key moments that the model is calibrated to match under benchmark parameterization. The parameters are chosen to match the distribution of firm-level human capital and TFP shocks. Table 4 provides the results of matching the data moments at the aggregate level. The model produces lower wage growth $(\log )$ volatility -1.48 than cash flows growth volatility -0.09 , which is close to the cash flow growth volatility in the data. The cash flow-output sensitivity is greater than one since the 
labor cost of firms is sticky. The model produces a lower wage-output sensitivity than what is found in the typical neoclassical production-based model. The model generates a lower wage-output sensitivity than the data. The per capita wage from the Compustat sample is the average wage among both administrative and manufacturing workers, so I expect to see a lower wage-output sensitivity once we are able to measure the wages of the skilled workers at the firm level 9

Table 4: Aggregate Results Under Baseline Parameterization

\begin{tabular}{lcc}
\hline \hline Moments & Model & Data \\
\hline Panel A: Wages and Cash Flows & & \\
$\operatorname{corr}(\Delta w a g e, \Delta y)$ & 0.22 & 0.22 \\
$\operatorname{corr}\left(\Delta \frac{C F}{y}, \Delta y\right)$ & 0.68 & 0.48 \\
$\beta(\Delta w a g e, \Delta y)$ & 0.09 & 0.25 \\
$\beta\left(\Delta \frac{C F}{y}, \Delta y\right)$ & 0.46 & 0.21 \\
$\log (\sigma(\Delta w a g e))$ & -1.48 & -1.83 \\
$\log (\sigma(\Delta C F))$ & -0.09 & -0.04 \\
$\log \left(\sigma\left(\Delta \frac{C F}{y}\right)\right)$ & -1.56 & -3.31 \\
& & \\
Panel B: Other Firm Characteristics & & \\
Market-to-Book Ratio & 1.68 & 1.8 \\
Exit Rate & $7.7 \%$ & $6.2 \%$ \\
\hline
\end{tabular}

The table presents aggregate results generated by the model's baseline parameterization compared to the moments from the data. The cash flow volatility $\sigma(\Delta C F)$ is the standard deviation of the simple first-order difference in firm-level cash flow over a ten-year rolling window. All the second moments are unconditional averages. The sensitivity estimates $\beta(\Delta$ wage, $\Delta y)$ and $\beta(\Delta C F, \Delta y)$ are from the pooled OLS regressions. The firm-level cash flow and investment characteristics data are from Compustat Fundamental Annual: 1960-2010.

\subsubsection{Joint Distribution of Wage-Output Sensitivity and Cash Flow Volatility}

Figure 6 shows the time series of the average cash flow volatility within different wageoutput sensitivity groups. The highest $\beta_{w, y}$ group on average is $70 \%$ lower than the lowest $\beta_{w, y}$ group in cash flow volatility. This magnitude is more than half of the unconditional

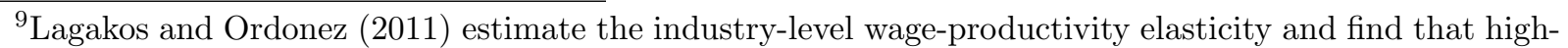
skilled industries have the most wage smoothing, with elasticity close to zero. Jensen and Murphy (1990) show a very weak relationship between the top-management compensation and shareholders' performance.
} 
standard deviation (1.30) of cash flow volatility in the whole sample. In fact, in the highest $\beta_{w, y}$ quantile, the cash flow volatility trends downward over time.

Table 5 shows the cash flow volatility of different wage-output sensitivity groups. The wage-output sensitivity $\beta_{w, y}$ is estimated using the regression coefficient of wage growth and output growth over a ten-period ${ }^{10}$ rolling window for each firm in the simulated economy. I also obtain estimates of firm-level cash flow volatility over the same window. All the firms are sorted into three groups based on $\beta_{w, y}$. The simulation is repeated 100 times. Table 5 reports the cross-simulation averages for each group.

Table 5 Panel B shows that there is a spread of $70 \%$ in cash flow volatility (among different wage-output sensitivity groups). The model also produces about $60 \%$ difference in cash flow volatility between highest $\beta_{w, y}$ group and the lowest $\beta_{w, y}$ group. The change in degree of insurance provided to the workers within the firm is correlated with the change in the firm-level cash flow volatility and hence the return volatility.

The model captures the joint distribution of wage dynamics and cash flow volatility in the data. Panel B of Table 5 shows a strong positive relationship between $\beta_{w, y}$ and cash flow volatility and a positive relationship between $\beta_{w, y}$ and firm-level stock return volatility. The fact that the cash flow volatility spread between the highest $\beta$ group and the lowest is the same as the wage volatility spread indicates that the variation in cash flow volatility is due to the variation in wage contract sensitivity. The wage leverage is more effective and stickier in the low $\beta_{w, y}$ group, where firm-level cash flow growth is more volatile. One exception is that the model does not generate the same magnitude of stock return volatility, since the risk premium and stochastic discount factor are not modeled here. However, the stock return volatility across $\beta_{w, y}$ groups decreases with respect to $\beta_{w, y}$, and the difference in volatility between the highest and the lowest $\beta_{w, y}$ groups is about $15 \%$ in the data.

\footnotetext{
${ }^{10} \mathrm{I}$ apply both five-period and fifteen-period window to estimate the wage-output sensitivity, the result is robust in general.
} 
Table 5: Volatility of Portfolios Sorted on $\beta(\Delta w, \Delta y)$

\begin{tabular}{lcccc}
\multicolumn{5}{c}{ Panel A: Model Portfolio Volatility } \\
\hline \hline Group $(\beta \Delta w, \Delta y)$ & $\log (\sigma \Delta$ wage $)$ & $\log (\sigma r e t)$ & $\log \left(\sigma \Delta \frac{C F}{y}\right)$ & $\log (\sigma \Delta C F)$ \\
low & -3.37 & -0.85 & -1.17 & 0.51 \\
median & -2.66 & -0.97 & -1.38 & 0.19 \\
high & -2.46 & -1.11 & -1.77 & -0.23 \\
\hline \multicolumn{5}{c}{} \\
\hline \hline Group $(\beta \Delta w, \Delta y)$ & $\log (\sigma \Delta w a g e)$ & $\log (\sigma r e t)$ & $\log \left(\sigma \Delta \frac{C F}{y}\right)$ & $\log (\sigma \Delta C F)$ \\
low & -2.30 & -3.69 & -3.38 & 0.31 \\
median & -2.26 & -3.72 & -3.55 & -0.19 \\
high & -1.81 & -3.84 & -4.08 & -0.52 \\
\hline
\end{tabular}

This table presents the volatility of wages and cash flows for the $\beta(\Delta w, \Delta y)$ sorted portfolios. $\frac{C F}{y}$ is the operating income scaled by sales. The volatility is in terms of $\log$ and is annualized. The volatility is computed within a ten-year rolling window and average across firms within the group. The cash flow volatility $\sigma(\Delta C F)$ is the standard deviation of the simple first-order difference in firm-level cash flow over a ten-year rolling window. The stock return volatility is computed using CRSP daily stock returns, and I derive the stock return volatility using observations within each year and then annualize the volatility estimates. Panel A reports the results from the simulation based on the benchmark choice of parameters. Panel B reports the results from the historical data (1960-2010).

\subsubsection{Joint Distribution of State Variables and Cash Flow Volatility}

I now show the empirical results that support the model mechanism and the consistent transitory dynamics of the state variables with cash flow volatility and the wage-output sensitivity. Two main predictions are obtained regarding the joint distribution of state variables and key second moments from both Corollary 2 and Proposition 3 First, the higher the maximal level of human capital, the lower is the wage sensitivity conditional on $\frac{h_{t}}{h_{\max , t-1}}>1$; second, the higher the maximal level of human capital, the higher is the cash flow volatility unconditionally.

Table 6 shows the portfolio cash flow volatility and portfolio wage-output sensitivity for different $h_{\max }$ groups conditional on $\frac{h_{t}}{h_{\max }}$ from the data. In Panel A, cash flow volatility increases with $h_{\max }$ unconditionally, with a $90 \%$ difference between high $h_{\max }$ group and low $h_{\max }$ group. In Panel $\mathrm{B}$, there is also consistent evidence that $\beta_{w, y}$ is lower when $h_{\max }$ gets 
Table 6: 3 Portfolios Sorted by State Variables (Data)

\begin{tabular}{rrccccr} 
& Panel A: & $\log \left(\sigma\left(\frac{C F}{y}\right)\right)$ & & Panel B: & $\beta(\Delta w, \Delta y)$ & \\
\hline & & $\frac{h_{t}}{h_{\max , t-1}}$ & & & $\frac{h_{t}}{h_{\max , t-1}}$ & \\
$\operatorname{Group}\left(h_{\max }\right)$ & $\leq 1$ & $>1$ & Total & $\leq 1$ & $>1$ & Total \\
low & -3.47 & -3.37 & -3.44 & 0.30 & 0.32 & 0.30 \\
median & -3.06 & -3.00 & -3.04 & 0.12 & 0.11 & 0.12 \\
high & -2.55 & -2.58 & -2.56 & 0.09 & 0.10 & 0.09 \\
\hline
\end{tabular}

This table presents the cash flows $\left(\frac{C F}{y}\right)$ growth volatility and wage-output sensitivity for the $h_{\text {max }}$-sorted and $\frac{h_{t}}{h_{\max , t-1}}$-sorted portfolios. Both the standard deviation and the sensitivity are computed within a ten-year rolling window and averaged across firms within the group. The volatility is the log of the standard deviation and is annualized. Data Source: Compustat Fundamental Annual: 1960-2010.

Table 7: 3 Portfolios Sorted by State Variables (Model)

\begin{tabular}{|c|c|c|c|c|c|c|}
\hline \multirow{4}{*}{$\operatorname{Group}\left(h_{\max }\right)$} & Panel A: & \multicolumn{2}{|c|}{$o g\left(\sigma\left(\frac{C F}{y}\right)\right)$} & \multicolumn{3}{|c|}{$\beta(\Delta w, \Delta y)$} \\
\hline & & $\frac{h_{t}}{h_{\max , t-1}}$ & & & $\frac{h_{t}}{h_{\text {max } t-t}}$ & \\
\hline & $\leq 1$ & $>1$ & Total & $\leq 1$ & $>1$ & Total \\
\hline & -1.62 & -1.66 & -1.65 & 0.03 & 0.06 & 0.03 \\
\hline median & -1.22 & -1.21 & -1.21 & 0.008 & 0.01 & 0.01 \\
\hline high & -1.13 & -1.19 & -1.18 & -0.15 & -0.25 & -0.16 \\
\hline
\end{tabular}

This table presents the cash flow $\left(\frac{C F}{y}\right)$ growth volatility and wage-output sensitivity estimated from the simulated economy using the benchmark calibration. The exact same procedure of estimation is conducted in the simulated economy. The standard deviation and sensitivity $\beta$ are computed within a ten-period rolling window and averaged across firms within the group. The volatility is in terms of log.

higher. In terms of predicting cash flow growth volatility, $\frac{h_{t}}{h_{\max }}$ does not play a significant role. Conditional on $\frac{h_{t}}{h_{\max }}>1$, cash flow growth volatility is on average higher, while the model predicts less risk allocated to the owners because part of the volatility is absorbed by the wage contract. The data do not show a strong effect of $\frac{h_{t}}{h_{\max }}$, mainly because over time there is a positive trend in $h_{t}$. In most of the sample period, $\frac{h_{t}}{h_{\max }}$ is a number slighly above 1 . In terms of model evaluation, the simulated economy also generate a reasonable distribution of cash flow growth volatility (see Table 7). The average cash flow volatility in the highest $h_{\max }$ group is $47 \%$ higher than the lowest $h_{\max }$ group. The group with $\frac{h}{h_{\max }}>1$ does not produce a much lower cash flow volatility than the group with $\frac{h}{h_{\max }} \leq 1$ due to the way I estimate 
the second moments. Cash flow volaitlity and wage-output sensitivity are both estimated

over a ten-period rolling window, so $\frac{h}{h_{\max }}>1$ at period $t$ does not gurantee that $\frac{h}{h_{\max }}>1$ in the following nine periods within the window. Wage-output sensitivity is higher on average in the group with $\frac{h}{h_{\max }}>1$, and there is a 0.21 spread between high $h_{\text {max }}$ group and the low $h_{\max }$ group. In the high $\beta_{w, y}$ group, the negative $\beta_{w, y}$ comes from workers 's turnover and the negative growth of output when the firm has a high-water mark of human capital. For the same reason as I match the aggregate moments, the model produces a relatively lower wage-output sensitivity than the data.

\subsection{Increasing Cash Flow Volatility 1960-2010}

Knowing how risk is allocated between capital and labor within the firm not only helps us to understand the cross sections of cash flow volatility, but also provides a novel explanation for the time-varying firm-level cash flow volatility. Capital owners of U.S. public firms bear more and more risk over the past few decades (Comin and Philippon (2005), Comin et al. (2009) and Kelly et al. (2012),etc.). Table 9 provides the key measure of intra-firm risksharing dynamics over different periods. On average, $h_{\max }$, cash flow growth volatility and wage growth volatility (i.e., firm-level volatility) all increase at the firm level, but within the firm, the wage-output sensitivity decreases $41 \%$ (Figure 5). The average U.S. public firms have become more and more human capital intensive and have provided better insurance to their workers over time (Figure 5).

As shown in Figure 5, risk allocation between labor and capital owners presents different patterns across industries. The industries with high $h_{\max }$ in equilibrium have lower wage sensitivity to output growth. Even industries that are currently experiencing positive productivity shocks have little flexibility in adjusting compensation since their production technologies rely heavily on human capital. If we look at the intra-firm risk allocation dynamics of different industries, the average wage-output sensitivity trends downward (Figure 5(b) , with information, computer and technology industry declining the most. In manufac- 
(a) Industry $h_{\max }$

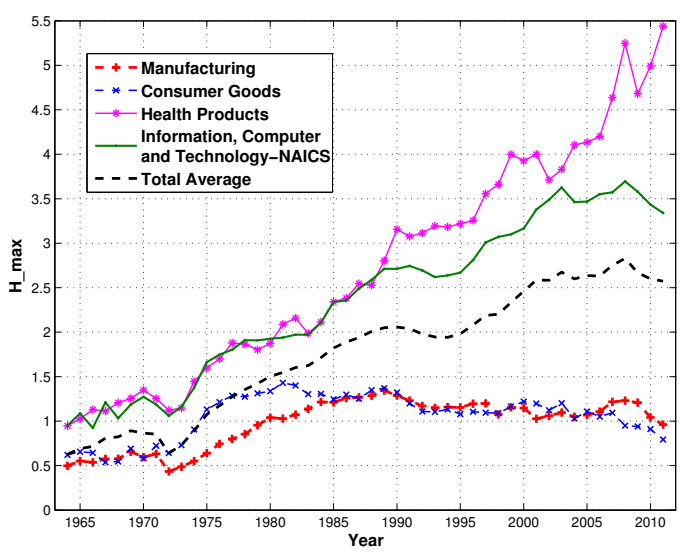

(b) Industry $\beta(\Delta w, \Delta y)$

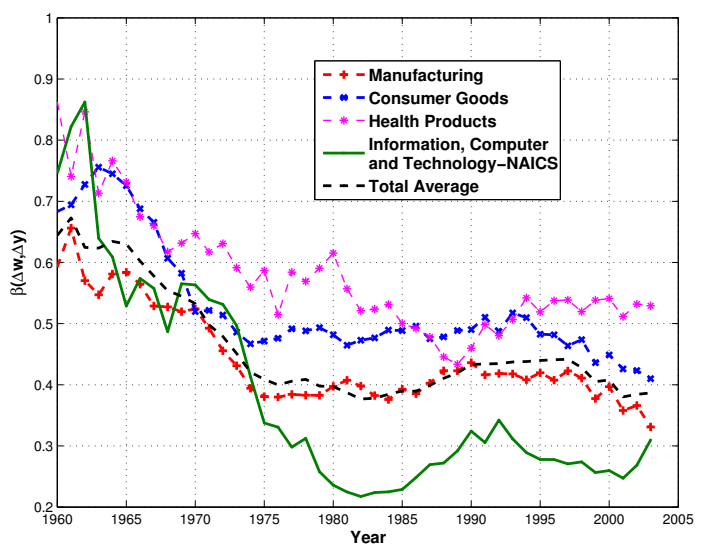

Figure 5: Time Series Historical Maximum of Firm-Level Human Capital and Wage-Output Sensitivity

The figure shows the time series of historical maximum of firm-level human capital and wage-output sensitivity for different industries. The maximum human capital level $h_{\max }$ is measured by the value-weighted $h_{t}$ over the past five years and scaled by the physical capital stock over the same period. The wage-output sensitivity at the industry level is the average of wage-output sensitivity estimates of firms within the industry. Sample period: 1960-2010.

turing and consumer goods, where cash flow volatility increased mildly before the 1980s, the firm-level human capital accumulation is relatively stable.

The secular rise in intangible capital is well-documented in macroeconomics and finance literature ${ }^{11}$. Since $h_{\max }$ has increased over time, I conduct a comparative-static excercise to see whether the model converges to a different equilibrium cash flow volatility by varying the human capital intensity parameter in the production function. Figure 13(a) shows that equilibrium $h$ distribution with different $\alpha$ values leads to heterogeneous cash flow volatility and wage-output sensitivity, which is highly consistent with the time series moments in Figure. 13(b).

As shown in Figure $12(\mathrm{~b})$, the fraction of firms with $\frac{h_{t}}{h_{\max , t-1}}$ lower than one increases over time, while $\frac{h_{t}}{h_{\max , t-1}}$ decreases over time, but on average is above one. The average firm in the

\footnotetext{
${ }^{11}$ Jovanovic and Rousseau (2008) emphasize the rise in firm specificity of human capital as a result of the growth of product variety. Falato et al. (2013) explores the rise in intangible assets as a fundamental driver of the secular trend in U.S. corporate cash holdings over the past few decades.
} 
market exhibits growth in firm-level human capital, implying that there is improvement in risk sharing at the firm-level. The ratio of the current human capital level to the historical maximal human capital level is relevant for this explanation. The ratio tends to be above one, on average, before 1980, and then decreases after 1980. The maturity indicates a high inflexibility in the labor sector of a firm, which creates a strong leverage effect on the firm's cash flow.

\subsection{Empirical Evidence From Panel Analysis}

As additional empirical examination of my theory, I conduct the panel analysis and confirm the model's implications using actual data. There are three key implications from the theory: 1) a positive relationship between the historical maximum of firm-level human capital and wage contracts; 2) a negative relationship between compensation sensitivity and the maximal firm-level human capital conditional on $\frac{h_{t}}{h_{\max , t-1}}>1$; 3) a positive relationship between cash flow volatility and maximal firm-level human capital unconditionally.

\subsubsection{Wage Contract and $h_{\max }$}

First, wage level is predicted by $h_{\max , t}$ controlling for current productivity shocks and other firm characteristics. The prediction is tested as follows:

$$
\text { wage }_{i t}=\alpha+\eta_{i}+\lambda_{t}+\beta_{1} h_{\max , i t}+\beta_{2} T F P_{i t}+\Gamma X_{i t}+\epsilon_{i t},
$$

where $X_{i t}$ is a vector of control variables, including market-to-book ratio, net sales, and market capitalization. The results are shown in Table 10 and Table 11 as the robustness check. Wage is measured using per capita labor expenses from Compustat dataset (wage I) or using per capita labor expenses with the missing total labor expenses replaced by per capita SG\&A (wage II). See Appendix C for details. Table 10 shows the regression results using the direct measure of $h_{\max }$. The dependent variable is $\log$ (wage I) in the columns (1) 
and (2) and is $\log ($ wage II) in the columns (3) and (4). Controlling for the current TFP level, $h_{\max }$ is positively correlated with wage level $\left(\beta_{1}>0\right)$. The result also holds when the historical maximum TFP level is used as the measure of the historical maximum of firm-level human capital accumulation. Table 11 reports the regression results using the value-weighted measure of $h_{\max , v w}($ see Appendix C).

The effect of the historical maximum of firm-level human capital on the average real wage is statistically significant and sizeable. Controlling for the current productivity level, a one standard deviation ${ }^{12}$ change in $h_{\text {max }}$ accounts for a $22 \%$ increase in the firm-level average real wage. Workers are compensated by firms' historical investment in human capital. Over the period from 1960 to 2010, the maximum of accumulated human capital has increased 267\% (about one standard deviation, see Table 9), while the average real wage at the firm level has increased by an average of $85 \%$. The historical maximum of firm-level human capital indicates an increase of greater than $25 \%$ in the average real wage in the sample.

\subsubsection{Risk Allocation and Firm-Level Human Capital Investment}

The model has direct implications for how wage contracts respond to output growth, conditional on the history of firm-level human capital. Wage-output sensitivity is positive when the firm hits a new running maximum of human capital, $h_{\max }$, but wage-output sensitivity is negatively correlated with maximal firm-level human capital conditional on $\frac{h_{t}}{h_{\max , t-1}}>1$.

I first conduct a regression of wage growth on dummy $D\left(h_{\max , i t}>h_{\max , i t-1}\right)=1$ if $h_{\max , i t}>h_{\max , i t-1}$, controlling for output growth, and adding the interaction term of $D\left(h_{\max , i t}>h_{\max , i t-1}\right)$ and output growth:

$\Delta$ wage $_{i t}=\alpha+\eta_{i}+\lambda_{t}+\beta_{1} D\left(h_{\max , i t}>h_{\max , i t-1}\right)+\beta_{2} \Delta y+\beta_{3}(D u m m y \times \Delta y)+\Gamma X_{i t}+\epsilon_{i t} .(17$

Wage growth is the difference in the log average real wage of each firm. As shown in the regression results in Table 12, the output growth is proxied by using labor productivity

\footnotetext{
${ }^{12}$ The standard deviation of $\log \left(h_{\max }\right)$ is 1.35 .
} 
growth (column (1)-(2)) and value-added growth (column (3)-(4)). Robust results are obtained by changing the measures for output. The wage growth is positive when firms invest in their firm-level human capital $\left(\beta_{1}>0\right)$, and is significantly positively correlated to output growth. With a one standard deviation increase in labor productivity growth, wage growth increases (on average) 11.5\%, contributing to $55 \%$ of the wage growth standard deviation. This result is consistent with the average labor share in U.S. public firms. The regression coefficient is negative in the interaction term, which is also aligned with the model's predictions. When firms increase their human capital accumulation, the sensitivity of wage growth to labor productivity growth declines. The following regression is needed to help explain the magnitude of this finding:

$$
\Delta \text { wage }_{i t}=\alpha+\eta_{i}+\lambda_{t}+\beta_{1} h_{\max , i t}+\beta_{2} \Delta y+\beta_{3}\left(h_{\max , i t} \times \Delta y\right)+\Gamma X_{i t}+\epsilon_{i t}
$$

A negative regression coefficient $\beta_{3}$ means that $h_{\max }$ increases, the wage-output sensitivity

declines. In the subsample $\frac{h_{t}}{h_{\max , t-1}}>1, \beta_{3}$ is significantly negative (Table 14 , column (2)). A one standard deviation increase in $h_{\max }$ absorbs $8 \%$ of the wage-output sensitivity, which is $13 \%$ of a standard deviation of $\beta_{w, y}$. The negativity of $\beta_{3}$ is robust to the change of measure of $\Delta y$ (Table 14, column (4)). In the subsample where $\frac{h_{t}}{h_{\max , t-1}} \leq 1, \beta_{3}$ is either non-negative or insignificant. Table 13 reports the results using wage (I) as the dependent variables. All results remain robust, except for the significant negative $\beta_{3}$ when using $\Delta t f p$ as the measure of $\Delta y$.

\subsubsection{Cash Flow Volatility and Human Capital Accumulation}

Finally, I examine whether the model's implication for cash flow volatility is also confirmed in the data. I test the positive correlation between cash flow volatility and historical human capital accumulation in the subsample where $\frac{h_{t}}{h_{\max , t-1}} \leq 1$, and then compare the results with 
the results where $\frac{h_{t}}{h_{\max , t-1}}>1$.

$$
\sigma(\Delta C F)=\alpha+\eta_{i}+\lambda_{t}+\beta_{1} h_{\max , i t}+\Gamma X_{i t}+\epsilon_{i t}
$$

Regression results are shown in Table 15. Cash flow volatility is significantly negatively correlated with $h_{\max }$. In column (3) when $\frac{h_{t}}{h_{\max , t-1}} \leq 1, h_{\max }$ predicts a higher cash flow volatility than when $\frac{h_{t}}{h_{\max , t-1}}>1$. Unconditionally, a one standard deviation increase in $h_{\max }$ leads to a $30 \%$ change in cash flow volatility. When $\frac{h_{t}}{h_{\max , t-1}} \leq 1$, the leverage effect of human capital is amplified and leads to $50 \%$ increase in cash flow volatility. Over the sample period from 1960 to 2010, firm-level $h_{\max }$ has increased by about one standard deviation, which predicts a $30 \%$ change in cash flow volatility on average. This result seems to underestimate the incremental size of cash flow volatility, but the intra-firm channel dominates other firm characteristics in predicting change in cash flow risk. I also check equity return volatility as a measure of firm-level cash flow risk. I find that equity return volatility is positively correlated with $h_{\max }$, but this significant positive correlation is found only in the sample where $\frac{h_{t}}{h_{\max , t-1}} \leq 1$. The labor "leverage" effect is stronger than the size effect from column (1).

\section{Conclusion}

Who bears more risk within the firm? It depends on the current and historical human capital of the firm. On the one hand, wage contracts can serve as a hedging device to the capital owner's cash flow risk when the firm has a higher current level of human capital than its historical maximum. On the other hand, wage contracts can behave like debt and leverage the cash flow risk when the historical level of human capital is higher than the current level.

To understand the heterogeneous roles of labor in the firm, I develop a theory in which the optimal wage contract and the optimal investment decision are both endogenously determined in equilibrium. This paper is the first to generate the joint distribution of cash 
flow volatility and wage-output sensitivity. Empirically, my predictions from the model line up with the cross-sectional and time series evidence in the data. The intra-firm risk allocation channel explains more than $50 \%$ of the cash flow volatility variation in the data. Over time, the decline in wage-output sensitivity coincides with the increase in firm-level cash flow volatility.

The intra-firm labor frictions bring a novel perspective to understanding the firm-level risk. Firms have invested more and more in the workers over the past few decades. This paper shows that investing in human capital can be potentially more costly than investing in physical capital. Better understanding of the endogenous investment cost on human capital and its implications for asset returns is an important part of the future research. 


\section{References}

Abowd, John M., John Haltiwanger, Ron Jarmin, Julia Lane, Paul Lengermann, Kristin McCue, Kevin McKinney, and Kristin Sandusky, "The Relation among Human Capital, Productivity, and Market Value: Building Up from Micro Evidence," in "Measuring Capital in the New Economy" NBER Chapters, National Bureau of Economic Research, Inc, 2005, pp. 153-204.

Ai, Hengjie, Dana Kiku, and Rui Li, "A Mechanism Design Model of Firm Dynamics: The Case of Limited Commitment," July 2013. Available at SSRN: http://ssrn.com/abstract=2347821.

Atkeson, Andrew and Patrick J. Kehoe, "Modeling and Measuring Organization Capital," Journal of Political Economy, October 2005, 113 (5), 1026-1053.

Baker, George, Michael Gibbs, and Bengt Holmstrom, "The Wage Policy of a Firm," The Quarterly Journal of Economics, November 1994, 109 (4), 921-55.

Beaudry, Paul and John DiNardo, "The Effect of Implicit Contracts on the Movement of Wages over the Business Cycle: Evidence from Micro Data," Journal of Political Economy, August 1991, 99 (4), 665-88.

Benmelech, Efraim, Nittai K. Bergman, and Amit Seru, "Financing Labor," NBER Working Papers 17144, National Bureau of Economic Research, Inc., June 2011.

Berk, Jonathan B. and Johan Walden, "Limited Capital Market Participation and Human Capital Risk," Review of Asset Pricing Studies, April 2013, 3 (1), 1-37.

_, Richard Stanton, and Josef Zechner, "Human Capital, Bankruptcy, and Capital Structure," Journal of Finance, June 2010, 65 (3), 891-926.

Bloom, Nicholas, "The Impact of Uncertainty Shocks," Econometrica, May 2009, 77 (3), 623-685.

Brynjolfsson, Erik, Loren Hitt, and Shinkyu Yang, "Intangible Assets: How the Interaction of Computers and Organizational Structure Affects Stock Market Valuations," Brookings Papers on Economic Activity, 2002, 33 (1), 137-198.

Clementi, Gian Luca and Dino Palazzo, "Entry, Exit, Firm Dynamics, and Aggregate Fluctuations," Working Paper Series 27-10, The Rimini Centre for Economic Analysis, January 2010.

Comin, Diego and Sunil Mulani, "Diverging Trends in Macro and Micro Volatility," Review of Economics and Statistics, May 2006.

_ and _ , "A theory of growth and volatility at the aggregate and firm level," Journal of Monetary Economics, November 2009, 56 (8), 1023-1042. 
- and Thomas Philippon, "The Rise in Firm-Level Volatility: Causes and Consequences," NBER Working Papers 11388, National Bureau of Economic Research, Inc., May 2005.

_ , Erica L. Groshen, and Bess Rabin, "Turbulent firms, turbulent wages?," Journal of Monetary Economics, January 2009, 56 (1), 109-133.

Corrado, Carol A., Charles R. Hulten, and Daniel E. Sichel, "Intangible Capital and Economic Growth," NBER Working Papers 11948, National Bureau of Economic Research, Inc., January 2006.

Corrado, Carol, Charles Hulten, and Daniel Sichel, "Measuring capital and technology: an expanded framework," Finance and Economics Discussion Series 2004-65, Board of Governors of the Federal Reserve System (U.S.) 2004.

Danthine, Jean-Pierre and John B Donaldson, "Labour Relations and Asset Returns," Review of Economic Studies, January 2002, 69 (1), 41-64.

Demarzo, Peter M., Michael J. Fishman, Zhiguo He, and Neng Wang, "Dynamic Agency and the q Theory of Investment," Journal of Finance, December 2012, 67 (6), 2295-2340.

Donangelo, Andres, "Labor Mobility: Implications for Asset Pricing," Journal of Finance, Forthcoming, May 2013.

Eisfeldt, Andrea L. and Dimitris Papanikolaou, "Organization Capital and the CrossSection of Expected Returns," The Journal of Finance, Feburary 2013, 68 (4), 1365 1406.

Falato, Antonio, Dalida Kadyrzhanova, and Jae Sim, "Rising Intangible Capital, Shrinking Debt Capacity, and the US Corporate Savings Glut," Technical Report, FEDS Working Paper No. 2013-67 September 2013.

Favilukis, Jack and Xiaoji Lin, "Does Wage Rigidity Make Firms Riskier? Evidence from Long-Horizon Return Predictability," Working Paper Series 2012-19, Ohio State University, Charles A. Dice Center for Research in Financial Economics, October 2012.

_ and _ , "Wage Rigidity: A Quantitative Solution to Several Asset Pricing Puzzles," July 2013. Fisher College of Business Working Paper No. 2012-03-016; Charles A. Dice Center Working Paper No. 2012-16. Available at SSRN: http://ssrn.com/abstract=2141275.

Garmaise, Mark J., "Production in Entrepreneurial Firms: The Effects of Financial Constraints on Labor and Capital," Review of Financial Studies, April 2008, 21 (2), 543-577.

Gomes, Joao F., "Financing Investment," American Economic Review, December 2001, 91 (5), 1263-1285.

Gourio, Francois, "Labor Leverage, Firms Heterogeneous Sensitivities to the Business Cycle, and the Cross-Section of Returns," 2008 Meeting Papers 149, Society for Economic Dynamics, 2008. 
Guiso, Luigi, Luigi Pistaferri, and Fabiano Schivardi, "Insurance within the Firm," Journal of Political Economy, October 2005, 113 (5), 1054-1087.

Hall, Robert E., "The Stock Market and Capital Accumulation," American Economic Review, December 2001, 91 (5), 1185-1202.

Harris, Milton and Bengt Holstrom, "A Theory of Wage Dynamics," Review of Economic Studies, July 1982, 49 (3), 315-33.

He, Zhiguo, "A model of dynamic compensation and capital structure," Journal of Financial Economics, May 2011, 100 (2), 351-366.

Hopenhayn, Hugo A, "Entry, Exit, and Firm Dynamics in Long Run Equilibrium," Econometrica, September 1992, 60 (5), 1127-50.

Hulten, Charles and Janet Hao, "Intangible Capital and the Market to Book Value Puzzle," Economics Program Working Papers 08-02, The Conference Board, Economics Program, June 2008.

Imrohoroglu, Ayse and Selale Tuzel, "Firm Level Productivity, Risk, and Return," 2011 Meeting Papers 21, Society for Economic Dynamics, 2011.

Irvine, Paul J. and Jeffrey Pontiff, "Idiosyncratic Return Volatility, Cash Flows, and Product Market Competition," Review of Financial Studies, March 2009, 22 (3), 11491177.

_ and _ , "Idiosyncratic Return Volatility, Cash Flows, and Product Market Competition," Review of Financial Studies, March 2009, 22 (3), 1149-1177.

Jensen, Michael C and Kevin J Murphy, "Performance Pay and Top-Management Incentives," Journal of Political Economy, April 1990, 98 (2), 225-64.

Jovanovic, Boyan and Peter L. Rousseau, "Specific Capital and Technological Variety," NBER Working Papers 13998, National Bureau of Economic Research, Inc., May 2008.

Jurado, Kyle, Sydney C. Ludvigson, and Serena Ng, "Measuring Uncertainty," NBER Working Papers 19456, National Bureau of Economic Research, Inc., September 2013.

Kelly, Bryan T., Hanno N. Lustig, and Stijn Van Nieuwerburgh, "The Volatility Factor Structure," November 2012. Chicago Booth Research Paper No. 12-54; Fama-Miller Working Paper.

_, _, and _, "Firm Volatility in Granular Networks," NBER Working Papers 19466, National Bureau of Economic Research, Inc., September 2013.

Kocherlakota, Narayana R, "Implications of Efficient Risk Sharing without Commitment," Review of Economic Studies, October 1996, 63 (4), 595-609. 
Koop, Gary, M. Hashem Pesaran, and Simon M. Potter, "Impulse response analysis in nonlinear multivariate models," Journal of Econometrics, September 1996, 74 (1), 119147.

Krueger, Dirk and Harald Uhlig, "Competitive risk sharing contracts with one-sided commitment," Journal of Monetary Economics, October 2006, 53 (7), 1661-1691.

Lagakos, David and Guillermo L. Ordonez, "Which workers get insurance within the firm?," Journal of Monetary Economics, September 2011, 58 (6), 632-645.

Lazear, Edward P., "Firm-Specific Human Capital: A Skill-Weights Approach," Journal of Political Economy, October 2009, 117 (5), 914-940.

Lev, Baruch and Suresh Radhakrishnan, "The Valuation of Organization Capital," in "Measuring Capital in the New Economy" NBER Chapters, National Bureau of Economic Research, Inc.,, July 2005, pp. 73-110.

Lustig, Hanno, Chad Syverson, and Stijn Van Nieuwerburgh, "Technological change and the growing inequality in managerial compensation," Journal of Financial Economics, March 2011, 99 (3), 601-627.

Malkiel, Burton, John Campbell, Martin Lettau, and Yexiao Xu, "Have Individual Stocks Become More Volatile? An Empirical Exploration of Idiosyncratic Risk," Journal of Finance, 02 2001, 56 (1), 1-43.

Michelacci, Claudio and Vincenzo Quadrini, "Financial Markets and Wages," The Review of Economic Studies, 2009, 76 (2), 795-827.

Olley, G Steven and Ariel Pakes, "The Dynamics of Productivity in the Telecommunications Equipment Industry," Econometrica, November 1996, 64 (6), 1263-97.

Shapiro, Matthew D, "The Dynamic Demand for Capital and Labor," The Quarterly Journal of Economics, August 1986, 101 (3), 513-42.

Tate, Geoffrey and Liu Yang, "The Bright Side Of Corporate Diversification: Evidence From Internal Labor Markets," Working Papers 13-40, Center for Economic Studies, U.S. Census Bureau., August 2013.

Thomas, Jonathan and Tim Worrall, "Self-enforcing Wage Contracts," Review of Economic Studies, October 1988, 55 (4), 541-54.

von Wachter, Till and Stefan Bender, "Do initial conditions persist between firms? : an analysis of firm-entry cohort effects and job losers using matched employer-employee data," IAB Discussion Paper 200719, Institut fr Arbeitsmarkt- und Berufsforschung (IAB), Nrnberg [Institute for Employment Research, Nuremberg, Germany] June 2007.

Whited, Toni M, "Debt, Liquidity Constraints, and Corporate Investment: Evidence from Panel Data," Journal of Finance, September 1992, 47 (4), 1425-60. 


\section{A Technical Appendix}

\section{A.1 Aggregation}

\section{Technical Assumptions}

(a) The space of input is a subset of the (non-negative) bounded real numbers, $\mathcal{H} \in\left[h_{\min }, \infty\right)$ and $h_{\text {min }} \in \mathcal{R}$. The stochastic process for the idiosyncratic shock $z$ has bounded support $z=[\underline{z}, \bar{z}],-\infty<\underline{z}<\bar{z}<\infty$; (b) the idiosyncratic shock follows a common stationary and increasing Markov transition function $Q\left(z_{t} \mid z_{t-1}\right)$ that satisfies the Feller property; (c) the productivity shock $z_{t}$ is independent across firms; (d) each period, the entrants draw their initial level of $z$ independently from a common distribution $\Psi(z)$; (e) the domain of feasible promised utility, $\Phi=[\underline{\varphi}, \bar{\varphi}]$.

Naturally, $\bar{\varphi}$ is the lifetime discounted utility of a worker in the firm with the highest human capital accumulation: 13

$$
\bar{\varphi}=\max _{\left\{w_{t}\right\}_{0}^{\infty}} \sum_{t=0}^{\infty} \beta^{t} u\left(w_{t}\right)
$$

subject to:

$$
\sum_{t=0}^{\infty} \beta^{t} w_{t} \leq W(\bar{h})
$$

where $W(h)=\frac{y(\bar{h}, z)}{1-\beta}+\beta \sum_{z^{\prime}} \pi\left(z^{\prime} \mid z\right) y\left(\bar{h}, z^{\prime}\right)$ is the present discounted social output.

Symmetrically, I can define the lower bound of promised utility to the worker by picking an arbitrary small positive $\underline{w}>0$ (smaller than the marginal product of $l$ at $h_{\text {min }}$, and define $\underline{\varphi}=u(\underline{w})$ as the lifetime utility from consuming the lowest possible income forever. Note that the boundary is loose enough that the equilibrium $\varphi$ might not hit either the lower or the upper bound.

\section{Aggregation}

Define the measure $\mu$ such that $\forall(h, \varphi, z) \in \mathcal{H} \times \Phi \times z, \mu(h, \varphi, z)$ denotes the mass of firms in the state $(h, \varphi, z)$ and $\Theta=\mathcal{H} \times \Phi \times \mathcal{Z}$. The law of motion of the state variable depends on the transition function from agents' optimality, but the invariant distribution of mass of the firm $\mu$ is determined by the exit-entry decision.

Let $\kappa$ be an indicator function defined by the policy function for the promised utility and human capital:

$$
\kappa\left(h^{\prime}, \varphi^{\prime}, z^{\prime} ; h, \varphi, z\right)= \begin{cases}1, & \text { if } \varphi^{\prime}\left(h^{\prime}, \varphi^{\prime}, z^{\prime} ; h, \varphi, z\right)=\varphi^{\prime} \& h^{\prime}\left(h^{\prime}, \varphi^{\prime}, z^{\prime} ; h, \varphi, z\right)=h^{\prime} \\ 0, & \text { elsewhere }\end{cases}
$$

\footnotetext{
${ }^{13} \bar{h}$, the existence of $\bar{h}<h^{*}$ is guaranteed by the decreasing return to scale production function.
} 
I can then define the transition function $\Lambda$ for $\Theta$ :

$$
\Lambda\left(\left(h^{\prime}, \varphi^{\prime}, z^{\prime}\right),(h, \varphi, z)\right)=Q\left(z^{\prime} \mid z\right) \kappa\left(h^{\prime}, \varphi^{\prime}, z^{\prime} ; h, \varphi, z\right) .
$$

I use $\Upsilon_{t}$ to denote a positive measure of the law of motion of state variables at time $t$. Its law of motion is implied by the transition function $\Lambda$ :

$$
\Upsilon_{t+1}\left(h^{\prime}, \varphi^{\prime}, z^{\prime}\right)=\int_{h_{\min }}^{\infty} \int_{\underline{\varphi}}^{\bar{\varphi}} \int_{\underline{z}}^{\bar{z}} \Lambda\left(\left(h^{\prime}, \varphi^{\prime}, z^{\prime}\right),(h, \varphi, z)\right) \mu_{t}(h, \varphi, z) d \Theta_{t},
$$

where $\mu_{t}(h, \varphi, z)$ is the measure of surviving firms in period t:

$$
\mu_{t}(h, \varphi, z)=\int_{h_{\min }}^{\infty} \int_{\underline{\varphi}}^{\bar{\varphi}} \int_{\underline{z}}^{\bar{z}} \eta(k, \nu, a) d \Lambda(k, \nu, a)
$$

In the invariant industry equilibrium, the mass of new entry equals the mass of the exit in that same period:

$$
\mu^{\prime}\left(h^{\prime}, \varphi^{\prime}, z^{\prime}\right)=\left\{\begin{array}{l}
\Lambda\left(\left(h^{\prime}, \varphi^{\prime}, z^{\prime}\right),(h, \varphi, z)\right) \mu(h, \varphi, z), \text { if } \varphi \leq \varphi^{*} \\
\Lambda\left(\left(h^{\prime}, \varphi^{\prime}, z^{\prime}\right),\left(h, \varphi_{\text {res }}(h), z\right)\right) \mu\left(h, \varphi_{\text {res }}(h), z\right), \text { if } \varphi>\varphi^{*}
\end{array}\right.
$$

\section{A.2 Proof of Lemma 1 and Lemma 2}

This is the standard proof following Stockey, Lucas and Prescott (1989).

Proof of Lemma 1. (Existence.) First, I show that the constraint set is non-empty. The value function is a mapping from a set of bounded and continuous functions $C(\mathcal{H} \times \Phi \times \mathcal{Z})$ to $C(\mathcal{H} \times \Phi \times \mathcal{Z})$. Second, I show that value function is a contraction in $C(\mathcal{H} \times \Phi \times \mathcal{Z})$. A standard contraction mapping theorem implies that there is a unique fixed point in $C(\mathcal{H} \times \Phi \times \mathcal{Z})$, and ensures the existence, strict monotonicity, and concavity of $V$.

(Monotonicity.) From Lemma 9.5 and Corollary 1 of Theorem 3.2 in Stokey, Lucas and Prescott (1989), it is straightforward that $V(h, \varphi, z)$ is strictly increasing in $h$ and $z$, and strictly decreasing in $\varphi$.

(Concavity.) To prove that $V(h, \cdot, z)$ is strictly concave, I first consider some $h$ and $\varphi_{1} \neq$ $\varphi_{2}$ and, for each $\varphi_{i}$, consider a stochastic sequence of optimal choice $\left.\left(y_{t, i}, \varphi_{t, i}, z_{t, i}, w_{t, i}\right)\right|_{t=0} ^{\infty}$ from iterating the solution to the dynamic programming problem forward, starting with $h_{0, i}=h$ and $\varphi_{0, i}=\varphi_{i}$. Given the boundedness, per iteration gives:

$$
\varphi_{i}=(1-\beta) E\left[\sum_{0}^{\infty} \beta^{t} u\left(w_{t, i}\right)\right]
$$

A similar iteration for $V(h, \varphi)$ yields:

$$
V\left(h, \varphi_{i}\right)=E\left[\sum_{0}^{\infty} \beta^{t} d_{t, i}\right]
$$


Consider now the convex combination $\varphi_{\lambda}=\lambda \varphi_{1}+(1-\lambda) \varphi_{2}$. A feasible plan is given by the convex combination of $\left(\varphi_{t, i}, w_{t, i}\right)_{t=0}^{\infty}$, with the concave utility:

$$
V_{\lambda}=E\left[\sum_{0}^{\infty} \beta^{t} d_{t, \lambda}\right]>\lambda V\left(h, \varphi_{1}\right)+(1-\lambda) V\left(h, \varphi_{2}\right),
$$

where $d_{\lambda}=\lambda d_{1}+\lambda d_{2}$, and the inequality is from the strict concavity of the utility function. Obviously, $V\left(h, \varphi_{\lambda}\right) \geq V_{\lambda}>\lambda V\left(h, \varphi_{1}\right)+(1-\lambda) V\left(h, \varphi_{2}\right)$.

Proof of Lemma 2, The uniqueness follows from the strict concavity of $V$, and the continuity follows from the maximum theorem.

\section{A.3 Proof of Proposition 1: Existence of Equilibrium}

Proof of Proposition 1. (1) $Q\left(z^{\prime} \mid z\right), h^{\prime}=h^{\prime}\left(\varphi, h ; \varphi^{\prime}\right)$ and $\varphi^{\prime}=\varphi^{\prime}\left(\varphi, h ; h^{\prime}\right)$ together induce a well-defined Markov transition function that satisfies the Feller property. The continuous policy function ensures this. According to Theorem 12.10 in Stokey, Lucas, and Prescott (1989), the existence of a stationary measure $\Psi$ is guaranteed.

(2) I show the unique existence of $\varphi_{\text {res }}$ from (14) and Lemma 1 that value function $V(\cdot)$ is continuous, and strictly increasing in $h$ and strictly decreasing in $\varphi$. Value function is concave in $h$ and $\varphi$; hence, from the zero profit condition (14) and the implicit function theorem, $\varphi_{\text {res }}$ is concave in $h$ too.

$$
\begin{gathered}
\frac{\partial \varphi_{\text {res }}}{\partial h}=-\frac{\partial V}{\partial h} / \frac{\partial V}{\partial \varphi}>0 \\
\frac{\partial^{2} \varphi_{r e s}}{\partial h^{2}}=-\frac{\partial^{2} V}{\partial h^{2}} / \frac{\partial V}{\partial \varphi}+\frac{\partial V}{\partial h} / \frac{\partial^{2} V}{\partial \varphi^{2}}<0 .
\end{gathered}
$$

\section{A.4 Proof of Proposition 2}

Proof. Since the exit takes place before the productivity shock is observed, firms know in advance whether or not they choose to exit in the next period. Exit decision is therefore completely determined by the current state and can be summarized by a threshold value for the idiosyncratic productivity level. The exit decision can be described by the cutoff $z^{*}$ as:

$$
\eta_{t+1}=\left\{\begin{array}{l}
1, \text { if } z_{t} \geq \max \left[z_{t}^{*}, \underline{z}\right] \\
0, \text { otherwise }
\end{array}\right.
$$

where $z_{t}^{*}$ is the cutoff value that satisfies $E_{t}\left[V_{t+1}\left(h_{t+1}, \varphi_{t+1}, z_{t+1}\right) \mid z_{t}^{*}\right]=0$.

Limited commitment imposes further constraints on problem $\mathcal{P}$. Firms solve the optimal investment and exit decisions by maximizing the expected dividend flows subject to 
the promise-keeping constraint (with multiplier $\omega_{t}$ ), the investment budget constraint (with multiplier $q_{t}$ ), and the participation constraints (with multiplier $\beta \theta_{t}\left(h^{\prime}, z^{\prime}\right)$ ). Maximizing value function

$$
V(h, \varphi ; z)=\max _{h^{\prime}, \varphi^{\prime}, w}\left(d_{t}+\beta \int V\left(h^{\prime}, \varphi^{\prime} ; z^{\prime}\right) Q\left(d z^{\prime} \mid z\right)\right),
$$

subject to constraint $(9)-(12)$ yields the Lagrangian equation:

$$
\begin{aligned}
L & =e^{z_{t}} f\left(h_{t}\right)-w_{t}-I_{t}-s+\beta \int V\left(h^{\prime}, \varphi^{\prime} ; z^{\prime}\right) Q\left(d z^{\prime} \mid z\right) \\
& +q_{t}\left(I_{t}-h_{t+1}+\left(1-\delta_{h}\right) h_{t}\right) \\
& +\omega_{t}\left[u\left(w_{t}\right)+\beta \int \varphi_{t+1} Q\left(d z^{\prime} \mid z\right)-\varphi_{t}\right] \\
& +\beta \iint \theta_{t}\left(h^{\prime}, z^{\prime}\right)\left[\varphi_{t+1}-\varphi_{r e s, t+1}\left(\phi h_{t+1}\right)\right] H(d h \mid h) Q\left(d z^{\prime} \mid z\right)
\end{aligned}
$$

where $\theta_{t}(h, z)$ is the multipliers of a series of constraints 12 for any feasible $z_{t+1} \in \mathcal{Z}$ and $h_{t+1} \in \mathcal{H}$.

The first-order conditions for $\left\{w_{t}, I_{t}, h_{t+1}, \varphi_{t+1}\right\}$ are:

$$
\begin{aligned}
-1+\omega_{t} u^{\prime}\left(w_{t}\right) & =0 \\
-1+q_{t} & =0 \\
\beta \int V_{h, t+1} Q\left(d z^{\prime} \mid z\right)-q_{t} & =\beta \int \theta_{t}\left(h^{\prime}, z^{\prime}\right) \varphi_{r e s, t+1}^{\prime}(h) Q\left(d z^{\prime} \mid z\right) \\
V_{\varphi, t+1}+\omega_{t}+\theta_{t}\left(h^{\prime}, z^{\prime}\right) & =0, \forall z^{\prime}>\max \left[z^{*}, \underline{z}\right], \forall h^{\prime} \in \mathcal{H},
\end{aligned}
$$

and the envelope conditions for the current capital level and promised utility are:

$$
\begin{aligned}
V_{h, t} & =e^{z_{t}} f^{\prime}\left(h_{t}\right)+q_{t}\left(1-\delta_{h}\right) \\
V_{\varphi, t} & =-\omega_{t} .
\end{aligned}
$$

Substituting (31) into (29), I obtain the investment Euler equation in $h$ :

$$
\begin{aligned}
1= & \beta \int\left[e^{z t+1} f^{\prime}\left(h_{t+1}\right)+\left(1-\delta_{h}\right)\right] Q\left(d z^{\prime} \mid z\right) \\
& -\beta \int \theta_{t}(h) \varphi_{r e s, t+1}^{\prime}\left(h_{t+1}\right) Q\left(d z^{\prime} \mid z\right) .
\end{aligned}
$$

Substituting (32) into (30), we obtain the investment Euler equation in promised utility $\varphi$ :

$$
V_{\varphi, t+1}=V_{\varphi, t}-\theta_{t}\left(h^{\prime}, z^{\prime}\right), \forall z^{\prime}>\max \left[z^{*}, \underline{z}\right], \forall h^{\prime} \in \mathcal{H} .
$$


Combining with (27), I obtain the law of motion of the lagged inverse marginal utility:

$$
\frac{-1}{u^{\prime}\left(w_{t+1}\right)}=-\frac{1}{u^{\prime}\left(w_{t}\right)}-\theta_{t}\left(h^{\prime}, z^{\prime}\right), \forall z^{\prime}>\max \left[z^{*}, \underline{z}\right], \forall h^{\prime} \in \mathcal{H} .
$$

From equation (35), it can be shown that wage is increasing over time, and strictly increasing when the participation constraint is binding (positive $\theta_{t}$ ).

Given $h_{t+1}$ and $z_{t}>\max \left[z^{*}, \underline{z}\right]$, when $\theta_{t}\left(h^{\prime}, z^{\prime}\right)=0$, the participation constraint is not binding; thus $-\frac{1}{u^{\prime}\left(w_{t+1}\right)}=\frac{\partial V_{t+1}}{\partial \varphi_{t+1}}=\frac{\partial V_{t}}{\partial \varphi_{t}}=-\frac{1}{u^{\prime}\left(w_{t}\right)}$. Hence, $w_{t}=w_{t+1}$ from the non-binding participation constraint for given $h_{t+1}$.

Given $h_{t+1}$ and $z_{t}>\max \left[z^{*}, \underline{z}\right]$, when $\theta_{t}\left(h^{\prime}, z^{\prime}\right)>0$, the participation constraint is binding; thus $-\frac{1}{u^{\prime}\left(w_{t+1}\right)}=\frac{\partial V_{t+1}}{\partial \varphi_{t+1}}<\frac{\partial V_{t}}{\partial \varphi_{t}}=-\frac{1}{u^{\prime}\left(w_{t}\right)}$. Due to the concavity of $u(\cdot), w_{t+1} \geq w_{t}$.

If $z_{t}<\max \left[z^{*}, \underline{z}\right], \varphi_{t+1}=\varphi_{r e s, t+1}$, and $w_{t+1}=w_{0}$.

The wage contract dynamics are governed by the tightness of the participation constraints (governed by $\theta_{t}(h, z)$ ). Since the equilibrium outside option $\varphi_{\text {res }}$ is independent of $z$, the relevant state variable is the human capital level $h$ if $z_{t}>\max \left[z^{*}, \underline{z}\right]$. Define an optimal wage function $W(h, \varphi)$ such that $W(h, \varphi)=\left(u^{\prime}\right)^{-1}\left(1 / \omega_{t}\right)$. Also, define the running maximum of $h_{t}: h_{\max , t}=\max \left\{h_{s}, s \leq t\right\}$. Conditional on $z_{t}>\max \left[z^{*}, \underline{z}\right]$ and the initial wage level $w_{0}$, the wage is determined by $h_{\text {max }, t}$ :

$$
w_{t}=\max \left\{w_{0}, W\left(h_{\max , t}, \varphi_{\max , t}\right)\right\} .
$$

Corollary 1: Corollary 1 is a direct implication from Proposition 2 since $h_{\text {max }, t}$ is nondecreasing as long as $z_{t}>\max \left[z^{*}, \underline{z}\right]$.

\section{B Computation Algorithm}

General Steps Solving this model includes three general steps: 1) Given the worker's outside option, solve the owner's optimization problem by iterating the value function. The value function and the optimal decision rule are solved on a grid in a discrete state space by iterating value function. 2) After solving the value function given worker's outside option, check the equilibrium free-entry condition and obtain an updated outside option. 3) Parameterize the outside option as a concave function of the human capital stock, and iterate steps 1) and 2) until the parameters converge.

\section{B.1 Choice of Grids}

- I specify a grid with 100 points for $h$ with upper bound $\bar{h}^{S}$ (large enough to be nonbinding at all times). The grids for human capital are constructed recursively, following McGrattan (1999), which is, $h_{i}=h_{i-1}+c_{h 1} \exp \left(c_{h 2}(i-2)\right)$, where $i=1,2, \ldots 100$ is the index of grid points, and $c_{h 1}$ and $c_{h 2}$ are two constants chosen to provide a desirable

upper bound $\bar{h}^{S}$. The method will generate more grids around the lower bound $h_{\min }$, where the value function has most of its curvature. 
- The grid for the promised utility to the worker $\varphi$ is constructed linearly by specifying the lower and upper bound of $\varphi$. The upper bound of $\varphi$ is chosen to be close to zero, and the lower bound is defined as the discounted worker's utility given that the wage is the lowest possible.

\section{B.2 Algorithm}

1. Initialization $t=0$.

- Initialize the outside option $\varphi_{r e s, t=0} \cdot \varphi_{\text {res }, t=0, i}=\frac{u\left(M P L\left(h_{i}\right)\right)}{1-\beta}$.

- Initialize the step for updating the outside option. Set $s_{0}=|\min (\varphi) / 100|$.

- Iterate to generate initial value function. Given the specification of the parameter and state variable grids, and find the optimal next period state variables $\left\{h^{\prime}, \varphi^{\prime}\right\}_{i}$. Iterate until the value function converges.

- Save the value function $v_{t=0}$.

2. Outer Loop $t>0$.

- While equilibrium condition is violated, $\max |\operatorname{err} 2|>1 e-6$.

- Inner loop

- Interpolate $\varphi_{\text {res }}(h)$ from $V_{t}(\underline{h}, h, \varphi)=0$.

- Estimate parameters $\mathcal{A}_{t}$ of the concave function $\tilde{\varphi}(h, \mathcal{A})$.

- Compute $\operatorname{err}_{p}=\max \left|\mathcal{A}_{t}-\mathcal{A}_{t-1}\right|$, which is the violation of the equilibrium condition.

- Set $\varphi_{r e s, t}=\tilde{\varphi}\left(h, \mathcal{A}_{t}\right)$.

- End.

\section{B.3 Calibration and Simulation}

Other Calibration Details Convexity of Adjustment Cost: Assume the adjustment cost is quadratic $g(h, I)=\frac{1}{2} \xi_{h}\left(\frac{I}{h}\right)^{2} h$. Set $\xi_{h}=3.2$ to match the the level and dispersion of Tobin's Q. Eisfeldt and Papanikolaou (2013) applied the same adjustment cost for organization capital. The convexity of adjustment cost also has implications on the adjustment time of human capital, but since there is little evidence on the adjustment time of human (intangible) capital in the literature, I take $\xi_{h}=3.2$ (implying more than three years adjustment time) to match the investment-capital ratio in the data. For physical capital, the adjustment cost is usually set within the range of adjustment period, which is from 6 to 24 months in the literature (e.g., Whited (1992), Hall (2001), Shapiro (1986)). The result is robust to the variation from 1.5 to 3.5 . 
Running Simulation The stochastic process for the level of technology for incumbents is assumed to follow a common stationary and monotonic Markovian process with a finite support. I proximate the finite support using $z=\left[-\sigma \sqrt{\frac{n-1}{1-\rho^{2}}}, \sigma \sqrt{\frac{n-1}{1-\rho^{2}}}\right]$, where $n$ is the number of grids for $z$ in the computation. The initial level of $z_{0}$ is drawn from the uniform distribution with the same support. When firms overshoot over boundaries, I replace that $z_{t}$ to its closest boundary value.

I simulate 3,000 firms for 300 periods. Whenever one firm exits, it will be replaced by an entrant with the starting productivity level drawn from the uniform distribution. The parameter $\alpha$ for each firm is also drawn randomly from $[\underline{\alpha}, \bar{\alpha}]$ at the point of the entry. To minimize the impact of the initial value, I drop the first 100 periods to make sure that firms in this simulated economy are in their steady states. I repeat the simulation 1,000 times. 


\section{Data Appendix}

\section{C.1 Data Sources}

The sample includes all the U.S. firms in CRSP-Compustat merge file from 1960-2010. For consistency, I include firms with fiscal year ending month in December (fyr=12), firms with non-missing SIC codes, firms with non-negative value of sales (SALE), and firms with nonmissing human capital investment (selling, general and administrative expenses). All variables are winsorized to ensure that results are not driven by outliers. The firm-level TFP is from Imrohoroglu and Tuzel (2011) ${ }^{14}$ where they apply the method in Olley and Pakes (1996) to estimate firm-level TFP using Compustat data.

\section{C.2 Definition and Measurement}

\section{C.2.1 Definition: Firm-Level Human Capital}

Different from the standard definition of general human capital ( for example, education and other individual characteristics), firm-level human capital is the capital accumulated in the process of production in the firm. The human capital that workers gain from production is defined as firm-level human capital. Firm-level human capital can be general human capital (completely portable) or firm-specific human capital (nonportable), as long as it contributes to the value of the firm. Measuring human capital by directly constructing proxies using individual-level data in the U.S. or by exploiting wage differences across groups defined by different individual characteristics (see Abowd et al. (2005) for a detailed survey) is not helpful for measuring firm-level human capital.

Firm-level human capital has more overlap with the intangible assets of the firm than with individual human capital. The definition of intangible assets varies from a firm's intellectual assets and innovation (R\&D expenses), to human capital, intellectual property (marketing and reputation), and to organizational structure (including IT and computer expenses (Brynjolfsson et al. $(2002))$ ). I focus on the firm-level intangible assets that have portability with the workers (the portable part of intangible assets) ${ }^{15}$

Industry classification is not precise enough to differentiate firm-level human capital because it can either substitute for or complement individual human capital (or skilled labor). Depending on the technology, there exists large spread of firm-level human capital intensity within an industry. Based on the reasons above, a new measure of firm-level human capital is needed.

\footnotetext{
${ }^{14}$ Thanks to Selale Tuzel for kindly sharing their TFP estimate with me.

${ }^{15}$ The theory emphasizes the stickiness of intangible leverage from the portability assumption, so the direct measurment of firm-level human capital should be restricted to the portability property. Although the historical investment of other intangible assets, such as marketing and advertising, will also creates a similar effect to that of the portable human capital, but through a different channel, which is not my focus here.
} 


\section{C.2.2 Industry Definition}

I examine four main industries in this paper: consumer goods, manufacturing, health product and information, computer and technology industry. The classification of consumer goods, manufacturing and health product industries are taken from Fama-French 5-industry classification. The information, computer and technology industry classification (defined according to NAICS) is from BEA Industry Economic Accounts, which consists of computer and electronic products; publishing industries (includes software); information and data processing services; and computer systems design and related services. I classified all the rest of the firms (including the finance industry) into other Industries.

\section{C.2.3 Variable Construction}

- $h: 30 \%$ of SG\&A expenses plus R\&D expenses. Investment spending is deflated by the production price index from NIPA. Apply perpetual inventory method to obtain the stock. $h$ is scaled by the level of physical capital given by gross property, plant, and equipment (PPEGT) from Compustat.

- $h_{\max }$ : The maximum of the whole history (available in the data)

- $h_{\max , v w}$ : The value weighted average of the past five-year firm level human capital stock $h_{t-4}, \ldots, h_{t}$.

- wage (I): Replace the missing XLR observations by SG\&A expenses ${ }^{16}$ Accordingly, we get the per capita labor cost by deviding EMP. XSGA is deflated by the Consumer Price Index from NIPA.

- wage (II): Total labor expenses (XLR) from Compustat and scaled by number of employees (EMP). XLR is scaled by the Consumer Price Index from NIPA.

- Cash Flow (CF): Operating Income before Depreciation and Amortization (OIBDP), deflated by the consumer price index from NIPA.

- Cash Flow Volatility: Cash flow growth is computed by $\Delta \frac{C F}{y}=\frac{C F_{t}-C F_{t-1}}{0.5 \text { Salest }_{t}+0.5 \text { Sales }_{t-1}}$. Cash Flow Volatility at year $t: \sigma_{t}(\Delta C F / y)=\left[\frac{1}{N} \sum_{\tau=t}^{\tau=t+N-1}\left(\Delta \frac{C F}{y_{\tau}}-\Delta \frac{\overline{C F}}{y}{ }_{t}\right)\right]$.

- Value Added: Sales - Materials, deflated by the GDP price deator from NIPA. Sales is net sales from Compustat (SALE). Materials is measured as Total expenses minus Labor expenses. Total expenses is approximated as [Sales - Operating Income Before Depreci- ation and Amortization (Compustat (OIBDP))]. Labor expenses is the Total Staff Expenses (XLR). When XLR is missing, labor expenses is calculated by multiplying the number of employees from Compustat (EMP) by average wages from the Social Security Administration). These steps follow those in Imrohoroglu and Tuzel (2011).

\footnotetext{
${ }^{16}$ For the firms in the Compustat dataset, firms who miss reporting labor cost expenses (XLR) usually include the managerial compensation in SG\&A and include the manufacturing labor expenses in Cost of Goods Sold.
} 
- Labor Productivity (LP): Value Added divided by EMP, i.e., per capita value added.

- Laborshare: Real total labor expenses (XLR) with missing observation replaced by real SG\&A expenses, divided by value added. 


\section{Tables}

Table 8: Summary Statistics

\begin{tabular}{lcccccc}
\hline \hline Variables & Mean & $\sigma$ & $5 \%$ & $95 \%$ & Median & $N$ \\
\hline$h$ & 2.04 & 2.59 & 0.09 & 6.97 & 1.15 & 62,982 \\
$h_{\max , v w}$ & 2.06 & 2.67 & 0.08 & 6.97 & 1.15 & 64,822 \\
$h_{\max }$ & 2.62 & 3.62 & 0.10 & 8.91 & 1.40 & 73,804 \\
$\frac{h}{h_{\max , v w}}$ & 1.2 & 0.40 & 0.59 & 1.79 & 1.09 & 55,060 \\
$\frac{h}{h_{\max }}$ & 0.95 & 0.42 & 0.31 & 1.68 & 0.94 & 52,045 \\
$\left.\beta_{w, y}(\Delta F)\right)$ & & & & & & \\
$\log \left(\sigma\left(\Delta \frac{C F}{y}\right)\right.$ & 0.18 & 0.65 & -0.51 & 1.31 & 0.05 & 58,129 \\
$\log (\sigma($ ret $))$ & -3.31 & 1.30 & -5.84 & -1.27 & -3.24 & 139,085 \\
$\log ($ wageI $)$ & -3.58 & 0.62 & -4.59 & -2.54 & -3.59 & 226,272 \\
$\Delta$ wageI & 9.67 & 1.16 & 7.74 & 11.31 & 9.70 & 187,224 \\
$\log ($ wageII $)$ & 0.02 & 0.28 & -0.38 & 0.44 & 0.016 & 166,851 \\
$\Delta$ wageII & 10.61 & 0.67 & 9.43 & 11.58 & 10.71 & 40,323 \\
$\Delta$ Value_Added & 0.02 & 0.15 & -0.20 & 0.25 & 0.017 & 35,496 \\
$\Delta$ Labor_Productivity $($ LP $)$ & 0.003 & 0.45 & -0.72 & 0.69 & 0.01 & 152,912 \\
$\log ($ TFP $)$ & -0.63 & 0.43 & -1.27 & 0.027 & -0.64 & 104,883 \\
$\Delta$ TFP & -0.02 & 0.27 & -0.44 & 0.41 & -0.01 & 91,901 \\
\hline \hline
\end{tabular}

The table reports the key moments of the variables used in the quantitative analysis. The details of data construction can be found in Appendix C. TFP is the total factor productivity at the firm level. TFP is the residual from estimating a log linear Cobb-Douglas production function for each firm and year. The estimates are provided by Imrohoroglu and Tuzel (2011). Data Source: Compustat Fundamental Annual: 1960-2010. 
Table 9: Data: State Variables and Volatility: Time Series

\begin{tabular}{lcccccc}
\hline \hline Year & $h_{\max }$ & $\frac{h}{h_{\max }}$ & $\log (\sigma \Delta$ wage $)$ & $\log \left(\sigma \Delta \frac{C F}{y}\right)$ & $\beta(\Delta C F, \Delta y)$ & $\beta(\Delta w, \Delta y)$ \\
$1960-1970$ & 0.71 & 1.30 & -2.06 & -3.75 & 1.24 & 0.54 \\
$1970-1980$ & 1.45 & 1.32 & -1.92 & -3.41 & 1.29 & 0.40 \\
$1980-1990$ & 1.85 & 1.14 & -1.88 & -3.19 & 1.27 & 0.38 \\
$1990-2000$ & 2.20 & 1.12 & -1.82 & -3.22 & 1.25 & 0.43 \\
$2000-2010$ & 3.27 & 1.11 & -1.93 & -3.20 & 1.40 & 0.39 \\
\hline \hline
\end{tabular}

The table presents the time series of the cash flow moments and average state variables within each time period. The standard deviation is computed within a ten-year rolling window and average across firms within the horizon. The volatility is the annualized $\log$ standard deviation. $C F$ stands for cash flow, measured using operating income (OIBDP). $y$ stands for output measured by value added. Data Source: Compustat Fundamental Annual: 1960-2010. 
Table 10: Wage Contract and Firm-Level Human Capital Accumulation History

\begin{tabular}{|c|c|c|c|c|}
\hline & \multicolumn{2}{|c|}{ wage(I) } & \multicolumn{2}{|c|}{ wage(II) } \\
\hline & (1) & (2) & (3) & (4) \\
\hline $\log \left(h_{\max , t}\right)$ & $\begin{array}{c}0.363^{* * *} \\
(0.085)\end{array}$ & & $\begin{array}{c}0.628 \\
(0.940)\end{array}$ & \\
\hline $\log \left(T F P_{\max , t}\right)$ & & $\begin{array}{c}0.281^{* * *} \\
(0.030)\end{array}$ & & $\begin{array}{c}0.195^{* * *} \\
(0.072)\end{array}$ \\
\hline $\log \left(T F P_{t}\right)$ & $\begin{array}{c}-0.089^{* * *} \\
(0.012)\end{array}$ & $\begin{array}{c}-0.119 * * * \\
(0.011)\end{array}$ & $\begin{array}{c}0.016 \\
(0.046)\end{array}$ & $\begin{array}{c}0.032 \\
(0.060)\end{array}$ \\
\hline MB & $\begin{array}{c}-0.062^{* * * *} \\
(0.020)\end{array}$ & $\begin{array}{c}-0.082^{* * * *} \\
(0.012)\end{array}$ & $\begin{array}{c}0.006 \\
(0.011)\end{array}$ & $\begin{array}{c}-0.033^{* * *} \\
(0.011)\end{array}$ \\
\hline Market Cap & $\begin{array}{c}0.156^{* * *} \\
(0.049)\end{array}$ & $\begin{array}{c}0.138^{* * *} \\
(0.028)\end{array}$ & $\begin{array}{l}-0.058^{*} \\
(0.032)\end{array}$ & $\begin{array}{c}0.004 \\
(0.032)\end{array}$ \\
\hline $\log$ (Sales) & $\begin{array}{c}0.213^{* * *} \\
(0.031)\end{array}$ & $\begin{array}{c}0.281^{* * *} \\
(0.023)\end{array}$ & $\begin{array}{c}0.197^{* * *} \\
(0.064)\end{array}$ & $\begin{array}{c}0.305^{* * *} \\
(0.035)\end{array}$ \\
\hline Constant & $\begin{array}{c}8.463^{* * *} \\
(0.310)\end{array}$ & $\begin{array}{c}9.417^{* * *} \\
(0.104)\end{array}$ & $\begin{array}{l}7.537^{* *} \\
(3.156)\end{array}$ & $\begin{array}{c}9.984^{* * *} \\
(0.133)\end{array}$ \\
\hline Year FE & $\mathrm{y}$ & $\mathrm{y}$ & $\mathrm{y}$ & $\mathrm{y}$ \\
\hline Firm FE & $\mathrm{y}$ & $\mathrm{y}$ & $\mathrm{y}$ & y \\
\hline$N$ & 43,322 & 106,353 & 2,913 & 13,988 \\
\hline R-squared & 0.062 & 0.046 & 0.122 & 0.136 \\
\hline Firm ID & 5,034 & 10,883 & 433 & 1,628 \\
\hline
\end{tabular}

This table reports the coefficients of the following regression:

$$
\text { wage }_{i t}=\alpha+\eta_{i}+\lambda_{t}+\beta_{1} h_{\max , i t}+\beta_{2} T F P_{i t}+\Gamma X_{i t}+\epsilon_{i t},
$$

Wage is log average real wage of each firm. TFP is the total factor productivity at the firm level. TFP is the residual from estimating a log linear Cobb-Douglas production function for each firm and year. The estimates are provided by Imrohoroglu and Tuzel (2011). $\log \left(h_{\max }\right)$ is the $\log$ maximum firm-level human capital level before year $t$. Market Cap is the log of market capitalization, which is equal to total asset + market value of equity - common equity. $\log ($ Sales $)$ is the $\log$ deflated net sales. The details of measurement and construction of all variables are included in Appendix C Data Source: Compustat Fundamental Annual 1960-2010. Standard errors in parentheses are clustered, ${ }^{* * *} p<0.01,{ }^{* *} p<0.05,{ }^{*} p<0.1$. 
Table 11: Wage Contract and Firm-Level Human Capital Accumulation History (ValueWeighted)

\begin{tabular}{|c|c|c|c|c|}
\hline & \multicolumn{2}{|c|}{ wage(I) } & \multicolumn{2}{|c|}{ wage(II) } \\
\hline & (1) & $(2)$ & $(3)$ & (4) \\
\hline $\log \left(h_{\max , v w, t}\right)$ & $\begin{array}{c}0.367^{* * *} \\
(0.026)\end{array}$ & & $\begin{array}{c}0.088^{* * *} \\
(0.034)\end{array}$ & \\
\hline $\log \left(T F P_{\max , v w, t}\right)$ & & $\begin{array}{c}0.167^{* * *} \\
(0.022)\end{array}$ & & $\begin{array}{c}0.036 \\
(0.039)\end{array}$ \\
\hline $\log \left(T F P_{t}\right)$ & $\begin{array}{c}-0.085^{* * *} \\
(0.010)\end{array}$ & $\begin{array}{c}-0.130 * * * \\
(0.009)\end{array}$ & $\begin{array}{l}-0.010 \\
(0.052)\end{array}$ & $\begin{array}{c}0.059 \\
(0.056)\end{array}$ \\
\hline MB & $\begin{array}{c}-0.044^{* * *} \\
(0.014)\end{array}$ & $\begin{array}{c}-0.081^{* * *} \\
(0.012)\end{array}$ & $\begin{array}{c}0.002 \\
(0.012)\end{array}$ & $\begin{array}{c}-0.031^{* * *} \\
(0.011)\end{array}$ \\
\hline Market Cap & $\begin{array}{c}0.109^{* * *} \\
(0.0347)\end{array}$ & $\begin{array}{c}0.127^{* * *} * \\
(0.029)\end{array}$ & $\begin{array}{c}-0.051 \\
(0.036)\end{array}$ & $\begin{array}{l}-0.002 \\
(0.032)\end{array}$ \\
\hline $\log$ (Sales) & $\begin{array}{c}0.170^{* * *} \\
(0.026)\end{array}$ & $\begin{array}{c}0.296^{* * *} \\
(0.023)\end{array}$ & $\begin{array}{c}0.180 * * * \\
(0.057)\end{array}$ & $\begin{array}{c}0.311^{* * *} \\
(0.036)\end{array}$ \\
\hline Constant & $\begin{array}{c}9.244^{* * * *} \\
(0.205)\end{array}$ & $\begin{array}{c}9.267^{* * * *} \\
(0.103)\end{array}$ & $\begin{array}{c}9.692^{* * *} \\
(0.169)\end{array}$ & $\begin{array}{c}9.843^{* * *} \\
(0.138)\end{array}$ \\
\hline Year FE & $\mathrm{y}$ & $\mathrm{y}$ & $\mathrm{y}$ & $\mathrm{y}$ \\
\hline Firm FE & $\mathrm{y}$ & $\mathrm{y}$ & $\mathrm{y}$ & $\mathrm{y}$ \\
\hline$N$ & 37,952 & 106,353 & 2,510 & 13,988 \\
\hline R-squared & 0.160 & 0.043 & 0.151 & 0.130 \\
\hline Firm ID & 4,908 & 10,883 & 414 & 1,628 \\
\hline
\end{tabular}

This table reports the coefficients of the following regression:

$$
\text { wage }_{i t}=\alpha+\eta_{i}+\lambda_{t}+\beta_{1} h_{\max , i t}+\beta_{2} T F P_{i t}+\Gamma X_{i t}+\epsilon_{i t} .
$$

Wage is log average real wage of each firm. TFP is the total factor productivity at the firm level. TFP is the residual from estimating a log linear Cobb-Douglas production function for each firm and year. The estimates are provided by Imrohoroglu and Tuzel (2011). $\log \left(h_{\max , v w}\right)$ is the $\log$ maximum value-weighted firm-level human capital level over the past five years. Market Cap is the log of market capitalization, which is equal to total asset + market value of equity - common equity. $\log ($ Sales $)$ is the $\log$ deflated net sales. The details of measurement and construction of all variables are included in Appendix C. Data Source: Compustat Fundamental Annual 1960-2010. Standard errors in parentheses are clustered, ${ }^{* * *} p<0.01,{ }^{* *}$ $p<0.05,{ }^{*} p<0.1$. 
Table 12: Wage Contract Sensitivity and Human Capital Investment

\begin{tabular}{|c|c|c|c|c|}
\hline & $\begin{array}{c}\Delta \text { wage }(I) \\
(1)\end{array}$ & $\begin{array}{c}\Delta \text { wage }(I I) \\
(2)\end{array}$ & $\begin{array}{c}\Delta \text { wage }(I) \\
(3)\end{array}$ & $\begin{array}{c}\Delta \text { wage }(I I) \\
(4)\end{array}$ \\
\hline Dummy & $\begin{array}{c}0.056^{* * *} \\
-0.003\end{array}$ & $\begin{array}{c}0.014 \\
(0.008)\end{array}$ & $\begin{array}{c}0.060^{* * *} \\
(0.003)\end{array}$ & $\begin{array}{c}0.015 \\
(0.011)\end{array}$ \\
\hline$\Delta(L P)$ & $\begin{array}{c}0.209^{* * *} \\
(0.004)\end{array}$ & $\begin{array}{c}0.275^{* * *} \\
(0.009)\end{array}$ & & \\
\hline Dummy $\times \Delta(L P)$ & $\begin{array}{c}-0.085^{* * *} \\
(0.009)\end{array}$ & $\begin{array}{c}0.054 \\
(0.058)\end{array}$ & & \\
\hline$\Delta($ Value_Added $)$ & & & $\begin{array}{c}0.036^{* * *} \\
(0.004)\end{array}$ & $\begin{array}{c}0.086^{* * *} \\
(0.007)\end{array}$ \\
\hline Dummy $\times \Delta($ Value_Added $)$ & & & $\begin{array}{c}-0.034^{* * *} \\
(0.007)\end{array}$ & $\begin{array}{c}0.042 \\
(0.052)\end{array}$ \\
\hline MB & $\begin{array}{c}-0.007 * * * \\
(0.001)\end{array}$ & $\begin{array}{c}-0.003^{* *} \\
(0.001)\end{array}$ & $\begin{array}{c}0.003^{* * *} \\
(0.001)\end{array}$ & $\begin{array}{l}-0.001 \\
(0.002)\end{array}$ \\
\hline Sales & $\begin{array}{c}0.048^{* * *} \\
(0.003)\end{array}$ & $\begin{array}{c}0.026^{* * *} \\
(0.004)\end{array}$ & $\begin{array}{c}0.069^{* * *} \\
(0.003)\end{array}$ & $\begin{array}{c}0.041^{* * *} \\
(0.004)\end{array}$ \\
\hline Market Cap & $\begin{array}{c}-0.033^{* * *} \\
(0.003)\end{array}$ & $\begin{array}{c}-0.013^{* * *} \\
(0.003)\end{array}$ & $\begin{array}{c}-0.050^{* * *} \\
(0.003)\end{array}$ & $\begin{array}{c}-0.028^{* * *} \\
(0.004)\end{array}$ \\
\hline Constant & $\begin{array}{c}-0.581^{* * *} \\
(0.007)\end{array}$ & $\begin{array}{c}-0.042^{* * *} \\
(0.014)\end{array}$ & $\begin{array}{c}-0.654^{* * *} \\
(0.008)\end{array}$ & $\begin{array}{c}-0.049^{* * *} \\
(0.016)\end{array}$ \\
\hline Year FE & $\mathrm{y}$ & $\mathrm{y}$ & $\mathrm{y}$ & $\mathrm{y}$ \\
\hline Firm FE & $\mathrm{y}$ & y & $\mathrm{y}$ & y \\
\hline$N$ & 146,218 & 32,226 & 146,218 & 32,226 \\
\hline R-squared & 0.135 & 0.272 & 0.017 & 0.041 \\
\hline Firm ID & 15,515 & 3,672 & 15,515 & 3,672 \\
\hline
\end{tabular}

This table reports the coefficients of the following regression:

$$
\Delta \text { wage }=\alpha+\eta_{i}+\lambda_{t}+\beta_{1} D\left(h_{\max , i t}>h_{\max , i t-1}\right)+\beta_{2} \Delta y+\beta_{3}(\text { Dummy } \times \Delta y)+\Gamma X_{i t}+\epsilon_{i t} .
$$

Wage growth is the difference in the log average real wage of each firm. $\Delta y$ is proxied using firm-level labor productivity growth and firm-level value added growth. Dummy $D\left(h_{\max , i t}>h_{\max , i t-1}\right)=1$ if $h_{\max , i t}>$ $h_{\max , i t-1} . h_{\max }$ is the log maximum value-weighted firm-level human capital level over the past five years. Market Cap is the log of market capitalization, which is equal to total asset + market value of equity common equity. $\log ($ Sales $)$ is the $\log$ deflated net sales. The details of measurement and construction of all variables are included in Appendix C. Data Source: Compustat Fundamental Annual 1960-2010. Robust standard errors in parentheses, ${ }^{* * *} p<0.01,{ }^{* *} p<0.05,{ }^{*} p<0.1$. 
Table 13: Wage Contract Sensitivity and State Variables (I)

\begin{tabular}{|c|c|c|c|c|}
\hline & $\begin{array}{l}\frac{h}{h_{\max }} \leq 1 \\
(1)\end{array}$ & $\begin{array}{c}\frac{h}{h_{\max }}>1 \\
(2)\end{array}$ & $\begin{array}{c}\frac{h}{h_{\max }} \leq 1 \\
(3)\end{array}$ & $\begin{array}{c}\frac{h}{h_{\max }}>1 \\
(4)\end{array}$ \\
\hline $\log \left(h_{\max , v w, t}\right)$ & $\begin{array}{c}-0.048^{* * *} \\
(0.008)\end{array}$ & $\begin{array}{c}-0.021 * * * \\
(0.007)\end{array}$ & $\begin{array}{c}-0.047^{* * *} \\
(0.008)\end{array}$ & $\begin{array}{c}-0.035^{* * *} \\
(0.008)\end{array}$ \\
\hline$\Delta($ ValueAdded $)$ & $\begin{array}{c}-0.009^{* *} \\
(0.005)\end{array}$ & $\begin{array}{l}-0.001 \\
(0.004)\end{array}$ & & \\
\hline $\log \left(h_{\max , v w, t}\right) \times \Delta($ ValueAdded $)$ & $\begin{array}{l}-0.002 \\
(0.003)\end{array}$ & $\begin{array}{c}-0.006^{* *} \\
(0.003)\end{array}$ & & \\
\hline$\Delta \log (T F P)$ & & & $\begin{array}{c}-0.094^{* * *} \\
(0.012)\end{array}$ & $\begin{array}{c}-0.104^{* * *} \\
(0.009)\end{array}$ \\
\hline $\log \left(h_{\max , v w, t}\right) \times \Delta \log (T F P)$ & & & $\begin{array}{c}-0.021^{* *} \\
(0.009)\end{array}$ & $\begin{array}{c}-0.002 \\
(0.007)\end{array}$ \\
\hline MB & $\begin{array}{l}-0.003 \\
(0.004)\end{array}$ & $\begin{array}{c}0.009^{* *} \\
(0.004)\end{array}$ & $\begin{array}{c}-0.007^{*} \\
(0.004)\end{array}$ & $\begin{array}{c}0.009^{* *} \\
(0.004)\end{array}$ \\
\hline Market Cap & $\begin{array}{c}-0.039 * * * \\
(0.012)\end{array}$ & $\begin{array}{c}-0.067^{* * *} \\
(0.010)\end{array}$ & $\begin{array}{l}-0.003 \\
(0.011)\end{array}$ & $\begin{array}{c}-0.032^{* * * *} \\
(0.011)\end{array}$ \\
\hline $\log$ (Sales) & $\begin{array}{c}0.125^{* * *} \\
(0.013)\end{array}$ & $\begin{array}{c}0.042^{* * *} \\
(0.009)\end{array}$ & $\begin{array}{c}0.165^{* * *} \\
(0.015)\end{array}$ & $\begin{array}{c}0.132^{* * * *} \\
(0.013)\end{array}$ \\
\hline Constant & $\begin{array}{c}-0.089^{* *} \\
(0.041)\end{array}$ & $\begin{array}{c}-0.296 \\
(0.291)\end{array}$ & $\begin{array}{l}-0.106 \\
(0.100)\end{array}$ & $\begin{array}{c}-0.190^{* * *} \\
(0.053)\end{array}$ \\
\hline Year FE & $\mathrm{y}$ & $\mathrm{y}$ & $\mathrm{y}$ & $\mathrm{y}$ \\
\hline Firm FE & $\mathrm{y}$ & y & $\mathrm{y}$ & y \\
\hline$N$ & 20,252 & 35,478 & 12,563 & 19,739 \\
\hline R-squared & 0.030 & 0.017 & 0.044 & 0.040 \\
\hline Firm ID & 4,107 & 6,460 & 2,494 & 3,877 \\
\hline
\end{tabular}

This table reports the coefficients of the following regression:

$$
\Delta \text { wage }=\alpha+\eta_{i}+\lambda_{t}+\beta_{1} h_{\max , i t}+\beta_{2} \Delta y+\beta_{3}\left(h_{\max , i t} \times \Delta y\right)+\Gamma X_{i t}+\epsilon_{i t} .
$$

Wage growth is the difference in the log average real wage of each firm, where the average real wage is wage (I). TFP is the total factor productivity at the firm level. TFP is the residual from estimating a $\log$ linear Cobb-Douglas production function for each firm and year. The estimates are provided by Imrohoroglu and Tuzel (2011). $\log \left(h_{\max , v w}\right)$ is the log maximum value-weighted firm-level human capital level over the past five years. Market Cap is the log of market capitalization, which is equal to total asset + market value of equity - common equity. $\log ($ Sales $)$ is the $\log$ deflated net sales. The details of measurement and construction of all variables are included in Appendix C Data Source: Compustat Fundamental Annual 1960-2010. Robust standard errors in parentheses, ${ }^{* * *} p<0.01,{ }^{* *} p<0.05,{ }^{*} p<0.1$. 
Table 14: Wage Contract Sensitivity and State Variables (II)

\begin{tabular}{|c|c|c|c|c|}
\hline & $\begin{array}{c}\frac{h}{h_{\max }} \leq 1 \\
(1)\end{array}$ & $\begin{array}{c}\frac{h}{h_{\max }}>1 \\
(2)\end{array}$ & $\begin{array}{c}\frac{h}{h_{\max }} \leq 1 \\
(3)\end{array}$ & $\begin{array}{c}\frac{h}{h_{\max }}>1 \\
(4)\end{array}$ \\
\hline $\log \left(h_{\max , v w, t}\right)$ & $\begin{array}{l}0.048^{*} \\
(0.026)\end{array}$ & $\begin{array}{c}0.008 \\
(0.031)\end{array}$ & $\begin{array}{l}0.055^{*} \\
(0.030)\end{array}$ & $\begin{array}{l}-0.001 \\
(0.026)\end{array}$ \\
\hline$\Delta($ ValueAdded $)$ & $\begin{array}{c}0.082^{* * *} \\
(0.031)\end{array}$ & $\begin{array}{l}0.041^{*} \\
(0.022)\end{array}$ & & \\
\hline $\log \left(h_{\max , v w, t}\right) * \Delta($ ValueAdded $)$ & $\begin{array}{c}0.003 \\
(0.025)\end{array}$ & $\begin{array}{c}-0.060^{* * *} \\
(0.012)\end{array}$ & & \\
\hline$\Delta \log (T F P)$ & & & $\begin{array}{c}0.079 \\
(0.067)\end{array}$ & $\begin{array}{c}-0.024 \\
(0.059)\end{array}$ \\
\hline $\log \left(h_{\max , v w, t}\right) \times \Delta \log (T F P)$ & & & $\begin{array}{l}-0.003 \\
(0.044)\end{array}$ & $\begin{array}{c}-0.076^{* * *} \\
(0.025)\end{array}$ \\
\hline MB & $\begin{array}{c}-0.017^{*} \\
(0.010)\end{array}$ & $\begin{array}{c}0.002 \\
(0.0093)\end{array}$ & $\begin{array}{l}-0.005 \\
(0.009)\end{array}$ & $\begin{array}{l}-0.005 \\
(0.011)\end{array}$ \\
\hline Market Cap & $\begin{array}{l}-0.002 \\
(0.024)\end{array}$ & $\begin{array}{c}-0.066^{* * *} \\
(0.024)\end{array}$ & $\begin{array}{l}-0.007 \\
(0.027)\end{array}$ & $\begin{array}{l}-0.006 \\
(0.028)\end{array}$ \\
\hline $\log$ (Sales) & $\begin{array}{c}0.074 \\
(0.089)\end{array}$ & $\begin{array}{c}0.069^{*} \\
(0.040)\end{array}$ & $\begin{array}{c}0.106 \\
(0.071)\end{array}$ & $\begin{array}{c}0.189^{* * *} \\
(0.069)\end{array}$ \\
\hline Constant & $\begin{array}{l}-0.031 \\
(0.112)\end{array}$ & $\begin{array}{l}-0.222^{*} \\
(0.116)\end{array}$ & $\begin{array}{l}-0.168 \\
(0.143)\end{array}$ & $\begin{array}{l}-0.289^{*} \\
(0.160)\end{array}$ \\
\hline Year FE & $\mathrm{y}$ & $\mathrm{y}$ & $\mathrm{y}$ & $\mathrm{y}$ \\
\hline Firm FE & $\mathrm{y}$ & $\mathrm{y}$ & $\mathrm{y}$ & $\mathrm{y}$ \\
\hline$N$ & 1,102 & 2,306 & 676 & 1,364 \\
\hline R-squared & 0.114 & 0.101 & 0.132 & 0.104 \\
\hline Firm ID & 296 & 519 & 155 & 296 \\
\hline
\end{tabular}

This table reports the coefficients of the following regression:

$$
\Delta \text { wage }=\alpha+\eta_{i}+\lambda_{t}+\beta_{1} h_{\max , i t}+\beta_{2} \Delta y+\beta_{3}\left(h_{\max , i t} \times \Delta y\right)+\Gamma X_{i t}+\epsilon_{i t} .
$$

Wage growth is the difference in the log average real wage of each firm, where the average real wage is wage (II). TFP is the total factor productivity at the firm level. TFP is the residual from estimating a log linear Cobb-Douglas production function for each firm and year. The estimates are provided by Imrohoroglu and Tuzel (2011). $\log \left(h_{\max , v w}\right)$ is the log maximum value-weighted firm-level human capital level over the past five years. Market Cap is the log of market capitalization, which is equal to total asset + market value of equity - common equity. $\log$ (Sales) is the log deflated net sales. The details of measurement and construction of all variables are included in Appendix C Data Source: Compustat Fundamental Annual 1960-2010. Robust standard errors in parentheses, ${ }^{* * *} p<0.01,{ }^{* *} p<0.05,{ }^{*} p<0.1$. 


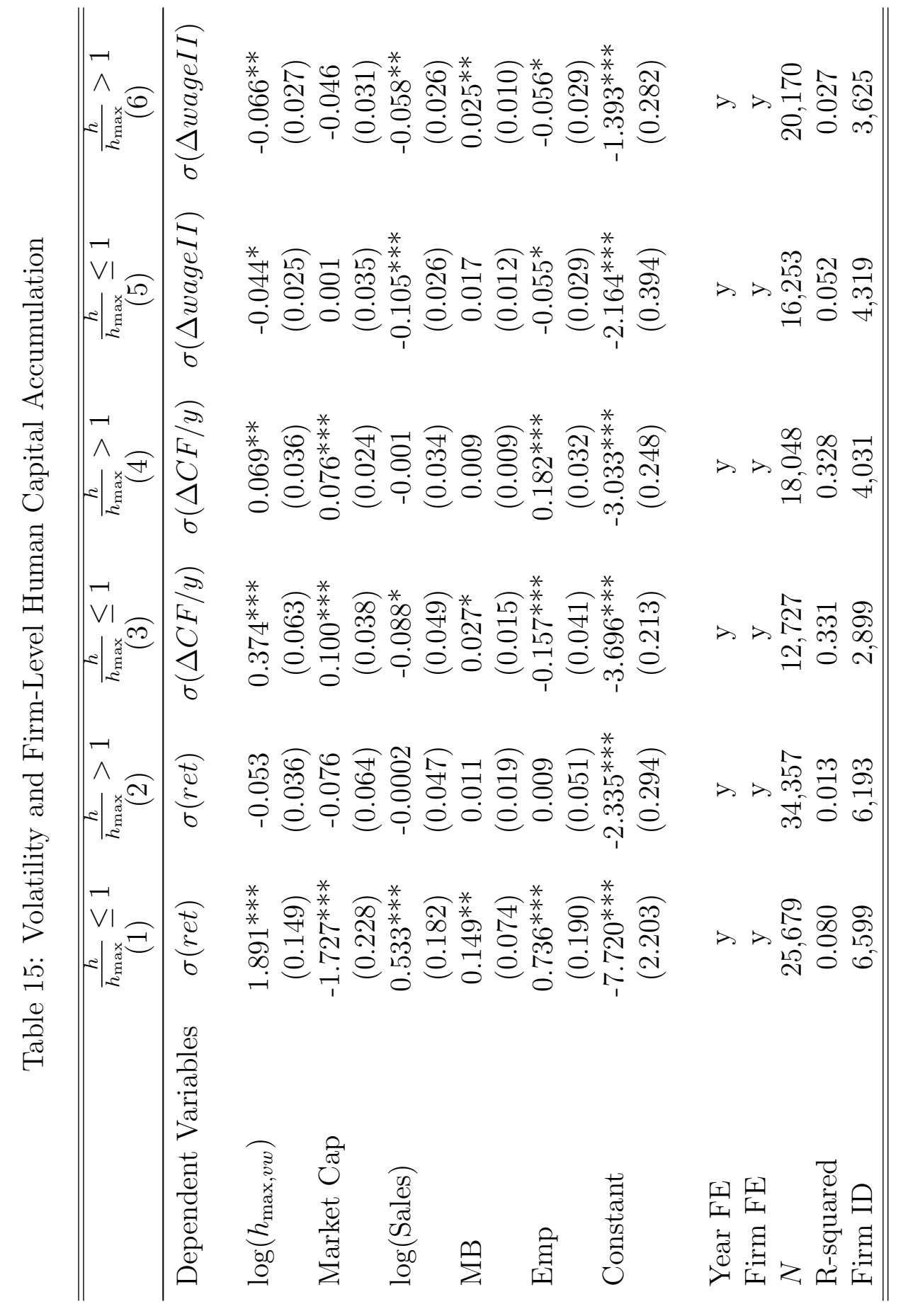

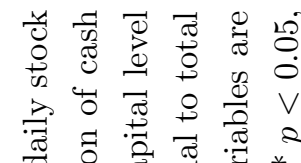

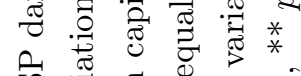

ऊิ

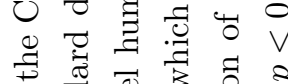

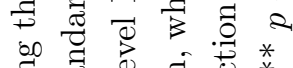

䎡焉

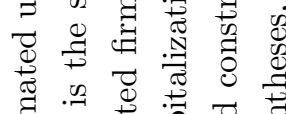

氙

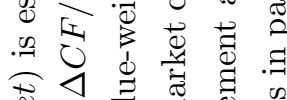

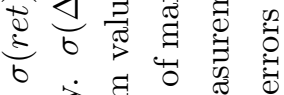

芯密蒠

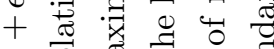

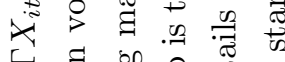

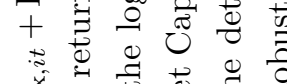

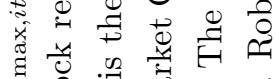

$\approx$. 1 .

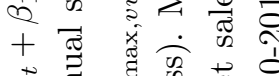

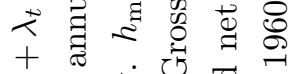

$\therefore \approx$ 完预

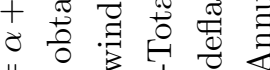

$11 \circ \infty$

$\ddot{0}$ 売

峦

का के

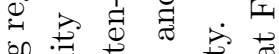

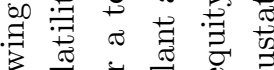

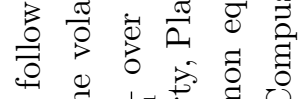

ॠ

ث.

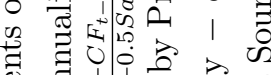

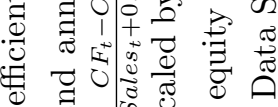

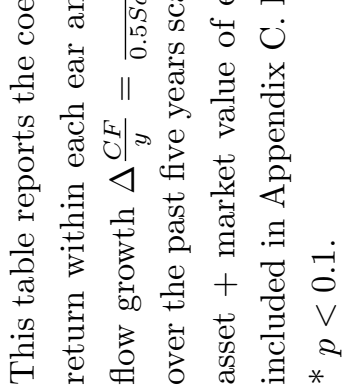




\section{E Figures}

Figure 6: Operating Income/Sales Volatility of $\beta(\Delta w, \Delta y)$ Group

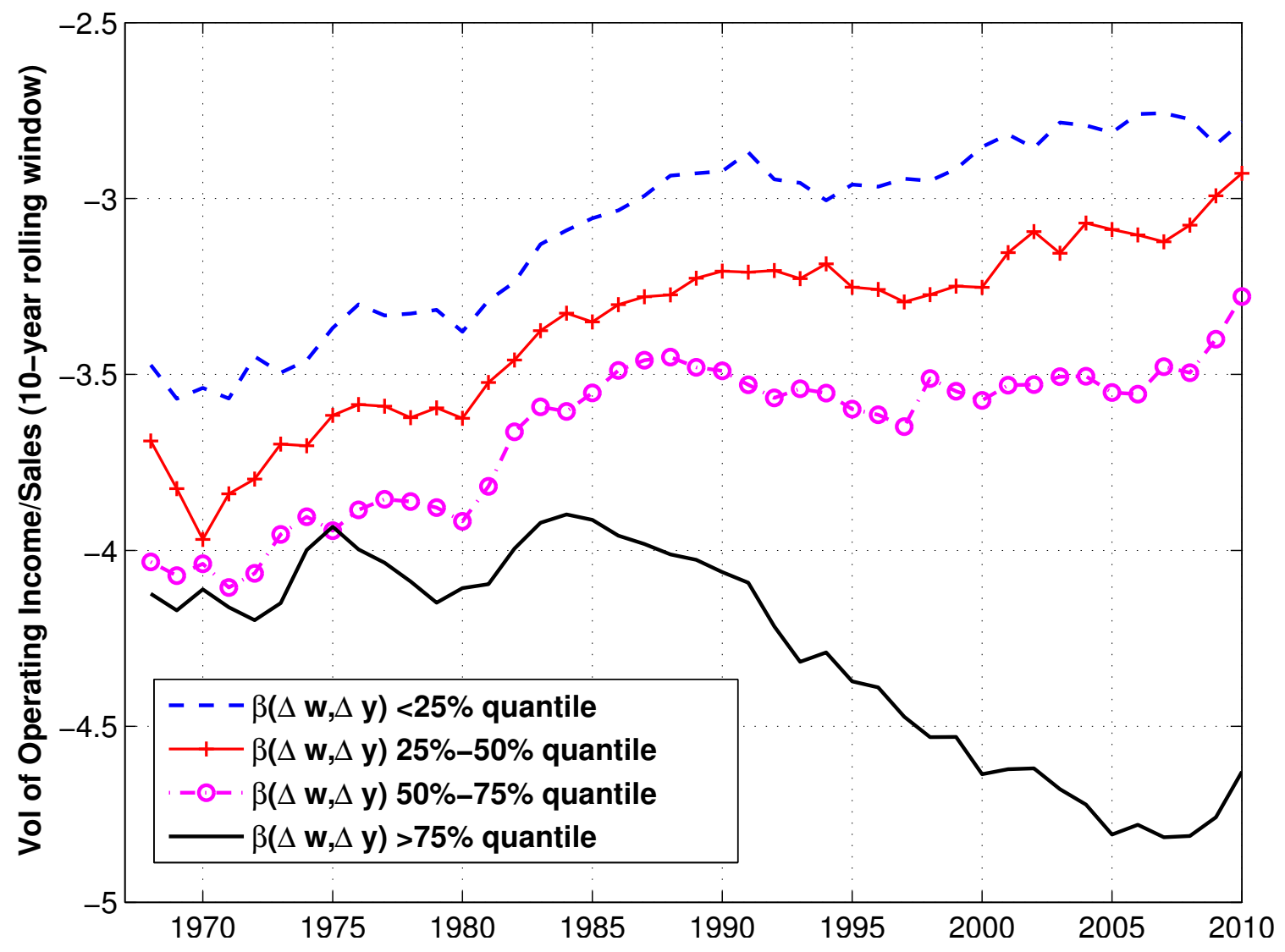

The figure shows the time series of cash flow volatility for different wage-output sensitivity $\beta_{w, y}$ quantiles. Cash flow growth is measured using operating income scaled by sales: $\frac{\text { ibd }_{t}-\text { oibdp } p_{t-1}}{0.5 \text { Sales }+0.5 \text { Sales } s_{t-1}}$. Volatility is estimated as the standard deviation of cash flow growth over a ten-year rolling window. Within each $\beta_{w, y}$ quantile, firm-level volatility is computed by taking a simple average at each year. 
Figure 7: Within-Industry Operating Income/Sales Volatility of $\beta(\Delta w, \Delta y)$ Group

(a) Consumer Goods

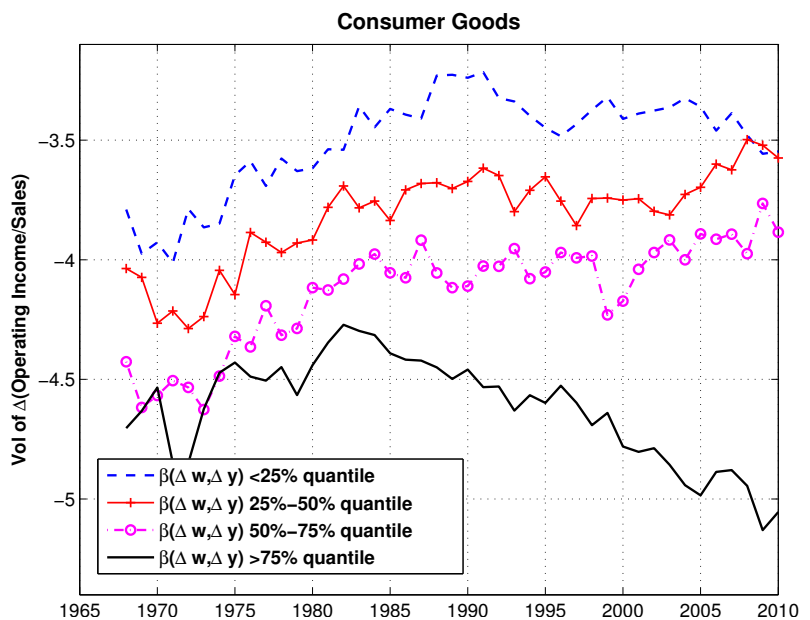

(c) Health Products

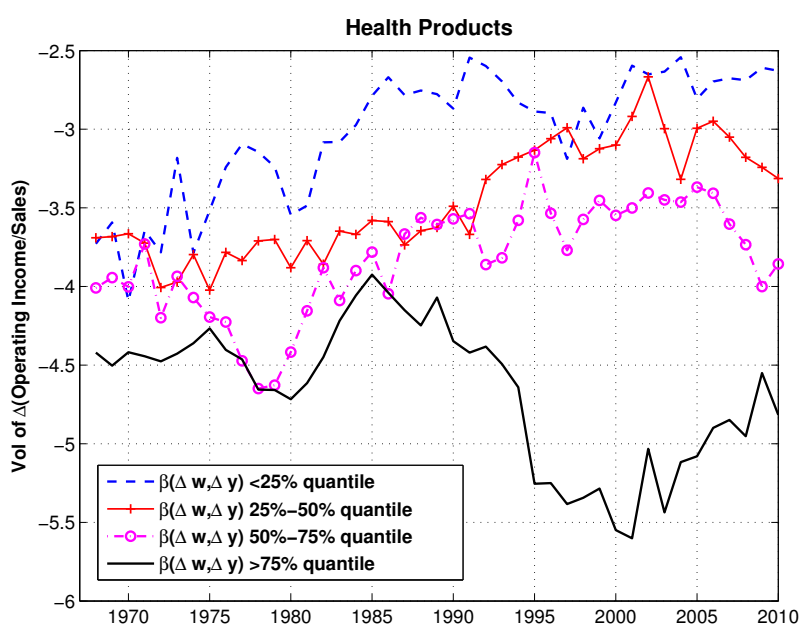

(b) Manufacturing

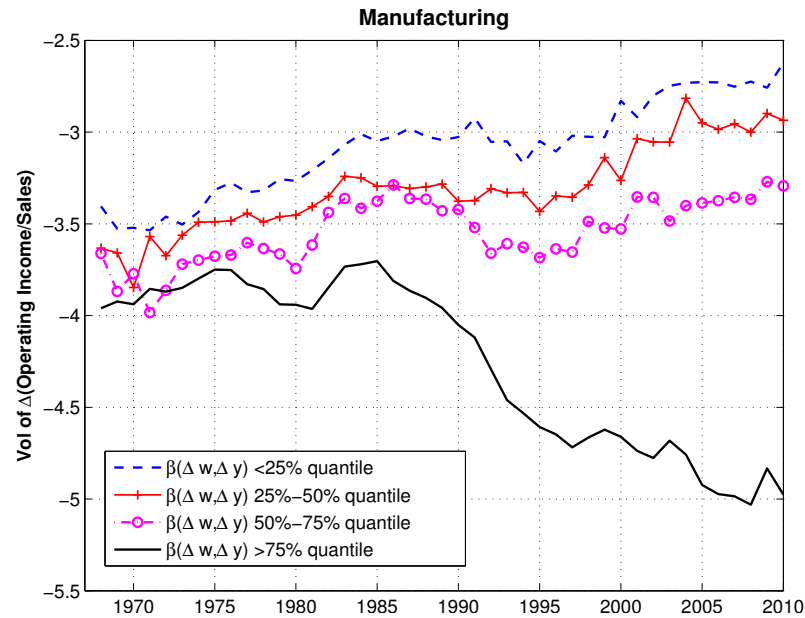

(d) Computer, Information and Technology

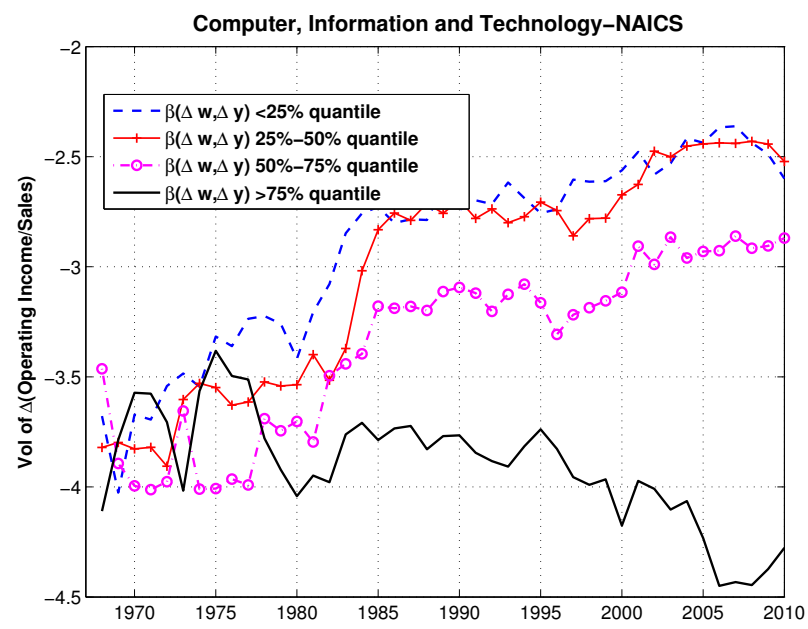

The figure shows the time series of cash flow volatility for different wage-output sensitivity $\beta_{w, y}$ quantiles within-industry. Cash flow growth is measured using operating income scaled by sales: $\frac{\text { oibdpt } \text { oibdpt-1 }_{t}}{0.5 \text { Salest }+0.5 \text { Salest }-1}$. Volatility is estimated as the standard deviation of cash flow growth over a ten-year rolling window. Within each $\beta_{w, y}$ quantile, firm-level volatility is computed by taking a simple average at each year. 
Figure 8: Policy Fucntions: $\beta(\Delta w, \Delta y), \sigma\left(\Delta \frac{C F}{y}\right)$

(a) $\sigma\left(\Delta \frac{C F}{y}\right)$

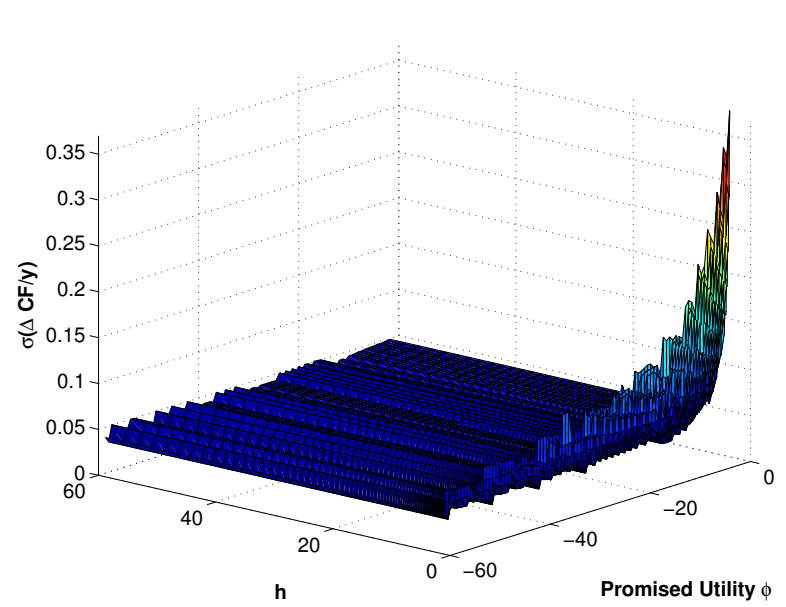

(b) $\beta(\Delta w, \Delta y)$

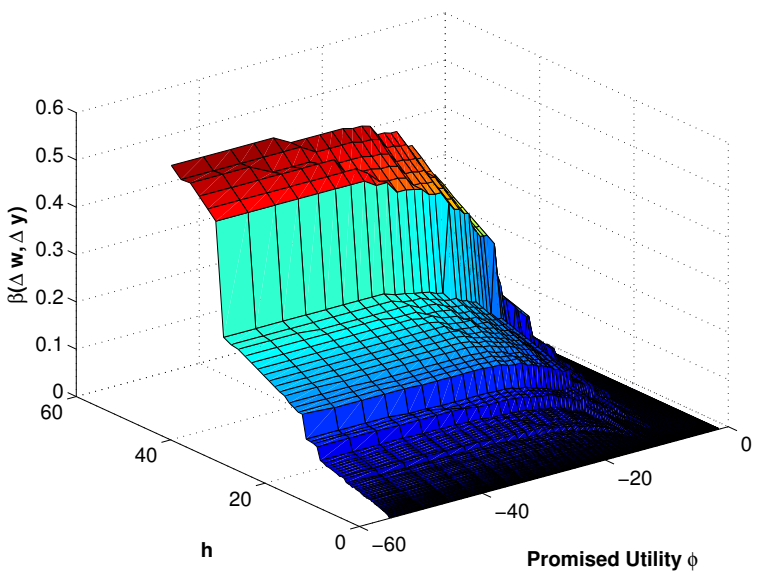

(c) Cross-Section of Policy Functions
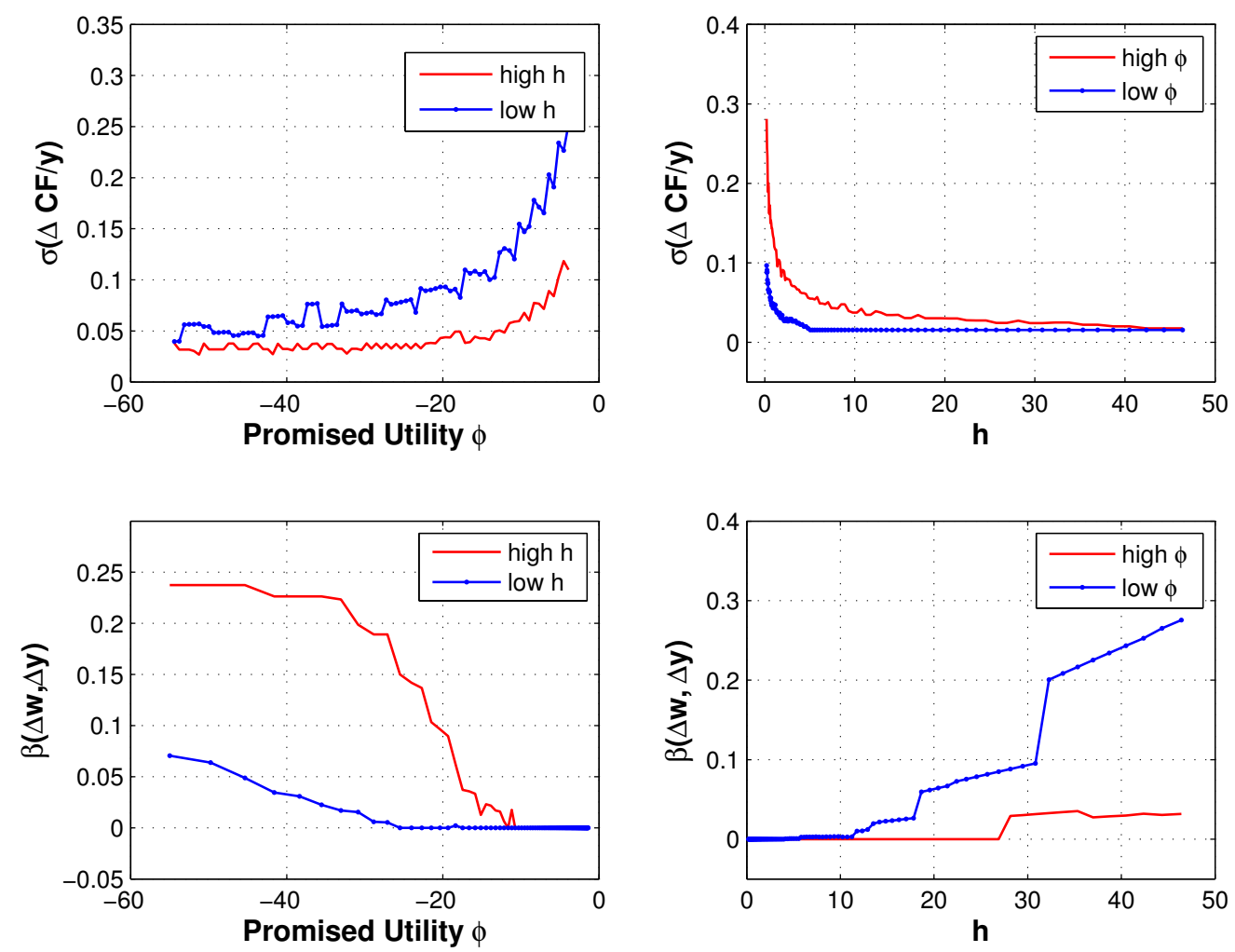

The figure reports the policy functions for $\beta(\Delta w, \Delta y)$ and $\sigma\left(\Delta \frac{C F}{y}\right)$. The parameter in the examples are $\alpha=0.85, \gamma=2, \beta=0.96, \phi=0.5, \sigma=0.3, \rho=0.7, \xi_{h}=3.2, \delta_{h}=0.2$. The promised utility $\varphi$ represents $h_{\max }$. Figure (a) and (b) is obtained by fixing $z$, and the bottom panel are the cross-section of figure (a) and (b). 
Figure 9: Impulse Response of a One-Standard Deviation Shock to $z_{t}$

(a) Impulse Response to Positive Shock
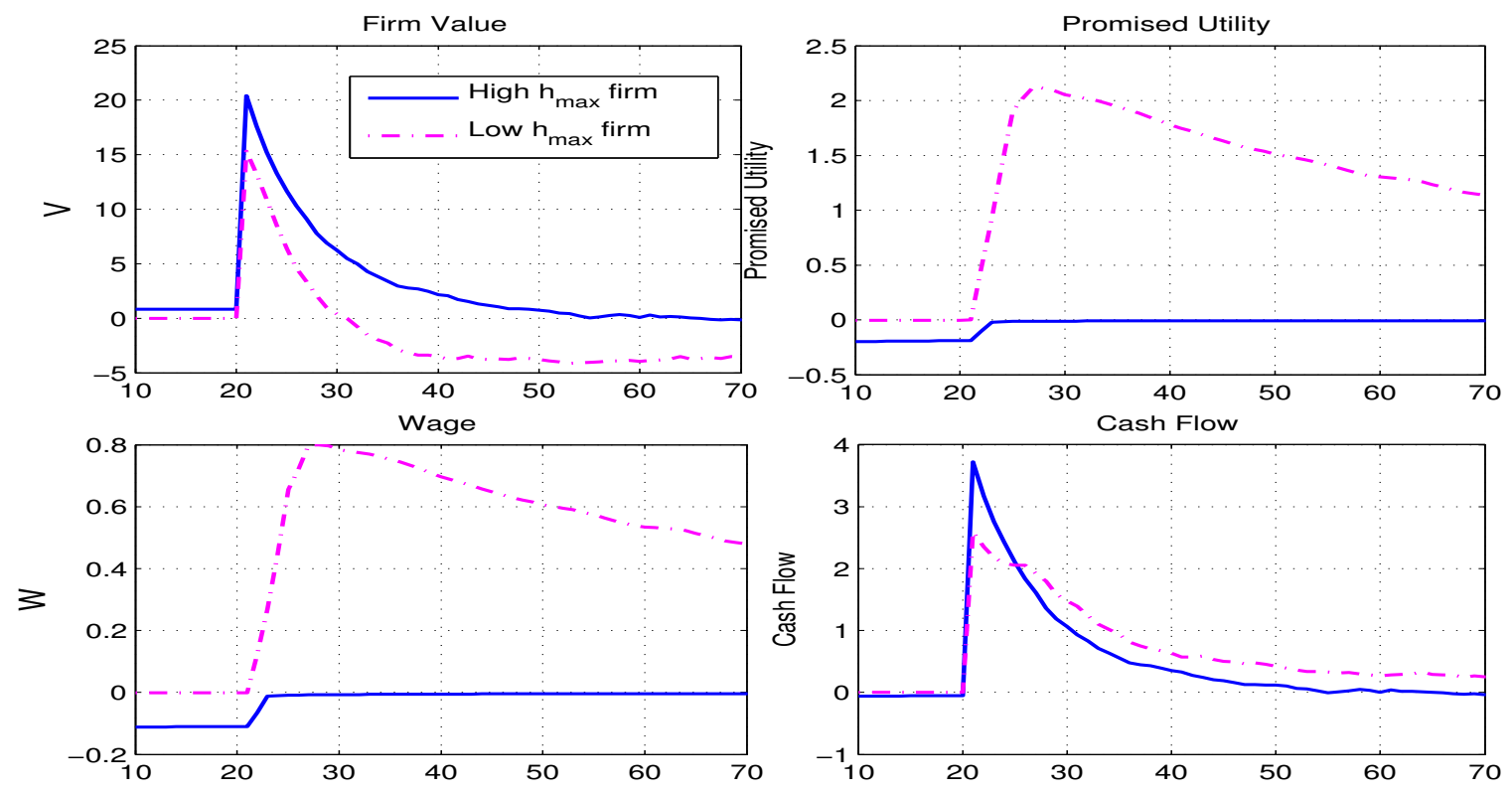

(b) Impulse Response to Negative Shock
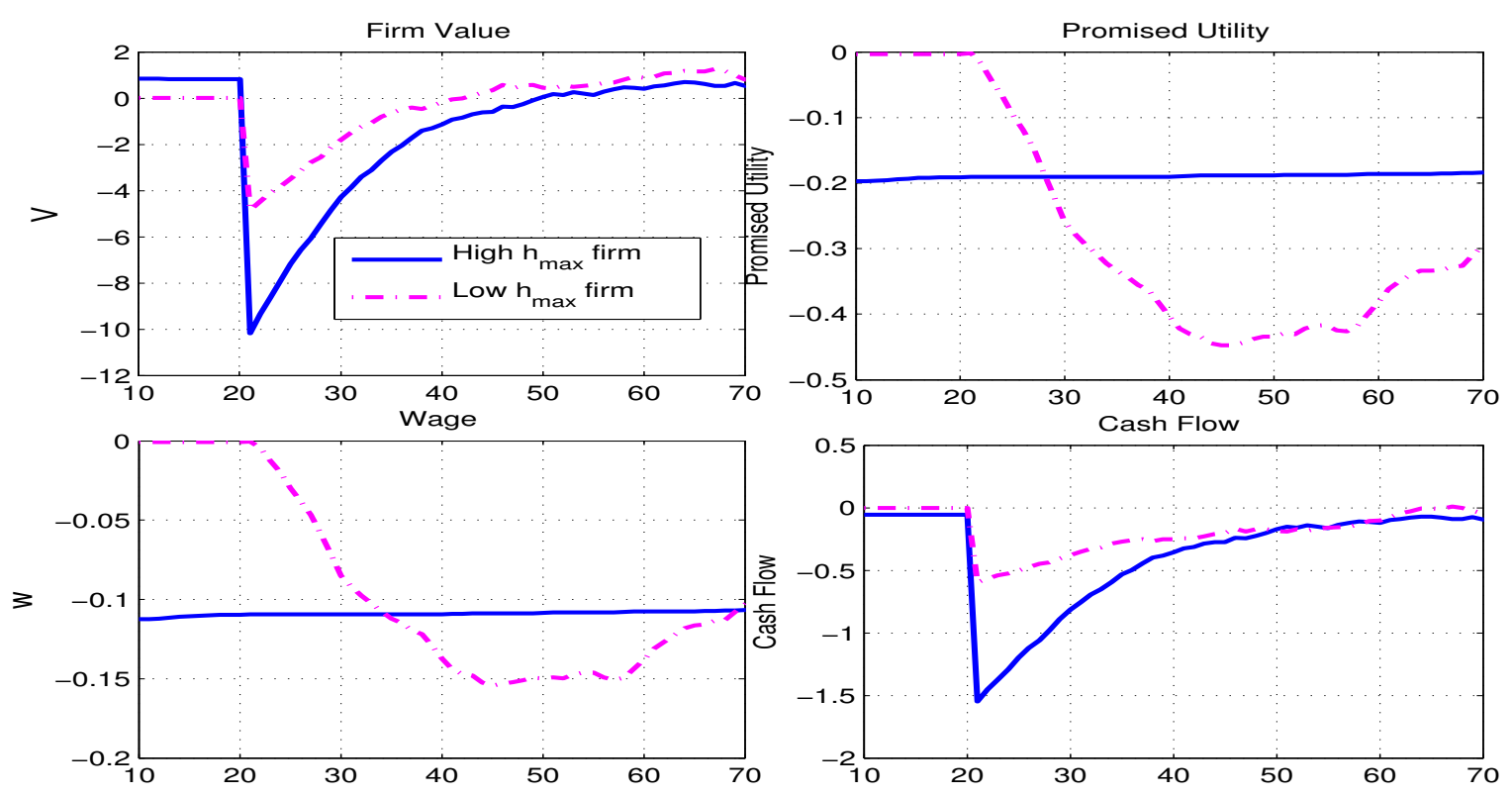

Impulse responses of cash flows and wage contracts to a one standard deviation shock to productivity level $z_{t}$ of value function and policy function. Following Koop et al. (1996), all figures show the difference between the economy with and without the one standard deviation shock. 
Figure 10: Risk Allocation in Equilibrium with Firm Dynamics

(a) Risk Allocation: Sensitivity

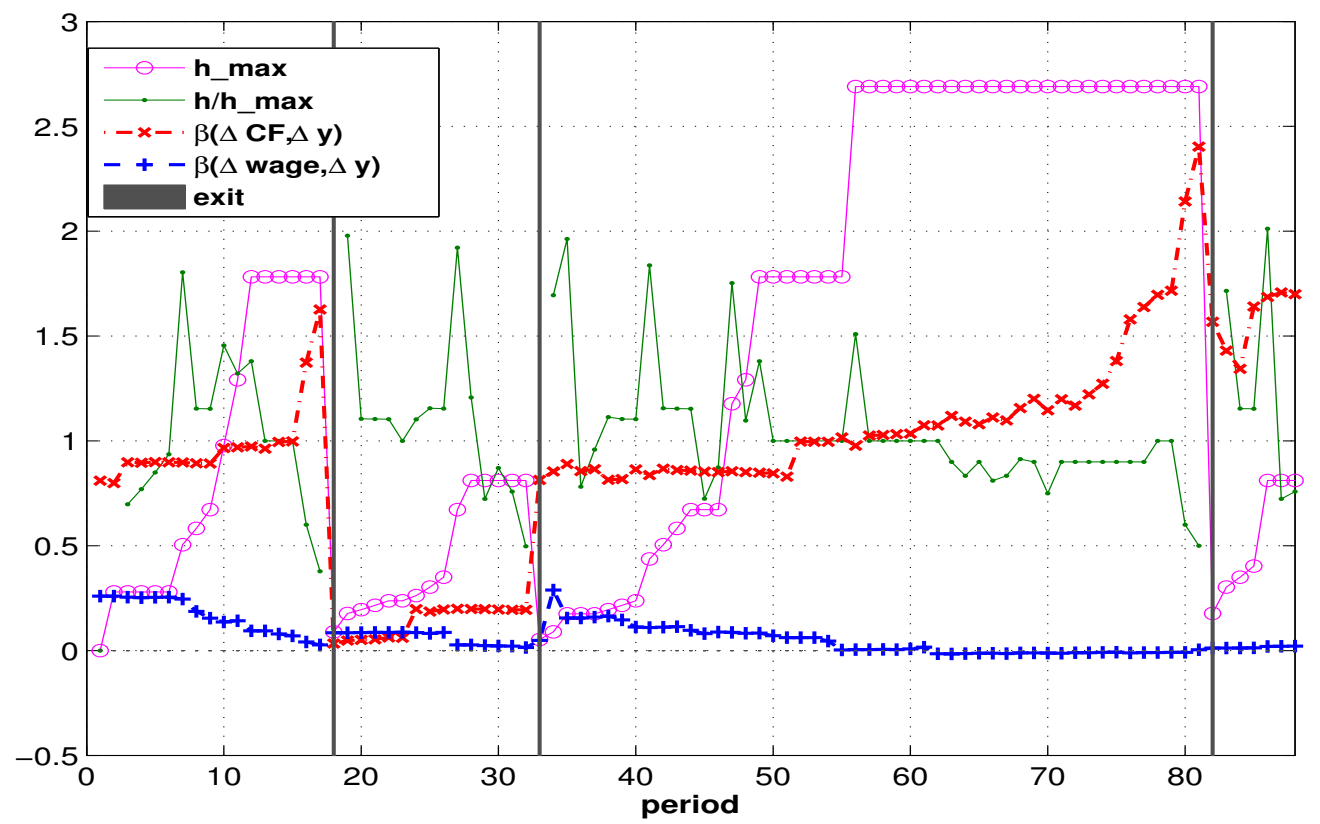

(b) Risk Allocation: Volatility

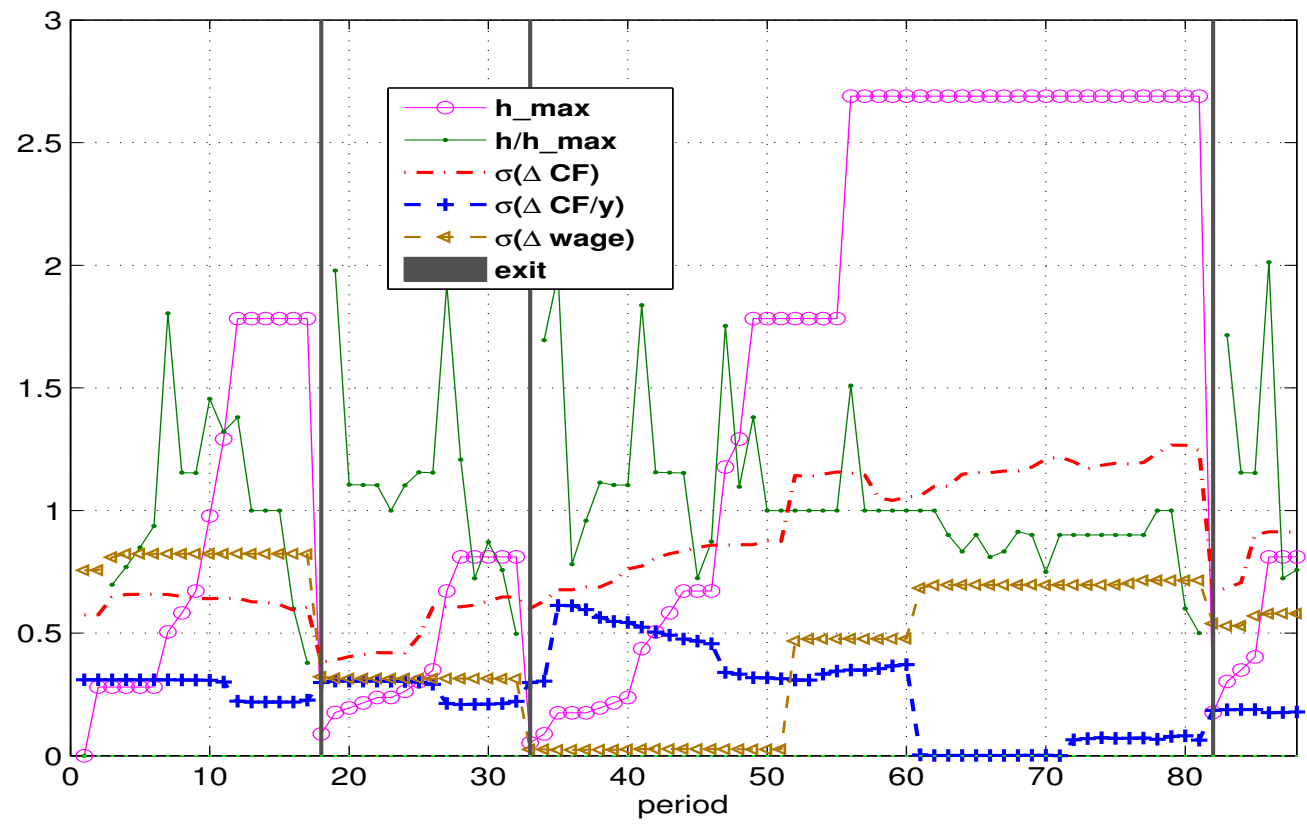

This figure shows cash flow volatility and contract sensitivity in equilibrium. Figure (a) shows the wageoutput sensitivity with respect to the state variables. Figure (b) shows the wage growth volatility and cash flow volatility with respect to the state variables. The grey area indicates the stopping time of the contract. $h_{\max }$ is scaled to the one-tenth of its original value. 
Figure 11: Time Series of State Variables: Industries

(a) Time Series of $h_{\max }$ in Industry Groups

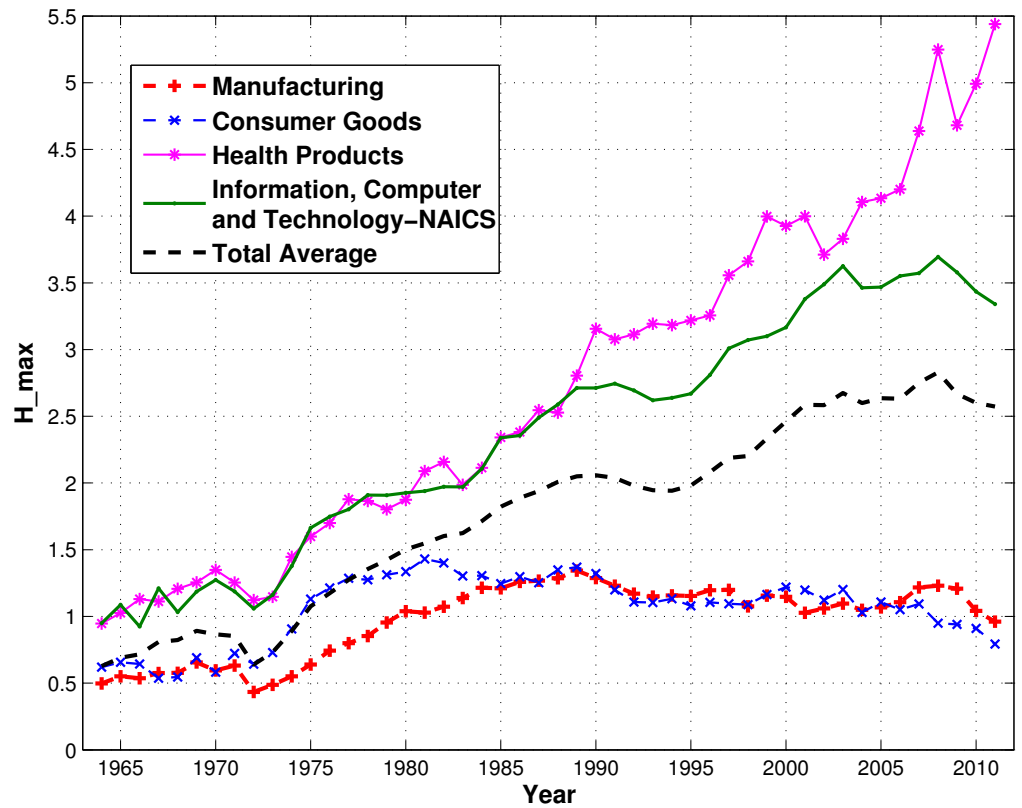

(b) Time Series of $\frac{h}{h_{\max }}$ in Industry Groups

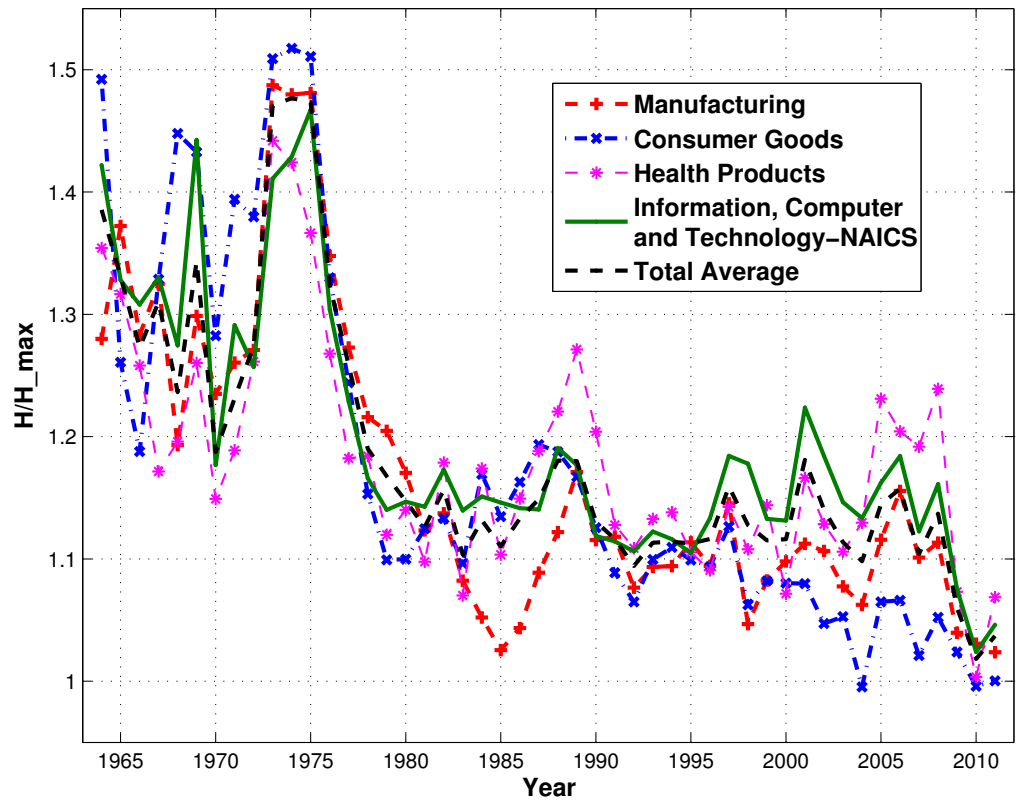

The figure shows the time series of the average $\hat{h}_{\max }$ and $\frac{\hat{h_{t}}}{h_{\max , t-1}}$ for different industries. The sample is from the Compustat Fundamental Annual 1960-2010. $\hat{h}_{\max }$ and $\frac{\hat{h_{t}}}{h_{\max , t-1}}$ are averaged across firms within an industry. The details of measurement and data construction are in Appendix $\mathrm{C}$. 
Figure 12: Time Series of State Variables in $\beta_{w, y}$ Groups

(a) Time Series of $h_{\max }$ in $\beta_{w, y}$ Groups

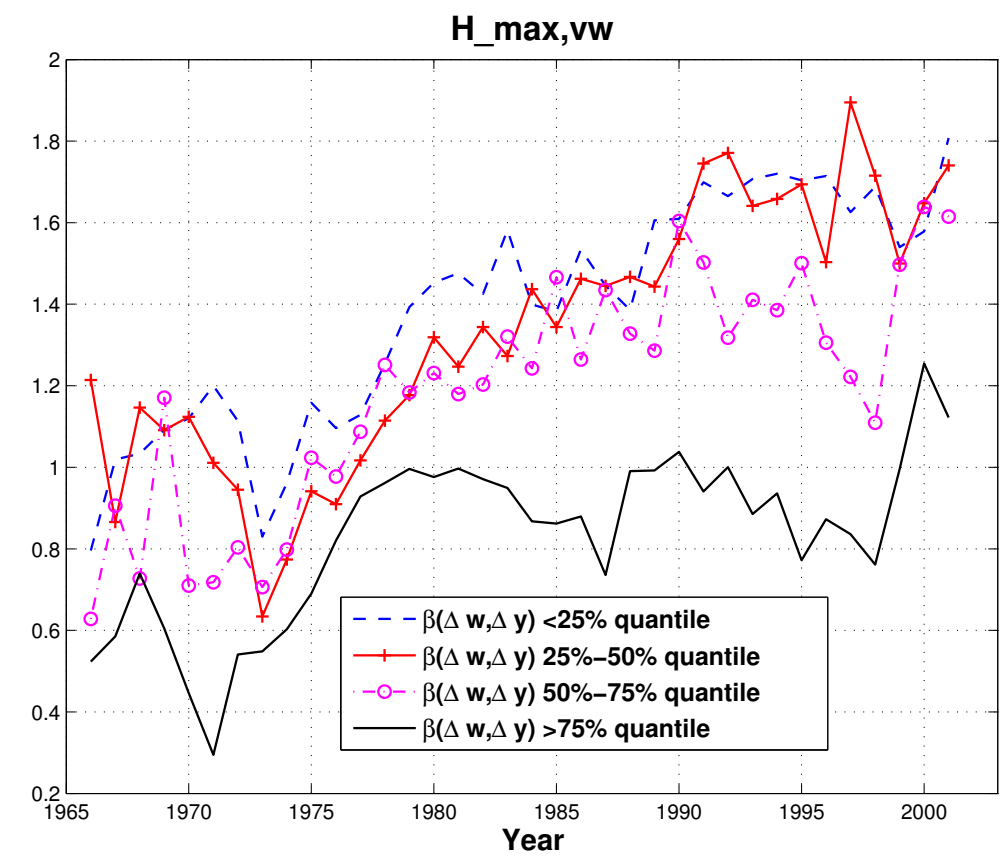

(b) Time Series of $\frac{h}{h_{\max }}$ in $\beta_{w, y}$ Groups

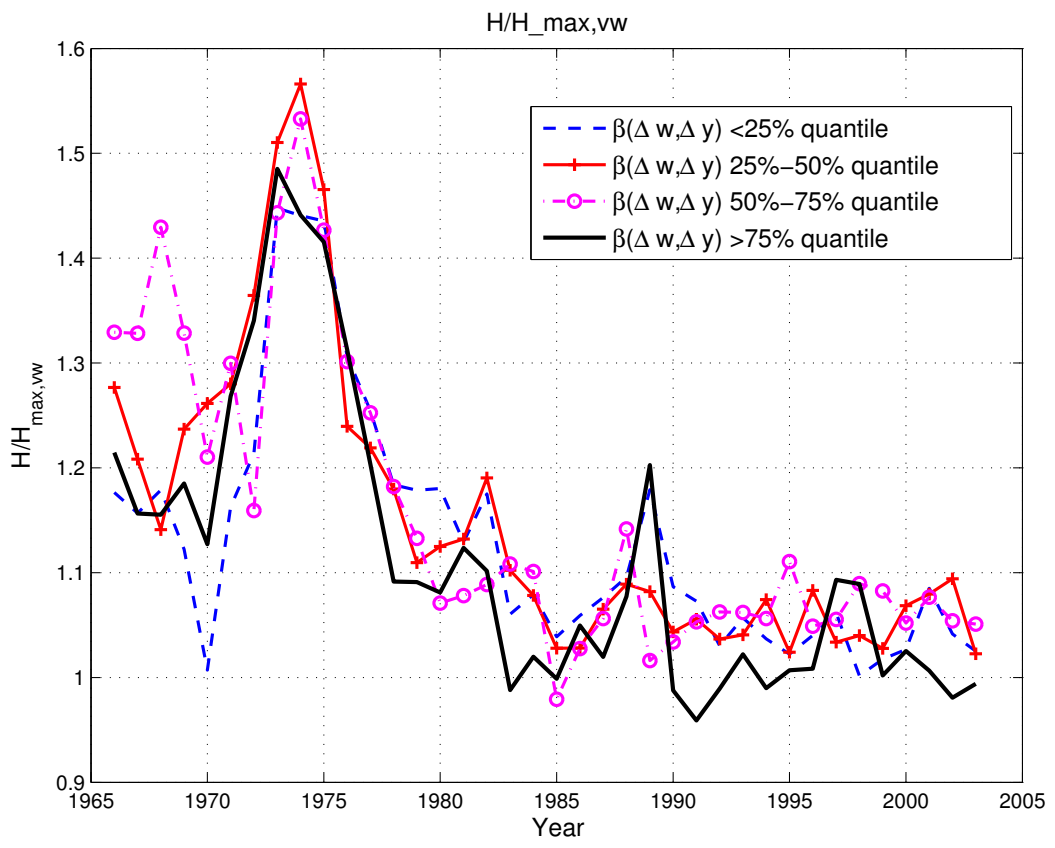

The figure shows the time series of $h_{\max }$ and $\frac{h}{h_{\max }}$ for different wage-output sensitivity $\beta_{w, y}$ quantiles. $h_{\max }$ is measured as the value-weighted firm-level human capital estimate $h_{t}$ over the past five years. $\frac{h}{h_{\max }}$ is the ratio between the current year firm-level human capital and the last year maximum human capital level, $h_{\max , t-1}$. Within each $\beta_{w, y}$ quantile, $h_{\max }$ and $\frac{h}{h_{\max }}$ are computed by taking a simple average at each year. 
Figure 13: Comparative Statics in $\alpha$ and Time-Series Cash Flow Volatility

(a) Comparative Statics: $\alpha$

h_max

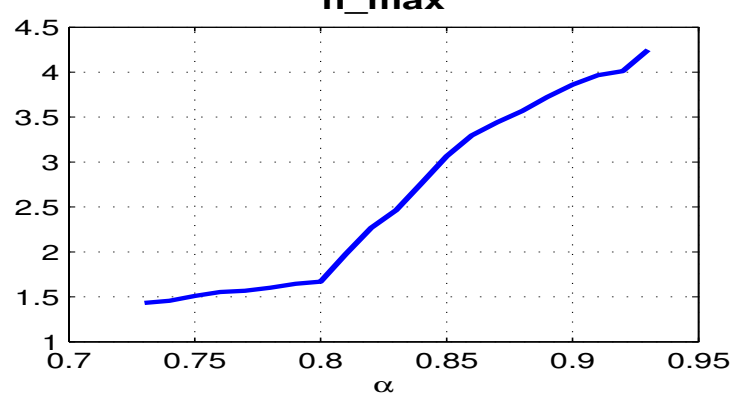

$\log (\sigma(\Delta \mathrm{CF} / \mathrm{y}))$

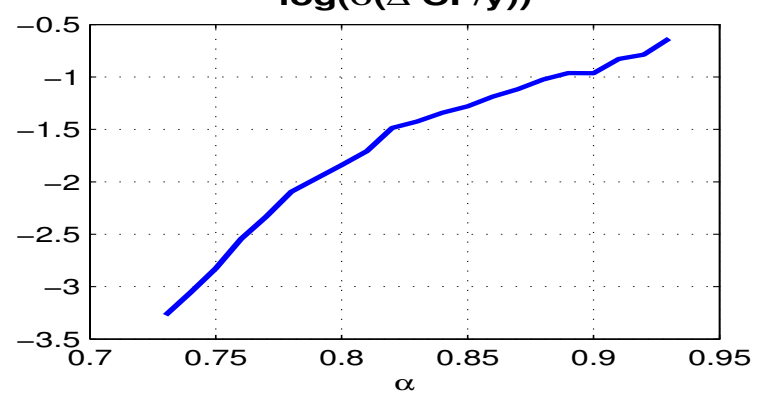

$\beta(\Delta \mathbf{w}, \Delta y)$

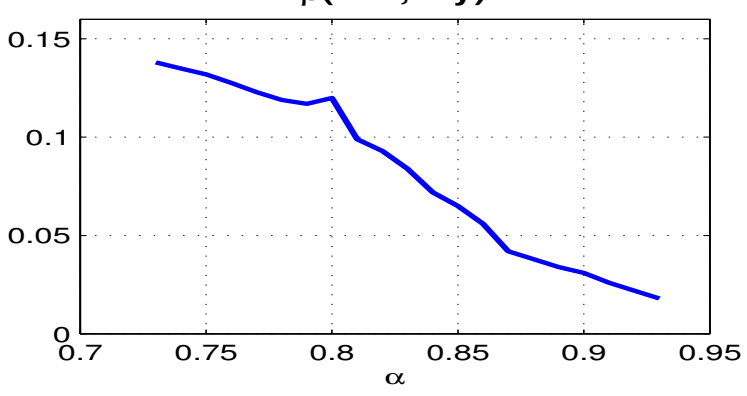

$\log (\sigma(\Delta$ CF $))$

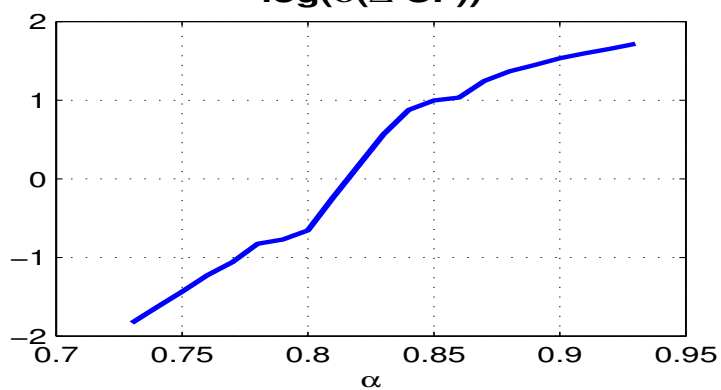

(b) Volatility and Sensitivity Time Series

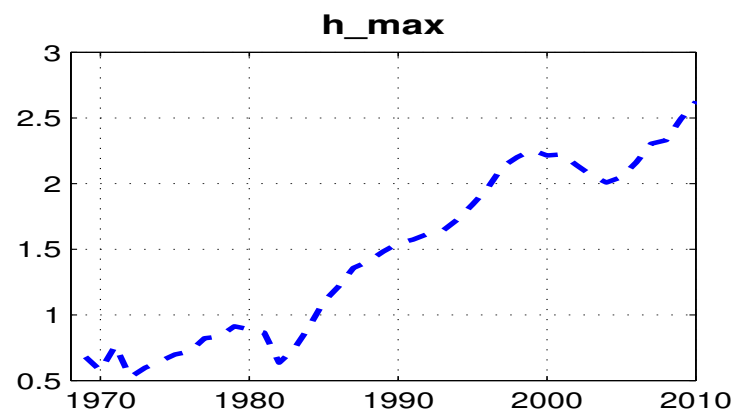

$\beta(\Delta \mathbf{w}, \Delta \mathbf{y})$

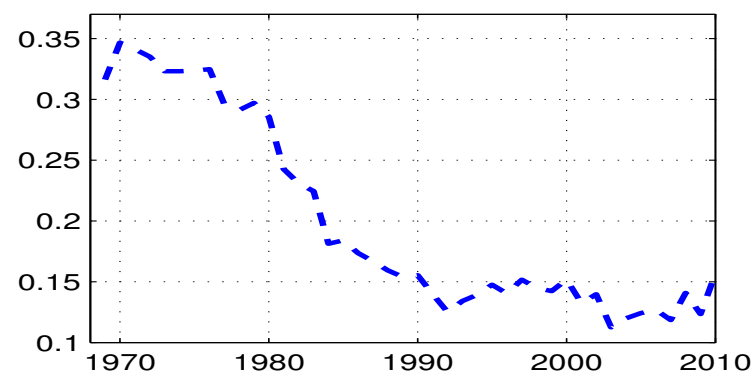

$\log (\sigma(\Delta \mathrm{CF} / \mathrm{y}))$
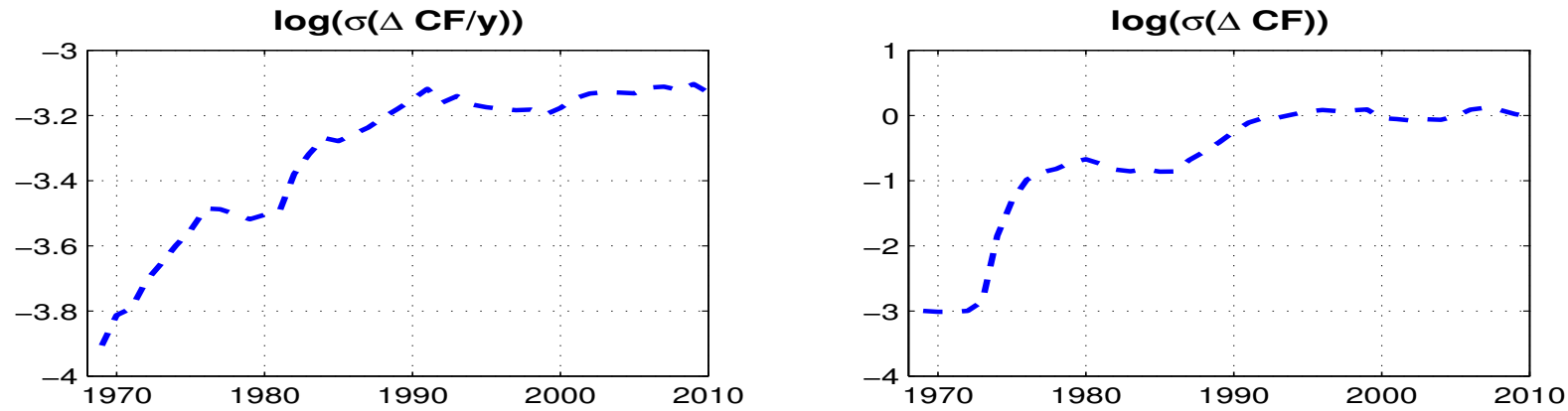

This figure shows the volatility and sensitivity of wages and cash flows estimated from the simulated economy under difference choices of $\alpha$. Simulate the economy for each $\alpha$ ( $\alpha$-simulated economy) under the same procedure described in Appendix B.3. $C F$ stands for cash flow. The standard deviation is computed within a ten-year rolling window. Sensitivity $\beta$ is computed within a ten-year rolling window. I average both across firms within each $\alpha$-simulated economy. The volatility is the log standard deviation. 